\title{
Sludge Treatment Project KOP Disposition - Thermal and Gas Analysis for the Cold Vacuum Drying Facility
}

Prepared for the U.S. Department of Energy

Assistant Secretary for Environmental Management

Contractor for the U.S. Department of Energy

under Contract DE-AC06-08RL14788

CHzMHILL

Plateau Remediation Company

P.O. Box 1600

Richland, Washington 99352 


\section{Sludge Treatment Project KOP Disposition - Thermal and Gas Analysis for the Cold Vacuum Drying Facility}

Project No: STP

Document Type: TR

Program/Project: STP

J. A. Swenson

AREVA

R. D. Crowe

Fluor Government Group

R. Apthorpe

M. G. Plys

Fauske \& Associates LLC

Date Published

March 2010

Prepared for the U.S. Department of Energy

Assistant Secretary for Environmental Management

Contractor for the U.S. Department of Energy

under Contract DE-AC06-08RL14788

\section{CH2NIHILL}

Plateau Remediation Company

P.O. Box 1600

Richland, Washington

$\frac{\text { Nevucy A Fonad }}{\text { Release Approval }} \frac{3-9-10}{\text { Date }}$

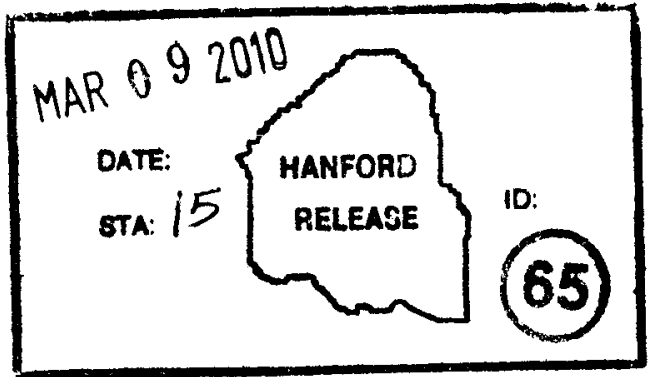

Release Stamp

Approved for Public Release;

Further Dissemination Unlimited 
TRADEMARK DISCLAIMER

Reference herein to any specific commercial product, process, or service by trade name, trademark, manufacturer, or

otherwise, does not necessarily constitute or imply its

endorsement, recommendation, or favoring by the United

States Government or any agency thereof or its contractors or subcontractors.

This report has been reproduced from the best available copy.

Printed in the United States of America

Total Pages: $|3|$ 


\section{Table of Contents}

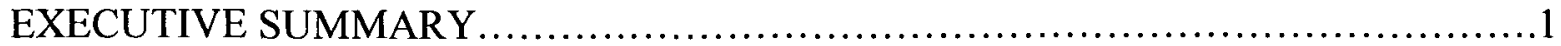

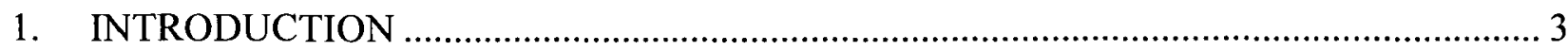

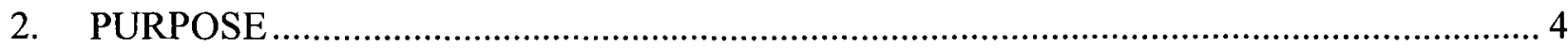

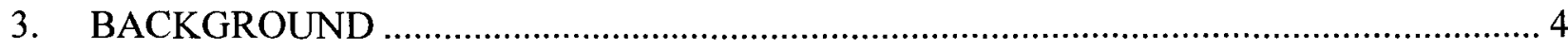

3.1 Differences from Spent Nuclear Fuel MCO and KOP Material MCO Analysis............ 5

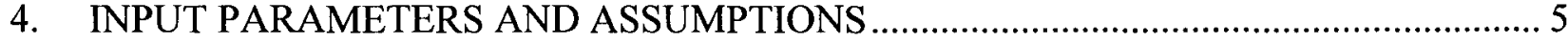

4.1 Summary of Data Book Data for Knock Out Pot Sludge ..................................... 5

4.2 Summary of Design Parameters......................................................................... 7

5. SOFTWARE APPLICATION, DESCRIPTIONS, INSTALLATION AND STATEMENT

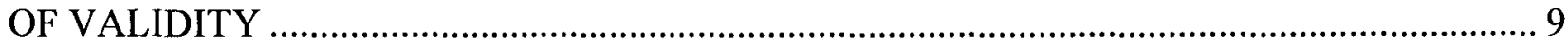

6. COLD VACUUM DRYING CASES, CALCULATIONS AND RESULTS ..................... 12

6.1 Base Case Behavior - Normal CVDF processing ............................................... 13

6.2 Degraded Vacuum Pumping with No Helium Purge ............................................... 16

6.3 Open MCO with loss of Annulus water............................................................ 20

6.4 Results Multi-canister Overpack Cooling Evaluation............................................ 22

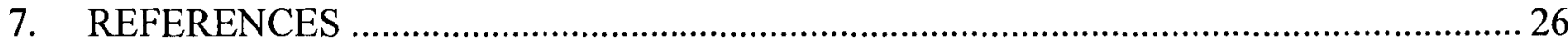

Figure 5-1 FATE model representation for CVD of KOP material in an insert block .............. 11 Figure 6-1 Case 1: CVD of 25\% Void Fraction KOP Material (Design Parameters) ................ 14

Figure 6-2 Case 5: CVD of Safety Basis KOP Material (Safety Basis Parameters) ................ 15

Figure 6-3 Case 2: Degraded Vacuum Pumping With No Helium Purge (Design Parameters) 17 Figure 6-4 Case 6: Degraded Vacuum Pumping With No Helium Purge (Safety Basis

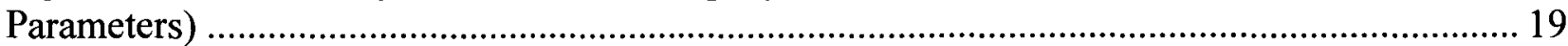

Figure 6-5 Case 3: Open MCO with Loss of Annulus Water (Design Parameters) .................. 21

Figure 6-6 Case 7: Open MCO With Loss of Annulus Water (Safety Basis Parameters)......... 22

Figure 6-7 Case 4: Cooling of MCO and KOP Sludge After Vacuum Drying (Design

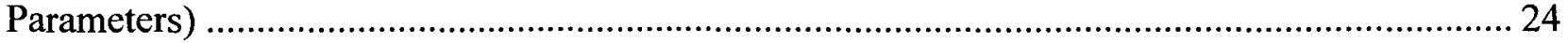

Figure 6-8 Case 8: Cooling of MCO and KOP Sludge After Vacuum Drying (Safety Basis

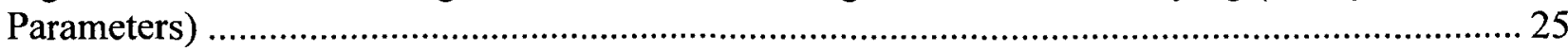




\section{List of Terms}

CSB Canister Storage Building

CVDF Cold Vacuum Drying Facility

FAI Fauske \& Associates, LLC

KOP Knock out pot

KW 105-K West

MCO multi-canister overpack

MLS MCO Loading System

PCM Primary cleaning machine

SNF Spent Nuclear Fuel

STP Sludge Treatment Project

TWS tempered water (annulus) system 


\section{PRC-STP-00187 REV 0}

\section{EXECUTIVE SUMMARY}

The purpose of this document is to present conceptual design phase thermal process calculations that support the process design and process safety basis for the cold vacuum drying of $\mathrm{K}$ Basin KOP material. This document is intended to demonstrate that the conceptual approach:

- Represents a workable process design that is suitable for development in preliminary design

- Will support formal safety documentation to be prepared during the definitive design phase to establish an acceptable safety basis.

The Sludge Treatment Project (STP) is responsible for the disposition of Knock Out Pot (KOP) sludge within the 105-K West $(\mathrm{KW})$ Basin. KOP sludge consists of size segregated material (primarily canister particulate) from the fuel and scrap cleaning process used in the Spent Nuclear Fuel process at K Basin. The KOP sludge will be pre-treated to remove fines and some of the constituents containing chemically bound water, after which it is referred to as KOP material. The KOP material will then be loaded into a Multi-Canister Overpack (MCO), dried at the Cold Vacuum Drying Facility (CVDF) and stored in the Canister Storage Building (CSB).

This process is patterned after the successful drying of 2100 metric tons of spent fuel, and uses the same facilities and much of the same equipment that was used for drying fuel and scrap. Table ES-1 present similarities and differences between KOP material and fuel and between MCOs loaded with these materials. The potential content of bound water bearing constituents limits the mass of KOP material in an MCO load to a fraction of that in an MCO containing fuel and scrap; however, the small particle size of the KOP material causes the surface area to be significantly higher. This relatively large reactive surface area represents an input to the KOP thermal calculations that is significantly different from the calculations for fuel MCOs.

\begin{tabular}{|l|c|c|c|}
\hline \multicolumn{4}{|c|}{ Table ES-1: Comparison of Key Parameters for KOP Material and Fuel MCOs } \\
\hline & Fuel & Scrap & KOP Material \\
\hline Particle Size & Fuel Assemblies & $>1 / 4$ & $>600$ \\
\hline Total Quantity & $\sim 2100$ tons & $\sim 36$ tons & $<1$ ton \\
\hline MCO Load & Up to $\sim 6$ tons & Up to $\sim 2$ tons & Up to $\sim 0.15$ ton \\
\hline MCO Reactive Surface & \multicolumn{2}{|c|}{ Up to $12 \mathrm{~m}^{2}$ for fuel and scrap } & Up to $\sim 46.3 \mathrm{~m}^{2}$ \\
\hline
\end{tabular}

The conceptual design provides for a copper insert block that limits the volume available to receive KOP material, enhances heat conduction, and functions as a heat source and sink during drying operations. This use of the copper insert represents a significant change to the thermal model compared to that used for the fuel calculations.

A number of cases were run representing a spectrum of normal and upset conditions for the drying process. Dozens of cases have been run on cold vacuum drying of fuel MCOs. Analysis of these previous calculations identified four cases that provide a solid basis for judgments on the behavior of $\mathrm{MCO}$ in drying operations. These four cases are

$>$ Normal Process

$>$ Degraded vacuum pumping

$>$ Open MCO with loss of annulus water

$>$ Cool down after vacuum drying 
The four cases were run for two sets of input parameters for KOP MCOs: (1) a set of parameters drawn from safety basis values from the technical data book and (2) a sensitivity set using parameters selected to evaluate the impact of lower void volume and smaller particle size on MCO behavior. Results of the calculations for the drying phase cases are shown in Table ES-2. Cases using data book safety basis values showed dry out in 9.7 hours and heat rejection sufficient to hold temperature rise to less than $25^{\circ} \mathrm{C}$. Sensitivity cases which included unrealistically small particle sizes and corresponding high reactive surface area showed higher temperature increases that were limited by water consumption.

\begin{tabular}{|l|c|c|c|}
\hline \multicolumn{4}{|c|}{ Table ES-2: Summary Results of Thermal Calculations } \\
\hline $\begin{array}{l}\text { Cases Using Databook Safety Basis Values } \\
(40 \% \text { Void Fraction \& } 1500 \mu \text { Particle })\end{array}$ & $\begin{array}{c}\text { Time to } \\
\text { Dry }\end{array}$ & Peak Temp & Comments \\
\hline 1. Normal Process & $9.7 \mathrm{hrs}$ & $57^{\circ} \mathrm{C}$ & Stable \\
\hline 2. Degraded Vacuum Pumping & $18 \mathrm{hrs}$ & $72^{\circ} \mathrm{C}$ & Stable \\
\hline 3. Open MCO - No Annulus $\mathrm{H}_{2} \mathrm{O}$ & N/A & $62^{\circ} \mathrm{C}$ & Stable \\
\hline $\begin{array}{l}\text { Sensitivity Cases } \\
\text { (25\% Void Fraction \& 600 } \mu \text { Particle })\end{array}$ & $\begin{array}{c}\text { Time to } \\
\text { Dry }\end{array}$ & Peak Temp & Comments \\
\hline 1. Normal Process & $9.7 \mathrm{hrs}$ & $70^{\circ} \mathrm{C}$ & Stable \\
\hline 2. Degraded Vacuum Pumping & $18 \mathrm{hrs}$ & $88^{\circ} \mathrm{C}$ & $\begin{array}{c}\text { Limited by water } \\
\text { availability }\end{array}$ \\
\hline 3. Open MCO - No Annulus $\mathrm{H}_{2} \mathrm{O}$ & N/A & $70^{\circ} \mathrm{C}$ & Stable \\
\hline
\end{tabular}

In this document and in the attachment (Apthorpe, R. and M.G. Plys, 2010) cases using Technical Databook safety basis values are referred to as nominal cases. In future calculations such cases will be called safety basis cases. Also in these documents cases using parameters that are less favorable to acceptable performance than databook safety values are referred to as safety cases. In future calculations such cases will be called sensitivity cases or sensitivity evaluations Calculations to be performed in support of the detailed design and formal safety basis documentation will expand the calculations presented in this document to include: additional features of the drying cycle, more realistic treatment of uranium metal consumption during oxidation, larger water inventory, longer time scales, and graphing of results of hydrogen gas concentration. 


\section{INTRODUCTION}

The Sludge Treatment Project (STP) is responsible for the disposition of Knock Out Pot (KOP) sludge within the $105-\mathrm{K}$ West $(\mathrm{KW})$ Basin. KOP sludge consists of size-segregated material (primarily canister particulate) from the fuel and scrap cleaning process used in the Spent Nuclear Fuel process at K Basin. The KOP sludge will undergo a physical separation process to remove fines and compounds bearing chemically bound water to ensure that Multi-Canister Overpack (MCO) water inventory limits are met; after processing the sludge is referred to as KOP material. The KOP material will then be placed in scrap baskets in an MCO. The MCO will be transported to the cold vacuum drying facility (CVDF). The MCO will be dried at CVDF and then placed in storage in a CSB storage tube.

CH2MHILL Plateau Remediation Company (CHPRC) contracted with Fauske \& Associates, LLC (FAI) to evaluate the thermal stability of KOP material during vacuum drying and during transport when the KOP material is submerged in water. Thus, during the latter half of FY09 FAI has worked interactively with the Sludge Treatment Project to evaluate the thermal and gas generation issues associated with placing KOP material into a MCO for cold vacuum drying at CVDF. On the design side, a number of potential designs, features, dimensions, and material loadings have been explored, and on the modeling side, physical models have evolved and been assessed.

FAI completed the analysis and documented the results in a report, FAI/10-28, Cold Vacuum Drying of Knock Out Pot Material in the Scrap Basket Insert Blocks (Apthorpe and Plys, 2010). The FAI report presents results for the current design using the most mature model approach. The crucial feature of results to be found is thermal stability of the KOP material under restrictive operating conditions and bounding design assumptions. Model features and inputs are selected to minimize the need for technical specifications that would require verification, so that results presented here are therefore conservative. Additionally, this conservative model is compared against a model using safety-basis parameters to illustrate the degree of conservatism in the conservative approach.

In simulation of the normal CVD processing of MCOs with KOP material using conservative, bounding values for the material characteristics, reaction rates, and $\mathrm{MCO}$ conditions, the KOP material is predicted to have stable temperature behavior and the MCO is expected to dry out after about 9.5 hours. Stable behavior is also predicted for one key accident scenario, loss of annulus water. Acceptable behavior is predicted for another key accident scenario, degraded vacuum pumping with no helium purge. In this case, the KOP material temperature is below 100 ${ }^{\circ} \mathrm{C}$ when the large residual water heel is evaporated after a duration of 18 hours. A case for $\mathrm{MCO}$ cool down is also presented here for comparison to backfill conditions required for the canister storage building (CSB).

Using safety basis KOP material properties, the KOP material is predicted to have stable temperature behavior and MCO dry out is expected at 9 hours. Approximately $3.4 \mathrm{~kg}$ of uranium dioxide is predicted to be produced. Cases analyzed using conservative KOP material properties bound those using safety basis material properties.

Section 3.0 of this document provides background including a description of the planned KOP process. Section 4 follows with the key input parameters and assumptions provided for FAI analysis. The cases and results are summarized in Section 5.0. The attachment to this document provides the complete copy of the FAI report. 


\section{PURPOSE}

The purpose of this document is to present conceptual design phase thermal process calculations that support the process design and process safety basis for the cold vacuum drying of $\mathrm{K}$ Basin KOP material. This document is intended to demonstrate that the conceptual approach:

- Represents a workable process design that is suitable for development in preliminary design

- Will support formal safety documentation prepared during the definitive design phase to establish an acceptable safety basis.

These calculations describe the thermal behavior of the process system. This document melds the thermal calculations prepared by FAI (Apthorpe and Plys, 2010) into the CHPRC document system. The document describes the cold vacuum drying system performance during nominal and bounding conditions.

\section{BACKGROUND}

KOP material will be loaded into copper inserts and the inserts placed in MCO Mark 1A scrap baskets. The retrieval, sorting, and loading processes that were used for spent fuel and scrap will be adapted to the KOP material, but once the baskets are loaded, they will be handled in the same manner as for spent fuel. Figure 3-1 shows an empty Mark 1A scrap basket and the scrap basket with copper inserts in place.

Figure 3-1. Mark 1A Scrap Baskets; Empty (L) and with Copper Inserts Installed (R)
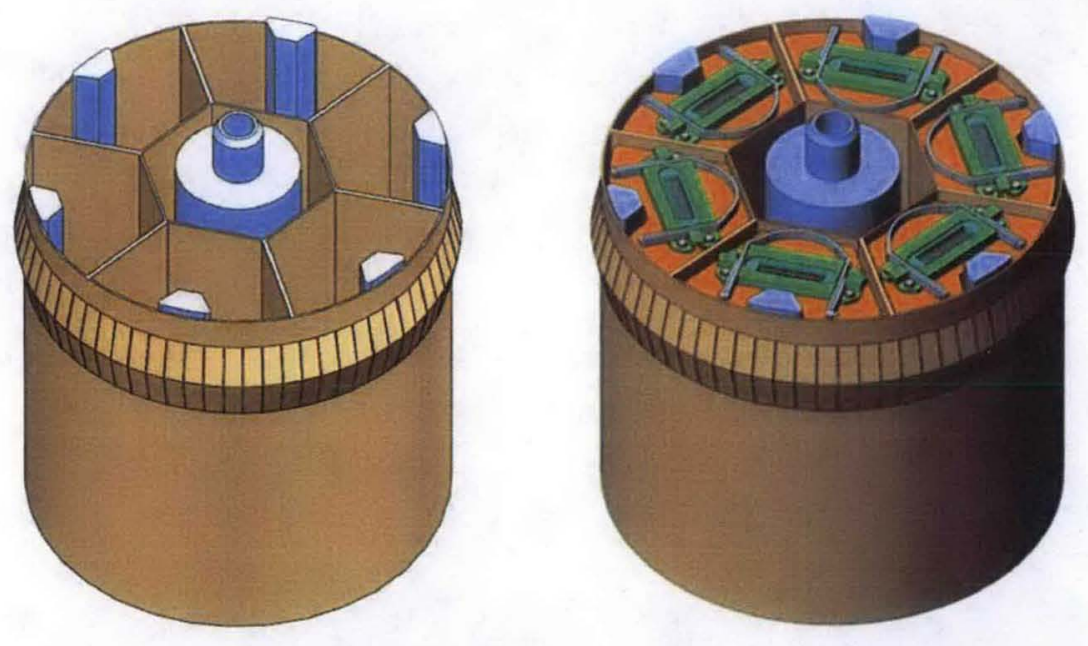

The loaded MCO scrap baskets will be placed in the MCO basket queue and moved from there to the MCO Loading System (MLS) shuttle. The MLS shuttle transports the MCO baskets to the MCO. The MLS gantry loads the baskets into a water filled MCO located in the MCO Cask and Immersion Pail assembly. The MCO is closed and transported to the Cold Vacuum Drying Facility. 
The MCO will be dried at CVDF. MCOs are received at CVDF and hooked up to the process system. MCO temperature is raised to process temperature and the bulk water removed. The pressure is drawn down causing the water to evaporate and be drawn off. After completing vacuum cycle a thermal reset is performed in which helium is introduced to bring the pressure back to near atmospheric and allow the MCO to return to thermal equilibrium at process temperature. After process behavior indicates dryness, a pressure rebound dryness test is performed. After dryness is demonstrated the MCO is cooled, filled with helium, sealed, transferred to CSB and placed in a storage tube. MCO load parameters in combination with dryness test results will demonstrate that the dried MCOs containing KOP material will fit within the safety envelope established for the MCOs containing Spent Fuel currently stored at CSB. The MCOs containing KOP material are planned to be shipped to the HLW Repository with the other MCOs containing Spent Fuel.

\section{Differences from Spent Nuclear Fuel MCO and KOP Material MCO Analysis}

The primary difference between this analysis and the original safety analysis report for MCO processing at CVDF (HNF-SD-SNF-CN-023, Thermal Analysis of Cold Vacuum Drying of Spent Nuclear Fuel) is that the original report analyzed N-Reactor fuel and N-Reactor fuel scrap in the MCO while the current analyses analyze KOP material in the MCO. The main differences between an SNF MCO and a KOP material MCO include the following:

- The bounding Mark IV fuel MCO had three baskets of fuel and two baskets of scrap. The KOP material MCO will use six Mark IA baskets, three baskets with KOP sludge in copper inserts and the remaining three baskets empty.

- The Mark IV-type MCO loading ranged from intact fuel pieces to small scrap pieces greater than 0.25 in $(6250 \mu \mathrm{m})$. The KOP material MCO will be loaded with sludge that consists of particles ranging in size from approximately $600 \mu \mathrm{m}$ to $6250 \mu \mathrm{m}$.

- The bounding Mark IV fuel MCO had an exposed uranium surface area of $12 \mathrm{~m}^{2}$. The KOP MCO based on safety basis parameter values has $49 \mathrm{~m}^{2}$.

- The maximum mass of Mark IV fuel in a scrap basket was limited to $980 \mathrm{~kg}$. The mass of KOP material that can be stored in a single MCO is constrained by the limit of the mass of hydrate and will be less than $200 \mathrm{~kg}$ or about $65 \mathrm{~kg}$ per basket containing KOP material.

\section{INPUT PARAMETERS AND ASSUMPTIONS}

\subsection{Summary of Data Book Data for Knock Out Pot Sludge}

The cases analyzed in this document are based upon key input parameters and specific process and equipment designs. The design basis accident scenarios exclude any operator intervention in order to estimate the behavior of an unmitigated accident based on just the physics and chemistry of the MCO under accident conditions. The most important input parameters affecting the thermal analysis of the MCO during CVDF processing are the following:

- Uranium-water reaction areas and rate enhancement factors

- Heat transfer rate through the annulus from the MCO to the cask 


\section{PRC-STP-00187 REV 0}

- Decay heat rate of KOP material

Detailed data for sludge properties, including KOP sludge, is defined in HNF-SD-SNF-TI-015, Vol. 2, Sludge Technical Data Book. The technical basis for selection of data in HNF-SD-SNFTI-015 is contained in SNF-7765, Supporting Basis for Spent Nuclear Fuel Project Sludge Technical Databook.

Knock-Out Pot (KOP)/Strainer Sludge is not a representative/controlling sludge - its composition is derived/calculated based on ratios to representative/controlling sludge sources (see Tables 3-2 and 5-1 of HNF-SD-SNF-TI-015, Vol.2). KOP sludge consists of size-segregated material from the fuel, canister, and scrap cleaning. The representative sludge for safety basis KOP is sizesegregated fuel piece sludge. Fuel piece sludge encompasses KE and KW Basins sludge dislodged when the fuel was cleaned in preparation for dry storage. Based on the physical state of the fuel and the fractured state of the uranium within the breached fuel elements, further breakage of the fuel elements also dislodged corroded uranium metal pieces with zirconium cladding. During fuel washing in the Primary Cleaning Machine (PCM), sludge removed from the fuel elements was passed through a $1 / 4$ in screen, and then passed through a strainer basket with $1 / 8$ in openings prior to going to the KOPs.

Containers of KOP material vary significantly in density and composition, but are known to contain uranium metal, hydrated forms of uranium, iron, and aluminum, as well as other foreign material. This sludge will be highly radioactive with relatively high concentrations of uranium metal. 
PRC-STP-00187 REV 0

Table 4-1 KOP Sludge Databook Values

\begin{tabular}{|c|c|c|}
\hline Property (per volume of wet sludge) & Safety Basis Values & Reference \\
\hline KOP sludge & $\begin{array}{l}\text { Size-Segregated Fuel } \\
\text { Piece Sludge }\end{array}$ & Databook, Vol. 2, Table 3-2 \\
\hline Wet sludge density & $10.5 \mathrm{~g} / \mathrm{cm}^{3}$ & Databook, Vol. 2, Table 4-1 \\
\hline Reaction rate Enhancement Factor & 3 & Databook, Vol. 1, Table 4-10a \\
\hline Decay power per volume of uranium & $\begin{array}{c}117 \mathrm{~W} / \mathrm{MTU} \\
\left(1100 \mathrm{~W} / \mathrm{m}^{3} \mathrm{U}\right)\end{array}$ & Databook, Vol. 2, Table 4-11 \\
\hline Thermal conductivity of sludge & $3.90 \mathrm{~W} / \mathrm{m} / \mathrm{K}$ & Databook, Vol. 2, Table 4-12 \\
\hline Total Uranium concentration & $9.40 \mathrm{~g} / \mathrm{cm}^{3}$ & Databook, Vol. 2, Table 4-3 \\
\hline $\begin{array}{r}\text { Reaction Rate with Liquid Water } \\
\text { (Oxygen Free) }\end{array}$ & $\begin{array}{l}\text { Same as for fuel } \\
\text { with water }\end{array}$ & Databook, Vol. 2, Table 4-4 \\
\hline Uranium Metal Concentration & $9.40 \mathrm{~g} / \mathrm{cm}^{3}$ & Databook, Vol. 2, Table 4-4a \\
\hline Water volume fraction & $40 \%$ & Databook, Vol. 2, Table-4-2 \\
\hline $\begin{array}{r}\text { Reactive Sludge Particle Size for Uranium } \\
\text { Metal - Segregated Diameter }\end{array}$ & $1500 \mu \mathrm{m}$ & Databook, Vol. 2, Tables 4-5b \\
\hline $\begin{array}{r}\text { Reactive Sludge Particle Size for Uranium } \\
\text { Long Term Survival Diameter }\end{array}$ & $2300 \mu \mathrm{m}$ & Databook, Vol. 2, Tables 4-5c \\
\hline Formula weight of $U$ oxide compounds & 288.6 & SNF-7765, page C-4 \\
\hline Uranium oxide density & $7.50 \mathrm{~g} / \mathrm{cm}^{3}$ & SNF-7765, page C-7 \\
\hline Uranium metal density & $19.0 \mathrm{~g} / \mathrm{cm}^{3}$ & SNF-7765, page C-7 \\
\hline Water density & $1.0 \mathrm{~g} / \mathrm{cm}^{3}$ & SNF-7765, page C-7 \\
\hline
\end{tabular}

HNF-SD-SNF-TI-015, Spent Nuclear Fuel Project Technical Databook, Vol 1

HNF-SD-SNF-TI-015, Spent Nuclear Fuel Project Technical Databook, Vol 2, Sludge

SNF-7765, Supporting Basis for SNF Project Technical Databook

It is assumed that a separations process will be used to remove most particles of less than 500 to 600 micron size. The purpose of the separations process is to eliminate very small particles that are known to prevent water draining and to greatly impede drying of the KOP material, and to eliminate material that was not part of the original KOP stream (which was all above 500 or 600 microns). KOP material is presently categorized as a K Basins sludge stream. Sludge properties are summarized in the HNF-SD-SNF-TI-015, Spent Nuclear Fuel Project Technical Databook, Vol 2, Sludge and supporting documents (SNF-7765, 2006, Supporting Basis for Spent Nuclear Fuel Project Sludge Technical Databook). Limited KOP material inspections confirmed that the density is less than that of fuel piece material. However, due to the assumed process to remove fines, fuel piece properties in Table 4-1 apply.

\section{4,2 Summary of Design Parameters}

The key input parameters used in the analysis for the bounding (safety basis) MCO are shown in Table 4-2. 
PRC-STP-00187 REV 0

Table 4-2 Key Input Parameters for Safety Basis (Bounding) Knock Out Pot MultiCanister Overpack

\begin{tabular}{|c|c|c|c|}
\hline \multirow[b]{2}{*}{ Parameter } & \multicolumn{2}{|c|}{ Value } & \multirow[b]{2}{*}{ Reference } \\
\hline & $\begin{array}{c}\text { Cases } 1,2 \\
\quad 3, \& 4\end{array}$ & $\begin{array}{l}\text { Cases 5, 6, } \\
\quad 7, \& 8\end{array}$ & \\
\hline \multicolumn{4}{|c|}{ KOP MCO Loading } \\
\hline $\begin{array}{l}\text { KOP basket insert loading height } \\
\text { (estimate) }\end{array}$ & \multicolumn{2}{|c|}{20 in } & \\
\hline KOP basket insert cross sectional area & \multicolumn{2}{|c|}{$4.25 \mathrm{in}^{2}$} & \\
\hline Volume of KOP material per basket insert & \multicolumn{2}{|c|}{$1.39 \mathrm{~L}$} & $\begin{aligned} 20 \mathrm{in} \times 4.25 \mathrm{in}^{2} & =85 \mathrm{in}^{3} \\
& =1.39 \mathrm{~L}\end{aligned}$ \\
\hline Number of inserts per KOP basket & \multicolumn{2}{|c|}{6} & \\
\hline Volume of KOP material per basket & \multicolumn{2}{|c|}{$8.36 \mathrm{~L}$} & $6 \times 1.39 \mathrm{~L}=8.36 \mathrm{~L}$ \\
\hline Number of baskets per KOP MCO & \multicolumn{2}{|c|}{3} & \\
\hline Maximum Total Sludge Volume per MCO & \multicolumn{2}{|c|}{$25 \mathrm{~L}$} & $3 \times 8.36 \mathrm{~L}=25 \mathrm{~L}$ \\
\hline \multicolumn{4}{|l|}{ Material Properties } \\
\hline Wet sludge density $\left(\mathrm{g} / \mathrm{cm}^{3}\right)$ & & 10500 & \\
\hline Total Uranium concentration $\left(\mathrm{g} / \mathrm{cm}^{3}\right)$ & 11,750 & 9400 & \\
\hline Uranium Metal Concentration $\left(\mathrm{g} / \mathrm{cm}^{3}\right)$ & 11,750 & 9400 & \\
\hline Water volume fraction & .25 & .40 & \\
\hline $\begin{array}{l}\text { Thermal conductivity of uranium metal } \\
(\mathrm{W} / \mathrm{m} / \mathrm{K})\end{array}$ & 26.9 & & \\
\hline $\begin{array}{l}\text { Thermal conductivity of KOP sludge with } \\
40 \% \text { water }(\mathrm{W} / \mathrm{m} / \mathrm{K})\end{array}$ & \multicolumn{3}{|c|}{$\begin{array}{l}\text { Thermal conductivity model described in Appendix B, Section } \\
\text { 3.4.3, KBC-38156, Conceptual Feasibility Report for KOP } \\
\text { Accelerated Disposition. }\end{array}$} \\
\hline Stainless steel density at $100^{\circ} \mathrm{C}\left(\mathrm{kg} / \mathrm{m}^{3}\right)$ & \multicolumn{2}{|c|}{8000} & \\
\hline $\begin{array}{l}\text { Stainless steel thermal conductivity } \\
(\mathrm{W} / \mathrm{m} / \mathrm{K})\end{array}$ & \multicolumn{2}{|c|}{16.0} & \\
\hline Stainless steel specific heat $(\mathrm{J} / \mathrm{kg} / \mathrm{K})$ & \multicolumn{2}{|c|}{500} & \\
\hline Copper insert density at $100^{\circ} \mathrm{C}\left(\mathrm{kg} / \mathrm{cm}^{3}\right)$ & \multicolumn{2}{|c|}{8954} & \\
\hline $\begin{array}{l}\text { Copper insert thermal conductivity } \\
(\mathrm{W} / \mathrm{m} / \mathrm{K})\end{array}$ & \multicolumn{2}{|c|}{398} & \\
\hline Copper insert specific heat $(\mathrm{J} / \mathrm{kg} / \mathrm{K})$ & \multicolumn{2}{|c|}{384} & \\
\hline \multicolumn{4}{|c|}{ Heat Generation Parameters } \\
\hline Particle Diameter (short term) $(\mu \mathrm{m})$ & 600 & 1500 & TI-0 I5, Tables 4-5a and 4-5b \\
\hline Particle Diameter (long term $)(\mu \mathrm{m})$ & & 2300 & TI-015, Table 4-5a \\
\hline \multicolumn{4}{|c|}{ Radiation Heat Transfer Parameters } \\
\hline Cladding emissivity & 0.7 & 0.7 & \\
\hline Inner shield plug emissivity & 0.3 & 0.3 & \\
\hline MCO wall emissivity & 0.3 & 0.3 & \\
\hline
\end{tabular}


PRC-STP-00187 REV 0

\begin{tabular}{|l|c|c|c|}
\hline \multicolumn{4}{|c|}{ Nominal Process Parameters } \\
\hline Vacuum pumping rate & 30 & $30 / 13$ & \\
\hline Helium purge rate & $1.5 \mathrm{scfm}$ & $1.5 \mathrm{scfm}$ & \\
\hline Free residual water after draining & 0.2 & 0.2 & \\
\hline Normal process bay temperature & 50 & 50 & \\
\hline
\end{tabular}

\section{SOFTWARE APPLICATION, DESCRIPTIONS, INSTALLATION AND STATEMENT OF VALIDITY}

The FATE ${ }^{\mathrm{TM}}$ computer program is used for this work [SNF-23281, Lee and Plys, 2006] (the TM symbol will be dropped for simplicity). The FATE sludge model was developed by FAI for the Hanford Spent Nuclear Fuel Program and the K Basins Closure Project under the FAI Quality Assurance Program. FATE has been used for K Basins sludge applications including scoping calculations, normal and off-normal behavior, and accidents including pump station spills and spray leaks at Cold Vacuum Drying Facility (CVDF).

The FATE computer program was modified to address differences between MCOs containing spent fuel and MCOs containing KOP Material. This modified program is suitable for the conceptual phase KOP Material scoping calculations presented in this document; QA and V\&V of this modified program will be conducted prior to the use of the model to perform next phase calculations that will be used for detailed design and formal safety analysis.

Briefly, FATE can model heat transfer, fluid flow, and chemical reactions in a vessel as well as the building or facility containing the vessel, and the environment. Decay power, oxidation power, and conversion of metal to oxide with the associated decrease of reactive surface area are included.

The thermal conceptual model of the MCO at the CVDF consists of the processes and physical phenomena that need to be modeled numerically. The numerical model, which is a computer code, incorporates the conceptual model and calculates the numerical results. The conceptual model for the cold vacuum drying process needs to incorporate heat and mass transfer mechanisms that include (1) thermal conduction in solids, liquids, and gas mixtures, (2) radiative heat transfer from solid to solid, (3) convection of gases, (4) water evaporation and condensation, (5) dynamic gas-solid chemical reactions in confined spaces, and (6) thermal decomposition of hydrates. A separate report, FAI/09-254 by M. Epstein, describes analyses of phenomena during CVD, models, and stand-alone assessments in detail.

The FATE model representation for CVDF processing of KOP material is shown in Figure 5-1. Since the copper block is nearly isothermal, by (thermal) symmetry the KOP material is modeled as a layer with $1 / 2$ inch thickness insulated in what would be the middle of the 1 inch thick fuel section. Conduction heat transfer across the steam/helium gap from the copper block to the scrap basket shroud to the MCO wall is considered. The gap distance is conservatively taken to be $0.0143 \mathrm{~m}$, a $0.00476 \mathrm{~m}$ gap between the MCO wall and the basket shroud plus two 3/16 in gaps between the basket shroud and copper block. The description of the conduction path through these gaps that appears on page 15 of the attachment is not consistent with the description presented here. The attachment describes a configuration of the model used in an earlier set of calculations and does not correctly reflect the calculations presented in these documents. 
Per the design, three baskets containing KOP material are separated by empty baskets with an empty basket in the bottom of the MCO. After draining, residual water remains in KOP material pores, and a heel of water remains on the MCO bottom, which can partially submerge KOP material if it is loaded in the bottom basket. Since the bottom basket is empty in the current design, submerged KOP material is not a concern in this analysis.

Calculations are based on a simplified drying cycle and assume vacuum is applied at the start of the cycle and continues uninterrupted until free water is removed. The actual drying cycle may be more complex and may include such steps as thermal resets requiring a return to atmospheric pressure. The simplified cycle has generated results suitable for these conceptual phase calculations.

The following input values are used for both the conservative and nominal calculations:

- $50{ }^{\circ} \mathrm{C}$ initial temperature (all cases except MCO cool down),

- $1.5 \mathrm{scfm}$ Helium purge rate (normal CVD only),

- 1" effective KOP material thickness, (modeled as $1 / 2$ " KOP thickness with one side insulated boundary),

- 3/8" gap between copper insert and scrap basket copper shroud,

- 20 liters free water heel at MCO bottom (all cases except MCO cool down), and

- $10 \mathrm{X}$ reaction rate law multiplier (literature rate multiplied by 10 )

In the conservative case ( $25 \%$ void fraction), we use:

- $600 \mu \mathrm{m}$ particle diameter for reactive surface area,

- $11.77 \mathrm{~kg} /$ liter uranium loading in the block,

- $75 \%$ volume fraction of uranium (25\% free volume),

- 12 vol\% residual free water in KOP material. 
PRC-STP-00187 REV 0

Figure 5-1 FATE model representation for CVD of KOP material in an insert block

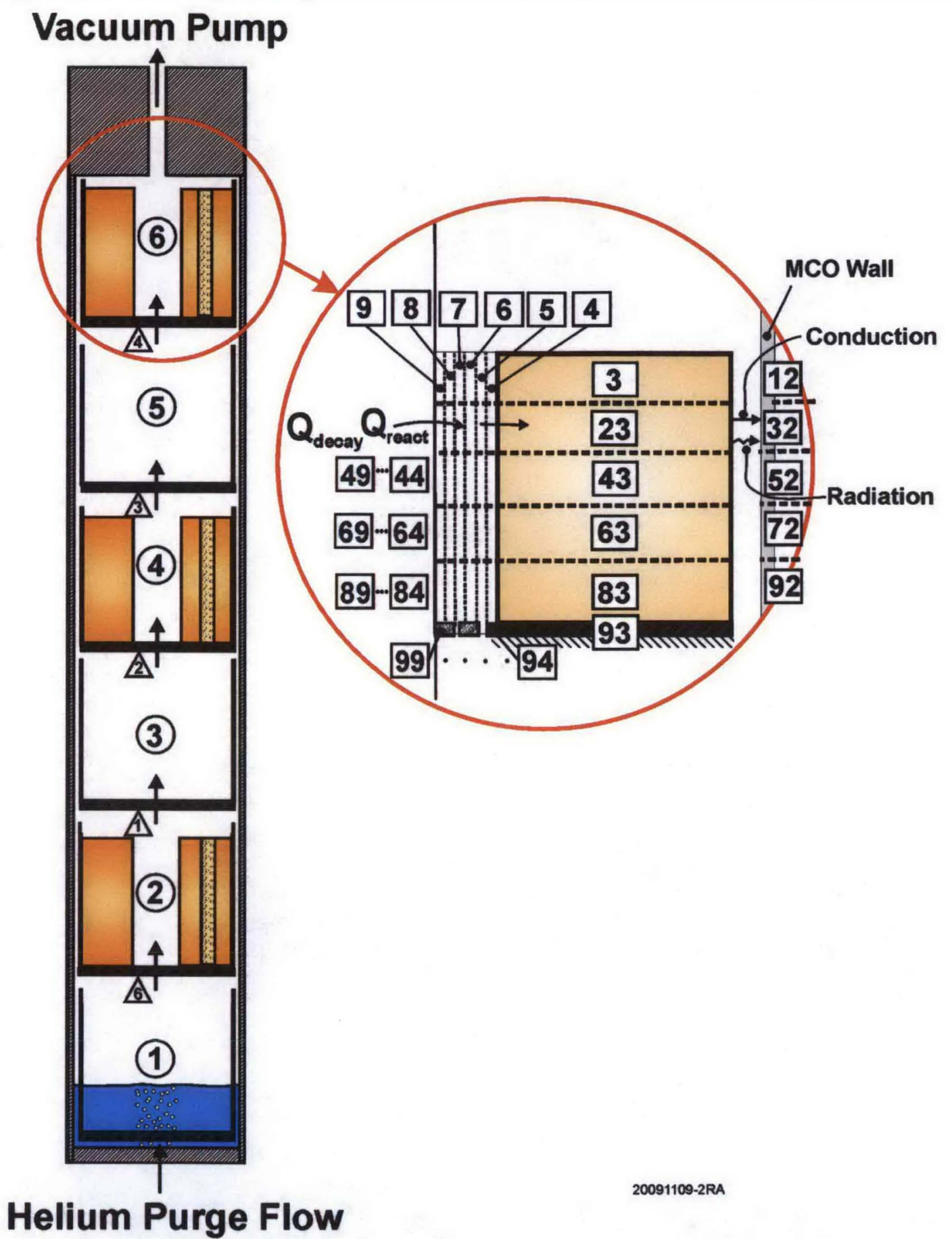

Several input values are used for the design calculations that are more conservative than the safety basis values supplied by the HNF-SD-SNF-TI-015, Vol. 2. The void fraction for the KOP material was reduced from $40 \%$ to $25 \%$ which increases the surface area and uranium metal and thus increases the KOP material oxidation rate. The 600 micron particle size is less than half the safety basis size of 1500 microns, so it provides 2.5 times the reactive surface area per unit 
volume. Since visual observation of KOP material indicates that a significant fraction of the material is larger than $600 \mu$, this represents a bounding case so that results are not sensitive to variations of a separations process. The volume fraction of residual water was previously estimated at $7.5 \mathrm{vol} \%$ in the nominal case (see Epstein, 2008), however in the conservative case it is assumed to be $12 \mathrm{vol} \%$ pending further investigation.

Water vapor available for reaction with KOP material is either residual water initially present in the pores in the KOP material, or it is water vapor that diffuses inward (i.e., upward or downward through the porous bed) from the local gas surrounding a copper insert. As water vapor diffuses into the relatively long and narrow porous bed, reacting with uranium, the water vapor mass fraction decreases. The reaction rate depends upon the square root of the water vapor partial pressure, which is proportional to the water vapor mass fraction. A model for this phenomenon is described in Section 6 of FAI/09-254, Correlations and Models in Support of FATE Computer Program Thermal Analyses of KOP Material During CVD and Shipping, (Epstein, 2009), and it provides a step-by-step prescription to evaluate the "reaction efficiency," which is the reduction of the reaction rate compared to what it would be if all the KOP material were exposed to water vapor at the pressure outside the copper block.

Note that if residual water remains on the KOP material, then steam is produced locally and the reaction is not limited by diffusion. If the saturation pressure of wetted KOP material, evaluated at the KOP material temperature, is above the MCO total pressure, this corresponds to boiling of the residual water. If the saturation pressure is below the $\mathrm{MCO}$ total pressure, then evaporation occurs just at the rate required to supply the reaction with uranium. This conservatively supplies reactant. If residual water has vanished and additional water to support the oxidation reaction can be supplied only from water vapor in the local gas surrounding the insert, then the diffusion limitation applies.

\section{COLD VACUUM DRYING CASES, CALCULATIONS AND RESULTS}

This chapter provides the description and results of cases analyzed for the KOP MCO in various processing states at the CVDF. The KOP process scenarios were selected based on their importance to understanding nominal performance and safety at the CVDF. The thermal models used in these calculations have been used previously to run a broad spectrum of cases for the processing of 2100 tons of $\mathrm{N}$ Reactor Fuel and scrap at CVDF. The set of cases run in this calculation have been shown by previous analyses to adequately represent the system performance (HNF-SD-SNF-CN-023). The cases are classified into four groups:

- Base CVD case

- Degraded Vacuum Pumping with No Helium Purge

- Open MCO with loss of Annulus water

- Cooling after vacuum drying

These four cases were re-analyzed here using safety basis KOP material properties $(1500 \mu \mathrm{m}$ diameter and $40 \%$ void fraction). The purpose of these analyses is to document the safety basis results. An additional purpose of the baseline CVD case is to document the amount of particulate generated. 


\subsection{Base Case Behavior - Normal CVDF processing}

Normal thermal behavior during vacuum processing depends on (1) the evaporation rate of water from KOP material and MCO structures (e.g., wall), (2) the thermal effects of evaporation (initial cooling of KOP sludge followed by temperature increases from decay heat and uranium-water and uranium hydride-water chemical reactions), (3) the removal rate of the water vapor from the $\mathrm{MCO}$, and (4) heat transfer from the KOP material. During normal operation, the vacuum rate is at least $30 \mathrm{ft}^{3} / \mathrm{min}$.

Detailed investigation has shown the copper blocks are nearly isothermal, which is essential to their feature in providing heat capacity to suppress temperature increases. Residual water on the KOP material is gone after about 30 minutes, so that for most of the drying period, water vapor is supplied by the bottom heel but a diffusion limitation occurs within KOP material. Results shown here are influenced in a conservative manner by the large residual water heel, and drying would be faster with a smaller heel. Also, this case is truly thermally stable, because heat losses are able eventually to equal heat sources (to observe this requires an alternate scenario with a considerably larger water heel, and duration of about 24 hours).

The results of simulating the normal processing at CVD with $25 \%$ void fraction KOP material are shown in Figure 6-1. These results demonstrate thermal stability during the MCO drying. The figure has three separate history plots as follows (figures for the other cases have equivalent plots):

Top: $\mathbf{M C O}$ pressure (Pa). The pressure gradually decreases as residual water is evaporated from various scrap baskets, and it decreases suddenly when the bottom water heel dries out. The KOP material dries out in approximately 30 minutes and the bottom water heel has evaporated after about 9.7 hours.

Middlet: KOP material temperature per tier, ${ }^{\circ} \mathbf{C}$. Temperatures stay within about 12 degrees of the initial temperature. "Noise" in the temperature and steam concentration early in the calculation is during the period when water is boiling inside the KOP material, and the end of the "noise" corresponds to dry-out of the KOP material.

Bottom: Reaction power per tier and decay power $(W)$. Reaction power far exceeds decay power, while local surface water is available. After the KOP material dries out, the reaction rate is limited by diffusion of steam into the KOP material. 
Figure 6-1 Case 1: CVD of 25\% Void Fraction KOP Material (Design Parameters)

KOPC19: KOP CVD, 25\% void, $11.77 \mathrm{kgU} / \mathrm{L}, 600$ micron, 10X, 12\% Res Water, $20 \mathrm{~L}$ Water Heel, Steam Diffusion Limited, $4.25 \mathrm{sq-in} \times 20$ " KOP in 1" Insert,

38 sq-in × 20" Cu Backplate, 1.5 CFM He Purge, 50C MCO, Baskets 2, 4. 6
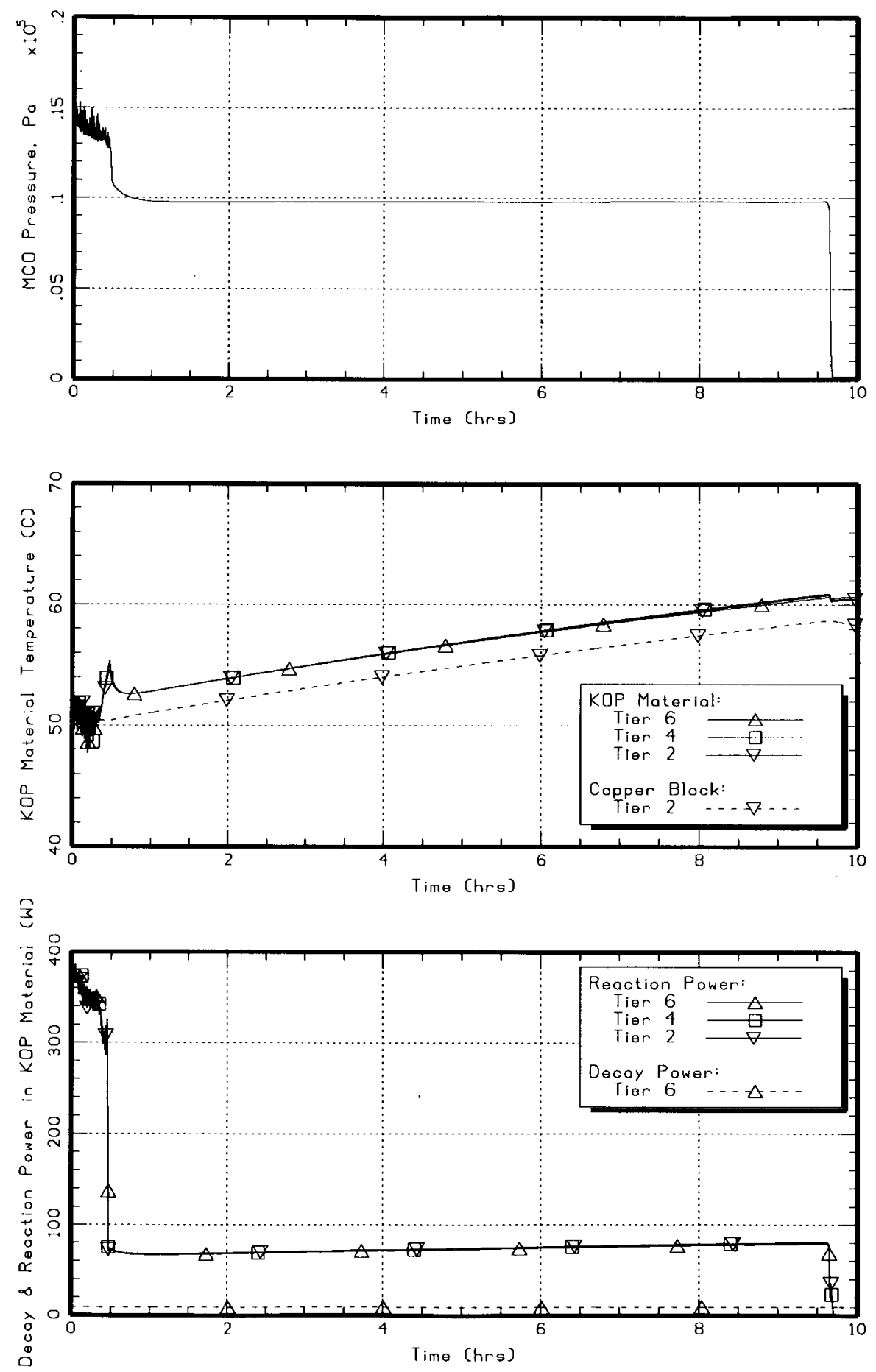

The results of simulating CVDF safety basis KOP material are shown in 


\section{PRC-STP-00187 REV 0}

Figure 6-2. The results also demonstrate thermal stability during the processing. Residual water in the scrap baskets boils away in slightly less than one hour, and the residual water heel evaporates in about 9.7 hours. Uranium dioxide is steadily produced with a maximum mass of $3.4 \mathrm{~kg}$ produced before the MCO is dry.

\section{Figure 6-2 Case 5: CVD of Safety Basis KOP Material (Safety Basis Parameters)}

KOPC18: KOP CVD, $25 \%$ void, $9.42 \mathrm{kgU} / \mathrm{L}, 1500$ micron, 10X, 12\% Res Water,

38 sq-in $\times 20$ " $\mathrm{Cu}$ Bockplate, $1.5 \mathrm{CFM} \mathrm{He} \mathrm{Purge,} 50 \mathrm{C} \mathrm{MCO}$, Baskets 2, 4, 6
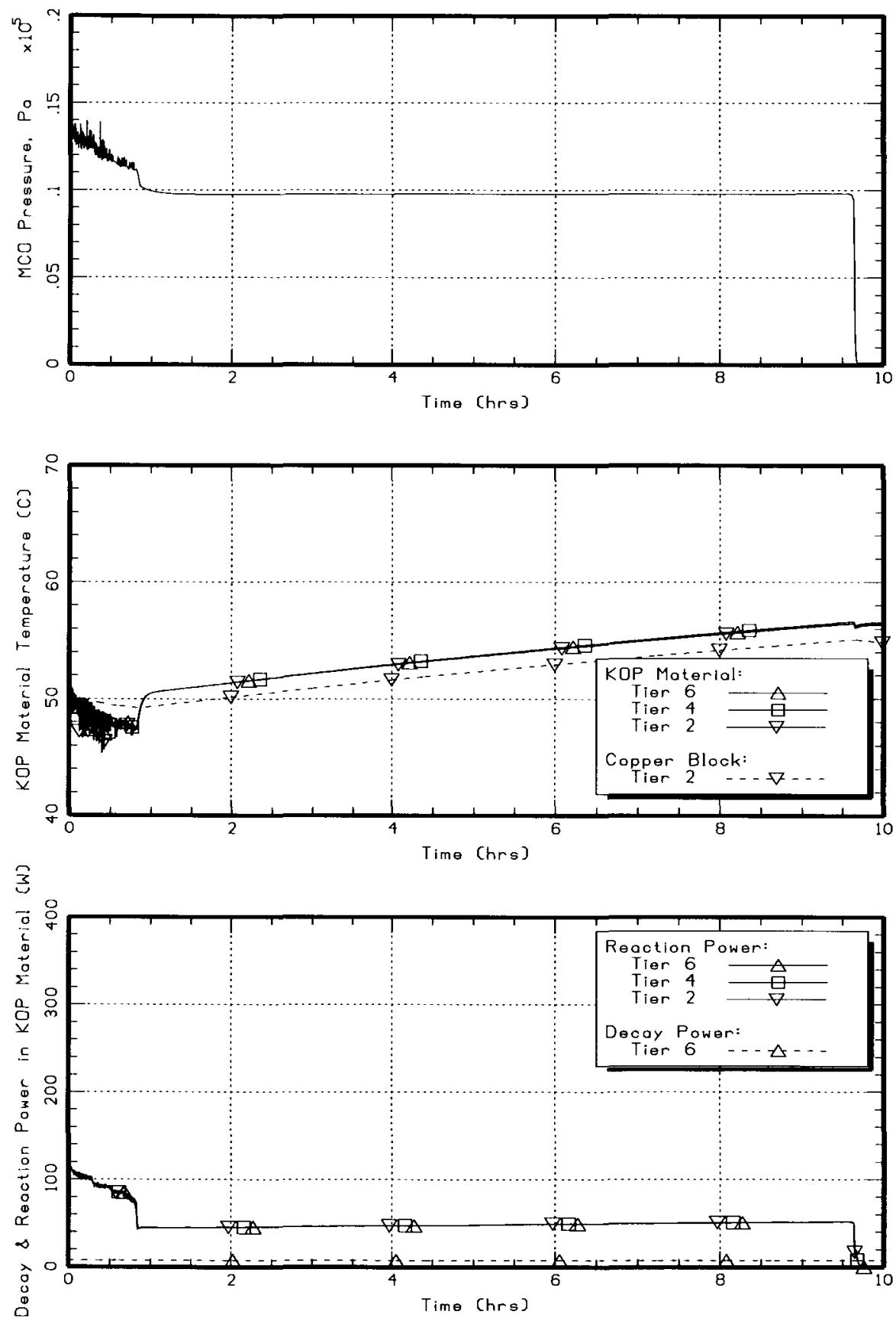


\section{PRC-STP-00187 REV 0}

\subsection{Degraded Vacuum Pumping with No Helium Purge}

The degraded vacuum pumping accident case considers a low vacuum pumping rate, $13 \mathrm{scfm}$ (compared to the normal rate of $30 \mathrm{scfm}$ ) and no helium injection flow. The degraded-vacuum case bounds all of the other vacuum cases in the original MCO accident calculations (HNF-SDSNF-CN-023). Based upon this experience, if the degraded vacuum case for KOP material is benign, there is no reason to simulate the other vacuum cases. 
PRC-STP-00187 REV 0

Figure 6-3 Case 2: Degraded Vacuum Pumping With No Helium Purge (Design Parameters)

KOP_VACXDG_19: KDP CVD, $11.77 \mathrm{kgU} / \mathrm{L}, 600$ micron, 10X, 12\% Res Water, $20 \mathrm{~L}$ Water Heel, (0.126m high), Steom Diffusion Limited, 3850 IN Cu No He Purge, Degraded Vacuum, 50C MCO, Baskets 2, 4, 6
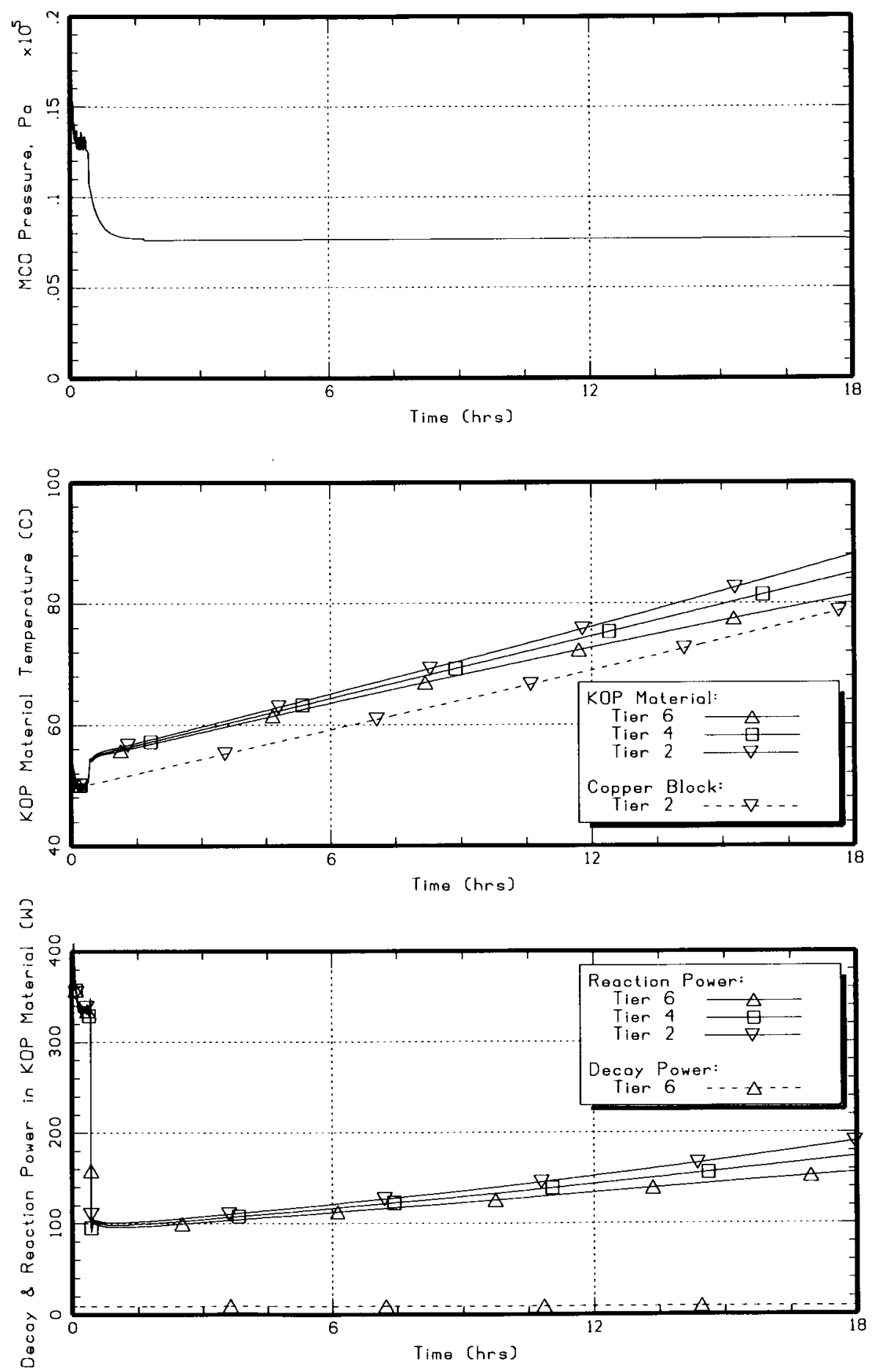


\section{PRC-STP-00187 REV 0}

Transient results histories for this case are shown in Figure 6-3 in the same format as described above for normal CVD. KOP material is thermally stable for this case with conservative values of parameters. The pressure is lower compared to normal CVD with the helium purge, so water in the KOP material boils off faster. However, the water heel evaporates more slowly without the helium purge, and dries out after about 18 hours. The KOP material temperature steadily rises while the heel evaporates, attaining about $88{ }^{\circ} \mathrm{C}$ in the lower basket.

The degraded-vacuum rate case bounds all of the other vacuum cases in the original report (HNF-SD-SNF-CN-023). So if the degraded vacuum case for KOP material is benign, then there is no reason to simulate the other vacuum cases to show the beneficial effects of helium during vacuuming or the 8-4-4 vacuum cycle. Also, the air-ingress case was benign with Mark IV fuel, so it would also be benign with KOP material with its small mass of uranium metal and large copper insert mass per basket and the smaller decay power.

Results for the safety basis degraded vacuum case are shown in Figure 6-4 KOP material is thermally stable, and the peak temperatures is $72{ }^{\circ} \mathrm{C}$, about $6{ }^{\circ} \mathrm{C}$ lower than for the design parameter case. The time for water heel evaporation is 18 hours. 


\section{PRC-STP-00187 REV 0}

Figure 6-4 Case 6: Degraded Vacuum Pumping With No Helium Purge (Safety Basis Parameters)

KOP_VACXDG: KOP CVD, $9.42 \mathrm{kgU} / \mathrm{L}, 1500$ micron, $10 \mathrm{X}, 12 \%$ Res Woter.

$20 \mathrm{~L}$ Water Heel, $(0.126 \mathrm{~m}$ high), Steam Diffusion Limited, $38 \mathrm{SQ}$ IN Cu

No He Purge, Degraded Vocuum, 50C MCO, Baskets 2, 4, 6
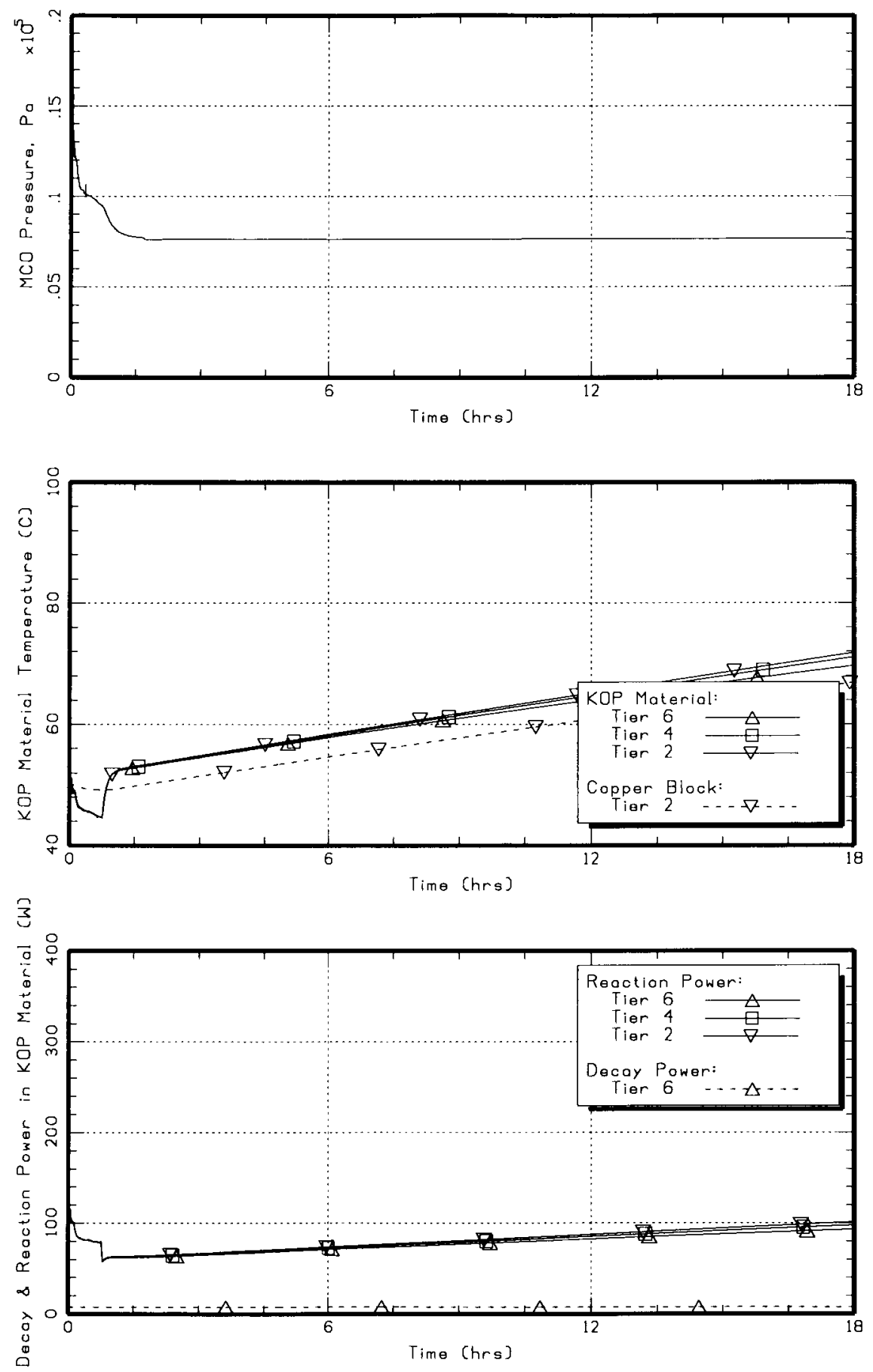


\subsection{Open MCO with loss of Annulus water.}

This case assumes the annulus water is lost during draining of the MCO at CVDF and air replaces the water in the annulus. Air has a thermal conductivity about 25 times smaller than that of water. The gap between the $\mathrm{MCO}$ and cask severely degrades the main mechanism for removing heat from the $\mathrm{MCO}$. The $\mathrm{MCO}$ is simulated with the KOP material at $50^{\circ} \mathrm{C}$ and partially drained but still containing $20 \mathrm{~kg}$ of residual water. To eliminate the benefits of oxygen poisoning, no oxygen is included in the $\mathrm{MCO}$ atmosphere. With the flow resistance in the piping and shield plug, little countercurrent flow of air into the vented MCO is expected.

Only one open vented MCO case needs to be analyzed, which has a loss of annulus water. This is the bounding thermal case for the SNF fuel and results in a thermal runaway after about 11 hours. The other open MCO cases in HNF-SD-SNF-CN-023 should not be needed for KOP material because the cases for Mark IV fuel/MCO should bound the cases for KOP material in regards to thermal behavior. Since the thermal runaway accident with KOP material is so much more benign (or not possible) than the thermal runaway with Mark IV fuel, all of the cases that were thermally stable with Mark IV fuel would also be thermally stable with KOP material and need not be rerun. 
Figure 6-5 Case 3: Open MCO with Loss of Annulus Water (Design

Parameters)

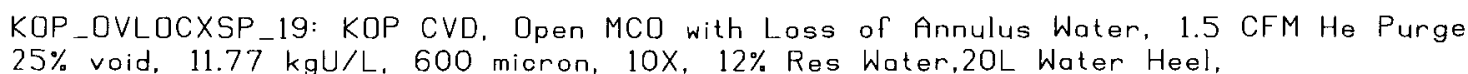

$25 \%$ void, $11.77 \mathrm{kgU/L}, 600 \mathrm{micron}, 10 \mathrm{X}, 12 \%$ Res Water, $20 \mathrm{~L}$ Water Heel,

Steam Diffusion Limited, 4.25 sq-in $\times 20^{\prime \prime}$ KOP in 1" Insert,50C MCO, Baskets 2 , 4, 6
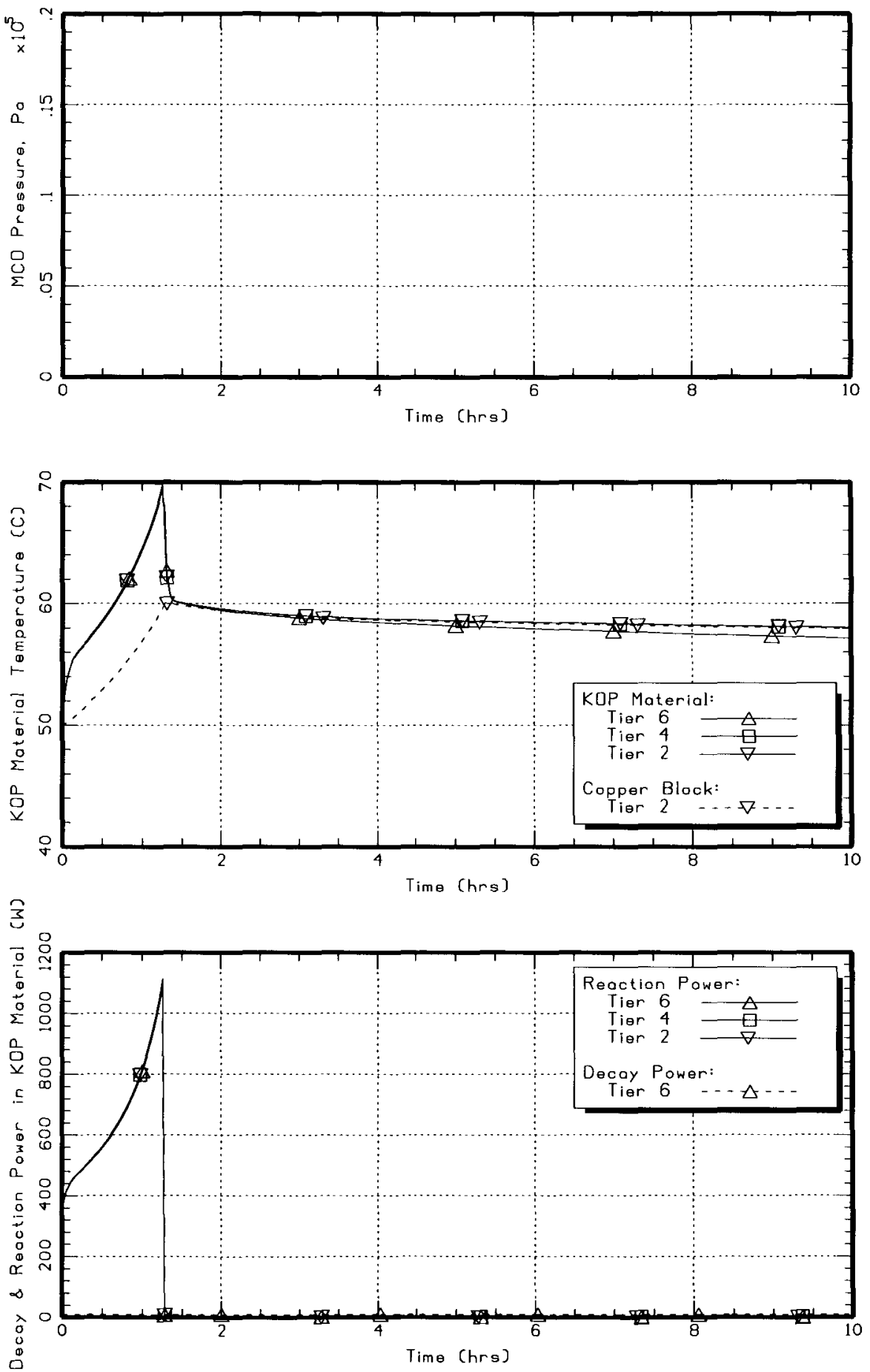

Results for the safety basis loss of annulus water are shown in Figure 6-6. The time period for evaporation of water on KOP material, and its complete local reaction with uranium metal, is 
about 5 hours. This process leads to increased reaction power and temperature rise in the KOP material compared to normal CVD. The KOP material temperature stabilizes near $60^{\circ} \mathrm{C}$ shortly after the residual water in the material is consumed. The residual water heel remains intact.

Figure 6-6 Case 7: Open MCO With Loss of Annulus Water (Safety Basis Parameters)
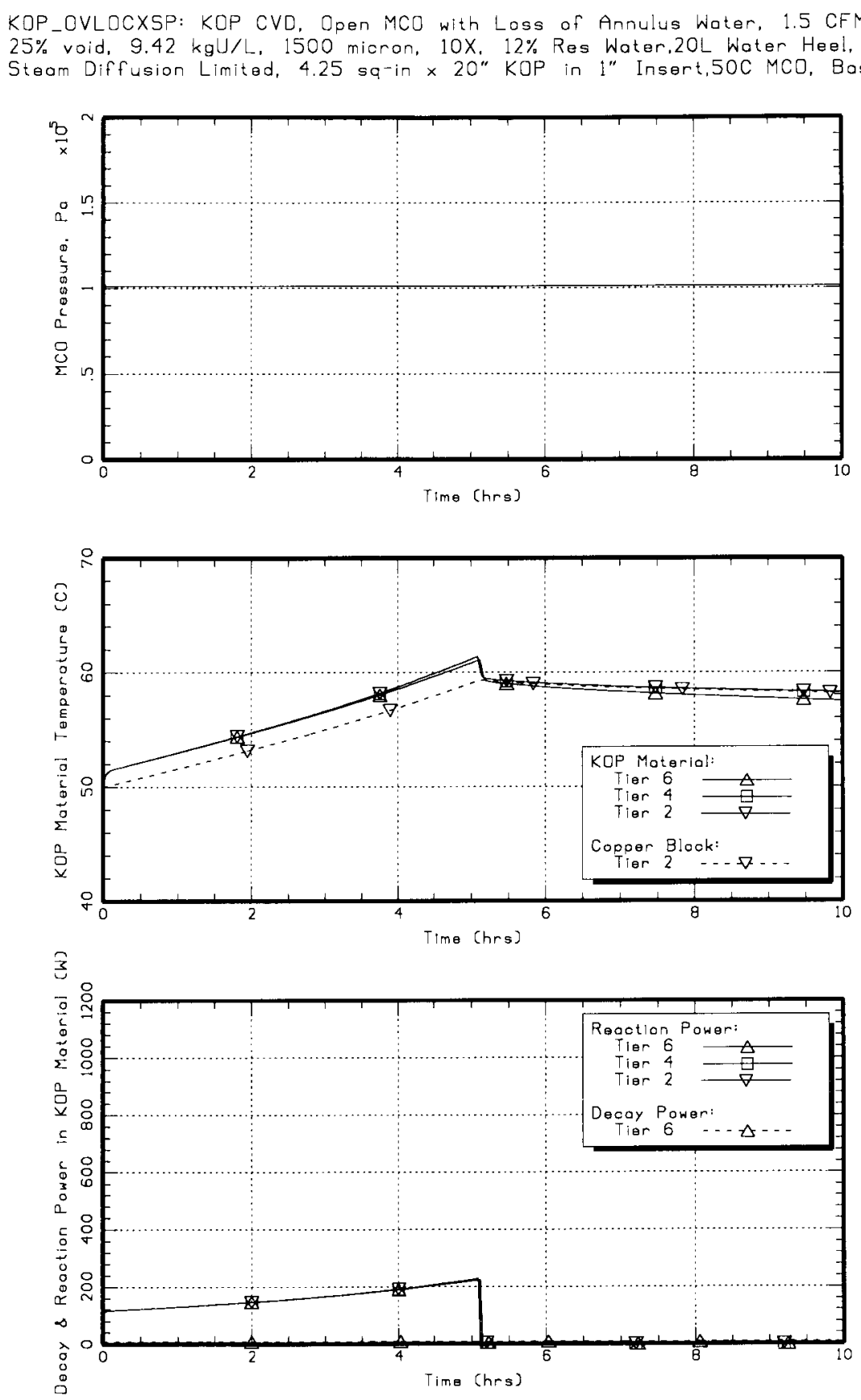

\subsection{Results Multi-canister Overpack Cooling Evaluation}

This case addresses the minimum fuel temperature after a thermal reset and before a pressure rebound test by simulating the cooling period after vacuum drying is completed and final pressure rebound test has been passed. After the rebound test, no more than $200 \mathrm{~g}$ of free water 


\section{PRC-STP-00187 REV 0}

with high flow resistance are left in the MCO. During cooling, the MCO is pressurized with helium to a pressure of $4 \mathrm{lb} / \mathrm{in}^{2}$ gauge. This case determines the maximum gas temperature during cooling with cooling water, $17^{\circ} \mathrm{C}$, injected into the annulus at a rate of 15 gallons per minute. 
Figure 6-7 Case 4: Cooling of MCO and KOP Sludge After Vacuum Drying (Design Parameters)
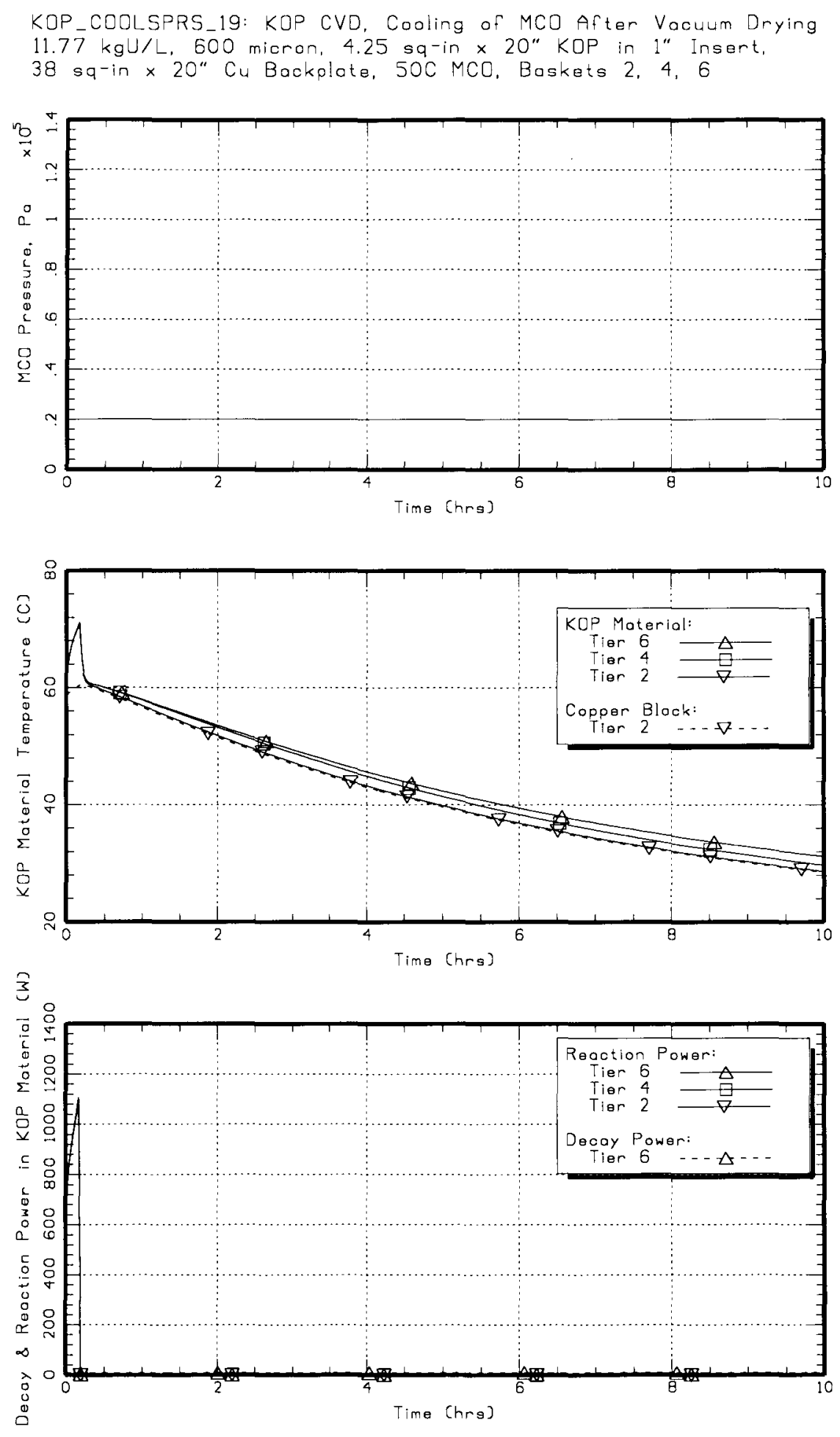


\section{PRC-STP-00187 REV 0}

Results for the safety basis cool down case are shown in Figure 6-8 These results are nearly identical to those presented for the design parameters. After residual water is consumed in about 45 minutes, $\mathrm{KOP}$ material slowly cools to about $30^{\circ} \mathrm{C}$ at the end of 10 hours.

\section{Figure 6-8 Case 8: Cooling of MCO and KOP Sludge After Vacuum Drying (Safety Basis} Parameters)
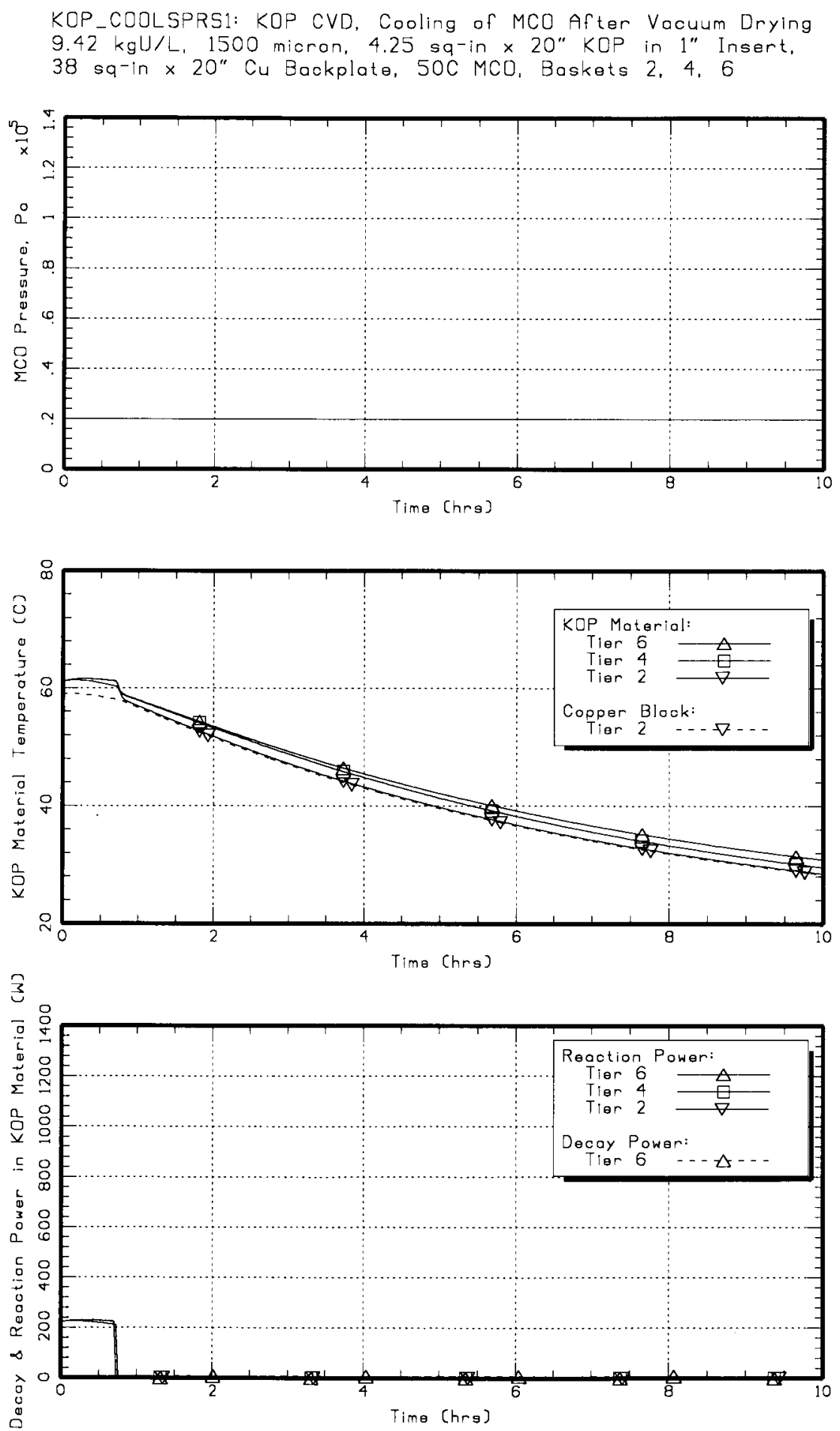


\section{REFERENCES}

Apthorpe, R. and M.G. Plys, M.G., 2010, Cold Vacuum Drying of Knock Out Pot Material in Scrap Basket Insert Blocks, FAI/10-28, Fauske \& Associates, LLC, submitted to CH2M Hill Plateau Remediation Company, Richland, Washington.

Epstein, M., 2008, "Residual Saturation Measurements," FAI Internal Memorandum to M.G. Plys, Fauske \& Associates, LLC., submitted to Fluor Hanford, Inc, Richland, Washington.

Epstein, M., 2009, Correlations and Models in Support of FATE Computer Program Thermal Analyses of KOP Material During CVD and Shipping, FAI/09-254, Rev. 1, Fauske \& Associates, LLC, submitted to CH2M Hill Plateau Remediation Company, Richland, Washington.

HNF-SD-SNF-CN-023, 2000, Thermal Analysis of Cold Vacuum Drying of Spent Nuclear Fuel, Rev 3, Fluor Hanford, Inc, Richland, Washington.

HNF-SD-SNF-TI-015, 2002, Spent Nuclear Fuel Project Technical Databook, Vol. 1, Rev 7A, Fluor Hanford, Inc, Richland, Washington.

HNF-SD-SNF-TI-015, 2009, Spent Nuclear Fuel Project Technical Databook, Vol. 2, Sludge, Rev 14A, CH2MHILL, Plateau Remediation Company, Richland, Washington.

KBC-38156, Conceptual Feasibility Report for KOP Accelerated Disposition, Rev 0, Fluor Hanford, Inc, Richland, Washington.

Lee, S.J., and Plys, M.G. 2006, "FATE 2.057 Software Change Specification and Testing Generic Models," FAI memorandum, August 25, Fauske \& Associates, LLC., submitted to Fluor Hanford, Inc, Richland, Washington.

Lee, S.J., and Plys, M.G., 2009, Cold Vacuum Drying of Knock Out Pot Material in Scrap Basket Insert Blocks, FAI/09-366, Fauske \& Associates, LLC, submitted to CH2M Hill Plateau Remediation Company, Richland, Washington.

Plys, M.G., and Lee, S.J. 2004, "FATE 2.0: Facility Flow, Aerosol, Thermal, and Explosion Model (Improved and Combined HANSF and HADCRT Models)", Fauske \& Associates, LLC., submitted to Fluor Hanford, Inc, Richland, Washington.

Plys, M.G., and S.J. Lee, 2008, "CVD of KOP Material in an MCO Insert Basket," FAI memorandum to J. Sloughter, C. Miska, and N. Sullivan, June 23, 2008, Fauske \& Associates, LLC., submitted to Fluor Hanford, Inc, Richland, Washington.

Sloughter, J. P., 2009, "Hydrate Analysis for Knock Out Pot Material", Interoffice Memorandum to N. J. Sullivan, 09STP-JPS-02, July 21, 2009, CH2MHill Plateau Remediation Company, Richland, Washington

SNF-23281, 2004, FAI/04-71, Facility Flow, Aerosol, Thermal and Explosion Model (Improved and Combined HANSF and HADCRT Models), Vols. $1 \& 2 \mathrm{FAI} / 04-71$, Two Volumes, Fluor Hanford, Inc., Richland, WA, November.Washington.

SNF-7765, 2006, Supporting Basis for Spent Nuclear Fuel Project Sludge Technical Databook, Rev 3B3C, Fluor Hanford, Inc, Richland, Washington. 


\section{PRC-STP-00187 REV 0}

\section{ATTACHMENT}

Apthorpe, R. and M.G. Plys, 2010, Cold Vacuum Drying of Knock Out Pot Material in Scrap Basket Insert Blocks, FAI/10-28, Fauske \& Associates, LLC, submitted to CH2M Hill Plateau Remediation Company, Richland, Washington. 


\title{
Report No.: FAl/10-28
}

Cold Vacuum Drying of Knock Out Pot Material in Scrap Basket Insert Blocks

\author{
Submitted to: \\ C2HM Hill Plateau Remediation Company \\ Richland, Washington
}

Prepared by:

Robert Apthorpe

Martin Plys

Reviewed by:

Sung Jin Lee

January, 2010 


\section{TABLE OF CONTENTS}

1.0 SUMMARY

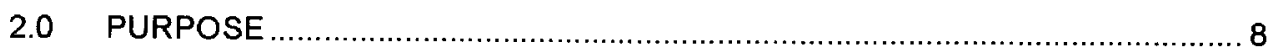

3.0 CONCEPTUAL DESIGN FOR CVD OF KOP MATERIAL ............................. 9

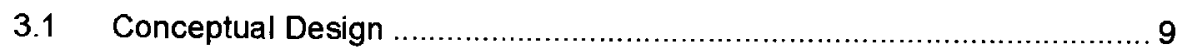

3.2 Assumed Process and KOP Material Properties .................................. 9

4.0 FATE MODEL REPRESENTATION AND PHYSICAL MODELS....................... 13

4.1 Thermal Stability Concern Background ................................................... 13

4.2 Model Representation ........................................................................ 13

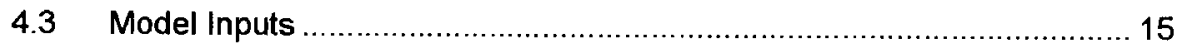

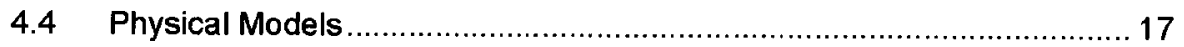

5.0 SIMULATION OF CVD OF 25\% VOID FRACTION KOP MATERIAL ................ 19

5.1 Case 1: KOPC19 - CVD of 25\% Void Fraction KOP Material ............... 19

5.2 Case 2: KOP_VACXDG_19 - Degraded Vacuum Pumping With No Helium Purge

5.3 Case 3: KOP_OVLOCXSP_19 - Open MCO With Loss of Annulus Water.

5.4 Case 4: KOP_COOLSPRS_19 - Cooling of MCO and KOP Sludge After Vacuum Drying.

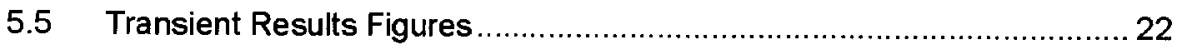

6.0 SIMULATION OF CVD OF 40\% VOID FRACTION KOP MATERIAL................. 31

6.1 Case 5: KOPC18 - CVD of Safety Basis KOP Material .......................... 31

6.2 Case 6: KOP_VACXDG - Degraded Vacuum Pumping With No Helium Purge

6.3 Case 7: KOP_OVLOCXSP - Open MCO With Loss of Annulus Water 
6.4 Case 8: KOP_COOLSPRS1 - Cooling of MCO and KOP Sludge After Vacuum Drying.

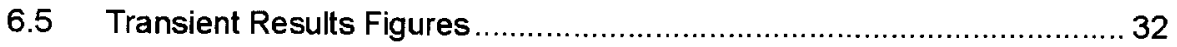

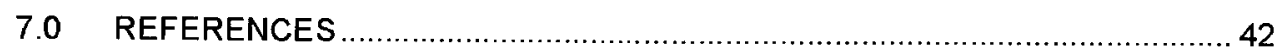

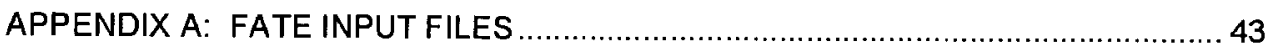




\section{LIST OF FIGURES}

Figure 3-1 Copper insert block plan and elevation views ............................... 10

Figure 3-2 Copper insert block plan and section view.................................... 11

Figure 4-1 FATE model representation for CVD of KOP material in an insert block....................................................................... 14

Figure 5-1 Case 1: CVD of 25\% Void Fraction KOP Material .............................. 23

Figure 5-2 Case 2: Degraded Vacuum Pumping With No Helium Purge ................ 25

Figure 5-3 Case 3: Open MCO With Loss of Annulus Water .......................... 27

Figure 5-4 Case 4: Cooling of MCO and KOP Sludge After Vacuum Drying ..........29

Figure 6-1 Case 5: CVD of Safety Basis KOP Material........................................ 33

Figure 6-2 Case 6: Degraded Vacuum Pumping With No Helium Purge ................. 36

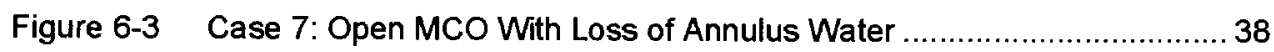

Figure 6-4 Case 8: Cooling of MCO and KOP Sludge After Vacuum Drying .......... 40 


\section{LIST OF TABLES}

Table 3-1 Conservative KOP Material Properties, Safety Basis Fuel Pieces

Table.3-2 Nominal KOP Material Properties, Safety Basis Fuel Pieces 


\subsection{SUMMARY}

During the latter half of FY09 Fauske \& Associates, LLC has worked interactively with the Sludge Treatment Project to evaluate the thermal and gas generation issues associated with placing Knock Out Pot (KOP) material into a Multi-Canister Overpack (MCO) for cold vacuum drying (CVD). On the design side, a number of potential designs, features, dimensions, and material loadings have been explored, and on the modeling side, physical models appropriate to the design have evolved and been assessed.

This report presents results for the current design using the most mature model approach. The crucial feature of results to be found is thermal stability of the KOP material under restrictive operating conditions and bounding design assumptions. Model features and inputs are selected to minimize the need for technical specifications that would require verification, so that results presented here are therefore conservative. Additionally, this conservative model is compared against a model using safety-basis parameters to illustrate the degree of conservatism in the conservative approach.

KOP material will be placed in a 1" wide slot within a copper block, six of which are loosely placed within the outer (coarse) sections of a Mark 1A scrap basket (see Section 3.) Three such baskets are loaded, in alternating positions (see Section 4.) Results using conservative KOP material properties are presented in Section 5 and results using safety basis KOP material properties are presented in Section 6 .

In simulation of the normal CVD process using conservative, bounding values for the material characteristics, reaction rates, and MCO conditions, the KOP material is predicted to have stable temperature behavior and the $M C O$ is expected to dry out after about 9.5 hours. Stable behavior is also predicted for one key accident scenario, loss of annulus water. Acceptable behavior is predicted for another key accident scenario, degraded vacuum pumping with no helium purge. In this case, the KOP material temperature is below $100{ }^{\circ} \mathrm{C}$ when the conservatively large residual water heel is evaporated after a duration of 18 hours. In theory, a similar case with even more water would eventually be thermally unstable. A case for MCO cooldown is also presented here for comparison to backfill conditions required for the canister storage building (CSB).

Using safety basis KOP material properties, the KOP material is predicted to have stable temperature behavior and $\mathrm{MCO}$ dryout is expected at 9 hours. Approximately $3.4 \mathrm{~kg}$ of uranium dioxide is predicted to be produced. Cases analyzed 


\section{PRC-STP-00187 REV 0}

FAl/10-28

Page 7 of 99

Rev. 0

January, 2010

using conservative KOP material properties bound those using safety basis material properties. 
PRC-STP-00187 REV 0

FAl/10-28

Page 8 of 99

Rev. 0

\subsection{PURPOSE AND SCOPE}

The purpose of this report is to describe the best available conceptual design calculation for CVD of KOP material, which represents the culmination of an interactive process between design, model refinement, and calculation during FY09. Normal CVD was considered in FY09, and in FY10 accident cases and new cases are now considered. The scope of this memorandum is to identify the design considered, summarize the models employed, list inputs related to KOP material and the CVD process, and present the calculation results for normal vacuum drying, two accident cases, and MCO cooldown. In a separate report, FAl/09-254 by M. Epstein, we describe analyses of phenomena during CVD, models, and stand-alone assessments in detail. In later FY10 work we will provide updates to the FATE documentation and Quality Assurance of model implementation. 


\subsection{CONCEPTUAL DESIGN FOR CVD OF KOP MATERIAL}

\subsection{Conceptual Design}

The conceptual design for a copper insert block in a coarse sector of a Mark IA scrap basket is shown in Figures 3-1 and 3-2 [Dwg. KOP-SK-510]. Key aspects of the design that enter into analysis are the number of square inches of copper and KOP material in a cross section, because these translate to the volume and mass of materials. There is a nominal $3 / 16^{\prime \prime}$ gap between the insert block and the basket walls for practical issues of tolerance and block insertion. For conservatism, the analysis considers a gap of $3 / 8^{n}$. Gases in the MCO can enter the KOP material region at the basket top and bottom, not via the copper sides. It is easily demonstrated that there is large flow resistance to this path compared to other paths, and the model is set up to be insensitive to flow split [Epstein, 2009].

\subsection{Assumed Process and KOP Material Properties}

It is assumed that a separation process will be used to remove most particles of less than 500 to 600 micron size. The purpose of the separations process is to eliminate very small particles that are known to prevent water draining and to greatly impede drying of the KOP material, and to eliminate material that was not part of the original KOP stream (which was all above 500 or 600 microns).

KOP material is presently categorized as a $\mathrm{K}$ Basins sludge stream. Sludge properties are summarized in the SNF Databook, Volume 2 [Schmidt, 2006] and supporting documents [Plys and Schmidt, 2006]. Limited KOP material sampling has confirmed that the density is less than that of fuel piece material, but due to the planned separations process, databook KOP material properties apply. In addition, for conservatism, we have been requested to assume a low water volume fraction of 0.25 (versus the commonly recognized minimum value of 0.40 ), and a limiting small particle diameter of 600 microns. Values used here are summarized in Table 3-1.

In the safety basis case, we assume a KOP material porosity of 0.40 and a particle diameter of 1500 microns. This particle diameter from the SNF Databook is a conservative estimate of the Sauter mean diameter, and it represents the correct reactive surface area for a particle size distribution. These and related values are summarized in Table 3-2. 

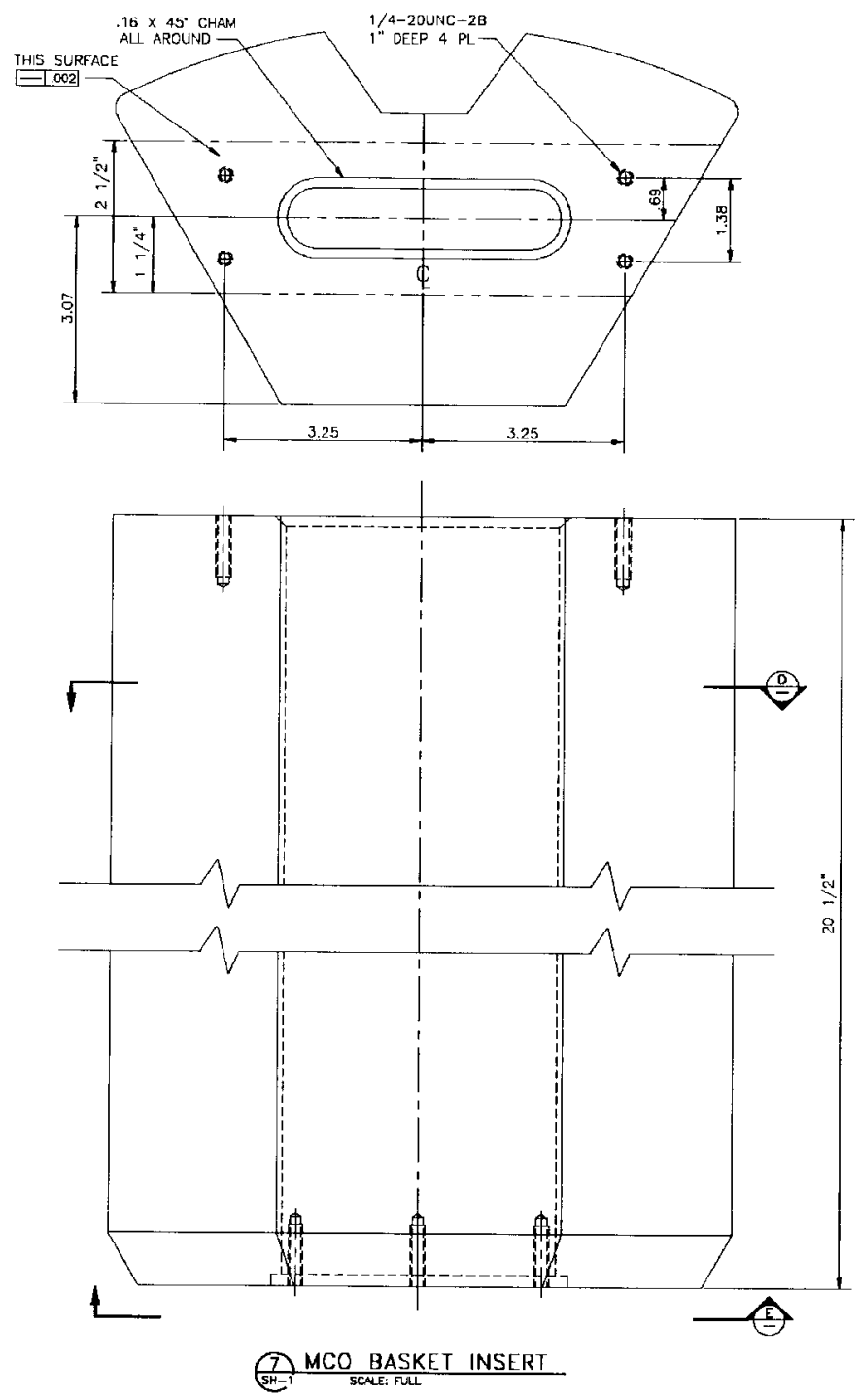

Figure 3-1: Copper insert block plan and elevation views. 


\section{PRC-STP-00187 REV 0}

FAl/10-28

Page 11 of 99

Rev. 0

January, 2010

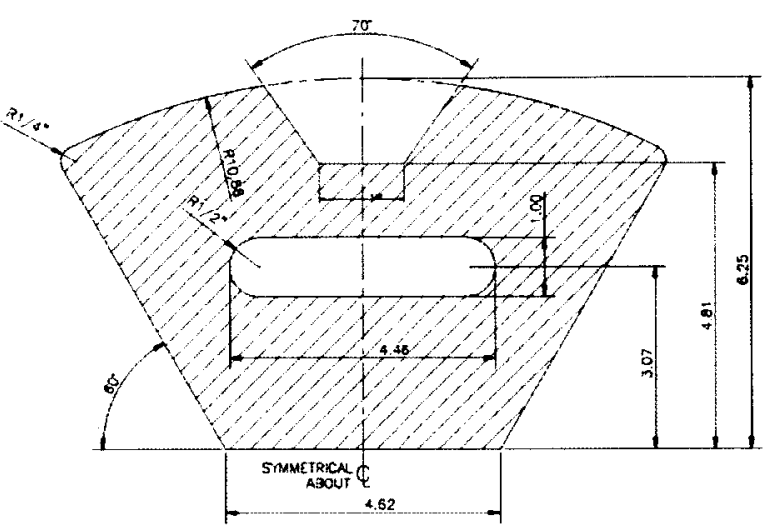

(D) SECTION

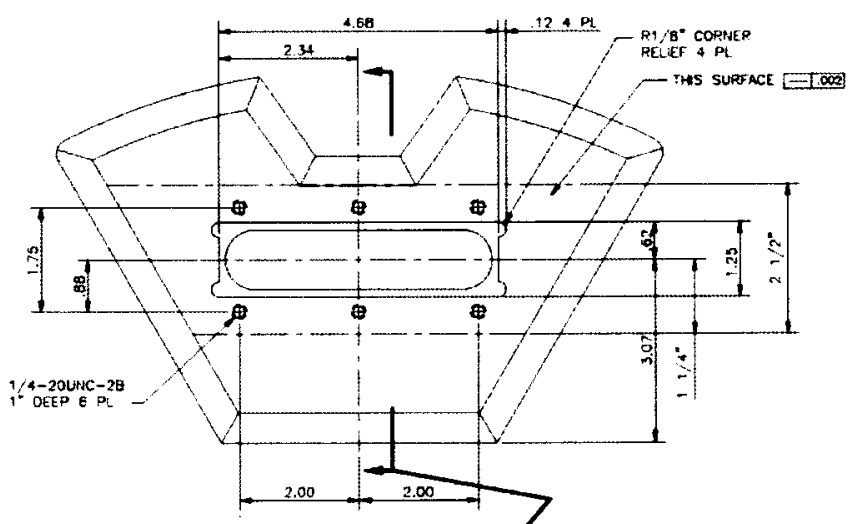

(E) VIEW

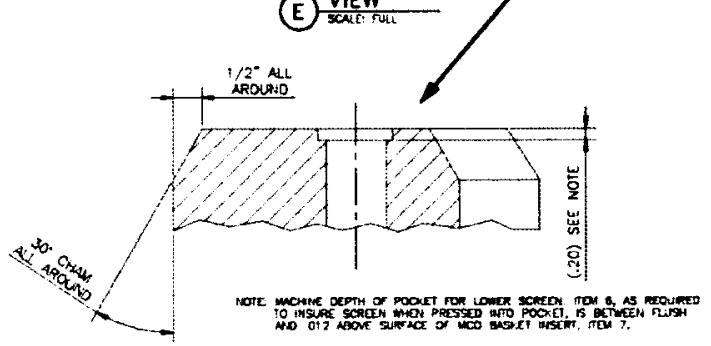

Figure 3-2: Copper insert block plan and section views. 


\begin{tabular}{|c|c|c|c|}
\hline $\begin{array}{l}\text { Water Volume } \\
\text { Fraction } \alpha\end{array}$ & $\begin{array}{l}\text { Particle Density } \\
\rho_{p}(1)\end{array}$ & $\underset{\text { Concentration }}{\text { Total }} \mathrm{C}_{\mathrm{U}}$ & $\underset{(2)}{\text { U Metal }} \underset{\text { Concentration }}{\mathbf{C}_{\text {Umet }}}$ \\
\hline 0.25 & $16832 \mathrm{~kg} / \mathrm{m}^{3}$ & $11750 \mathrm{~kg} / \mathrm{m}^{3}$ & $11750 \mathrm{~kg} / \mathrm{m}^{3}$ \\
\hline Decay Power & $\begin{array}{c}\text { Decay Power } \\
Q_{v}{ }^{(3)} \\
\end{array}$ & $\begin{array}{c}\text { Reactive Particle } \\
\text { Size } d_{p}\end{array}$ & $\begin{array}{c}\text { Reactive Area per } \\
\text { Volume }^{(4)}\end{array}$ \\
\hline 117 WIMTU & $1837 \mathrm{~W} / \mathrm{m}^{3}$ solids & $600 \mu \mathrm{m}$ & $6184 \mathrm{~m}^{2} / \mathrm{m}^{3}$ \\
\hline \multicolumn{4}{|c|}{$\begin{array}{l}\text { (1) Databook KOP values are based upon a combination of } U \text { metal and } \mathrm{Zr} \text { cladding } \\
\text { at about } \eta=82.63 \mathrm{vol} \% \mathrm{U}, 1-\eta=17.37 \mathrm{vol} \% \mathrm{Zr} \text {. Therefore } \rho_{\mathrm{p}}=\left(19000^{*} \eta+\right. \\
\left.6520^{*}(1-\eta)\right)=16832 \mathrm{~kg} / \mathrm{m}^{3} \text {. The equivalent KOP wet sludge value is } \rho_{\text {wet }}=(1-\alpha) \rho_{p}+ \\
1000^{*} \alpha .=12874 \mathrm{~kg} / \mathrm{m}^{3} \text {. } \\
\text { (2) Databook value adjusted for porosity: } C_{u}=C_{\text {Umet }}=(0.75 / 0.60)^{*} 9400=11750 \text {. } \\
\text { (3) } Q_{v}=0.117^{*} 19000^{*} 0.8263=1837 \mathrm{~W} / \mathrm{m}^{3} \text { solids. } \\
\text { (4) } A N=\left(6 / d_{p}\right)\left(C_{U \text { met }} / \rho_{m}\right)=(6 / 0.0006)^{*}(11750 / 19000)=6184 \text {. }\end{array}$} \\
\hline
\end{tabular}

\begin{tabular}{|c|c|c|c|}
\hline $\begin{array}{l}\text { Water Volume } \\
\text { Fraction } \alpha\end{array}$ & $\begin{array}{l}\text { Particle Density } \\
\rho_{p}(1)\end{array}$ & $\underset{(2)}{\text { Total } \mathbf{U}}$ & $\underset{(2)}{\text { U Metal }} \underset{\underset{(2)}{\text { Concentration }} \mathrm{C}_{\text {Umet }}}{ }$ \\
\hline 0.40 & $16832 \mathrm{~kg} / \mathrm{m}^{3}$ & $9400 \mathrm{~kg} / \mathrm{m}^{3}$ & $9400 \mathrm{~kg} / \mathrm{m}^{3}$ \\
\hline Decay Power & $\begin{array}{c}\text { Decay Power } \\
Q_{v}{ }^{(3)} \\
\end{array}$ & $\begin{array}{c}\text { Reactive Particle } \\
\text { Size } d_{p}\end{array}$ & $\begin{array}{l}\text { Reactive Area per } \\
\text { Volume }^{(4)}\end{array}$ \\
\hline 117 W/MTU & $1837 \mathrm{~W} / \mathrm{m}^{3}$ solids & $1500 \mu \mathrm{m}$ & $1978 \mathrm{~m}^{2} / \mathrm{m}^{3}$ \\
\hline \multicolumn{4}{|c|}{$\begin{array}{l}\text { (1) Databook KOP values are based upon a combination of } U \text { metal and } \mathrm{Zr} \text { cladding } \\
\text { at about } \eta=82.63 \mathrm{vol} \% \mathrm{U}, 1-\eta=17.37 \mathrm{vol} \% \mathrm{Zr} \text {. Therefore } \rho_{p}=\left(19000^{*} \eta+\right. \\
\left.6520^{*}(1-\eta)\right)=16832 \mathrm{~kg} / \mathrm{m}^{3} \text {. The equivalent KOP wet sludge value is } \rho_{\text {wet }}=(1-\mathrm{a}) \rho_{p}+ \\
1000^{*} \mathrm{a} .=10499 \mathrm{~kg} / \mathrm{m}^{3} \text {. } \\
\text { (2) Databook value for } 40 \% \text { void fraction: } C_{U}=\text { CUmet }=9400 \text {. } \\
\text { (3) } Q_{v}=0.117^{*} 19000^{*} 0.8263=1837 \mathrm{~W} / \mathrm{m}^{3} \text { solids. } \\
\text { (4) } A / V=\left(6 / d_{p}\right)\left(C_{\text {Umet }} / \rho_{m}\right)=(6 / 0.0015)^{*}(9400 / 19000)=1978 \text {. }\end{array}$} \\
\hline
\end{tabular}




\subsection{FATE MODEL REPRESENTATION AND PHYSICAL MODELS}

\subsection{Thermal Stability Concern Background}

Fuel previously stored in the $\mathrm{K}$ Basins was fabricated from metallic uranium and zirconium cladding. Damage to cladding exposes metallic uranium, which chemically reacts with liquid water in the basins and with water vapor during CVD, producing hydrogen gas and heat. The greatest amount of reactive surface area is present in scrap baskets, designed to hold fuel pieces as small as $1 / 4$ inch. MCO scrap baskets were designed with a copper outer shroud and internal copper spokes to help remove the chemical reaction power. Most power is lost to the MCO wall, and a small amount is lost to gas leaving the MCO.

Because KOP material has greater reactive surface area per unit volume than scrap previously considered, a key concern is its thermal stability during any step of processing and storage. When generated heat can be removed and steady temperatures are maintained, this is known as thermal stability. If the heat source exceeds heat losses, then fuel will heat up, and reaction rates will increase, resulting in greater power generation. This is a positive feedback process known as thermal instability and fuel temperature can escalate considerably. Thermal instability and "ignition" of uranium has been observed under numerous circumstances at Hanford and throughout the DOE complex.

The technical safety basis for CVD of MCOs containing fuel and scrap baskets is documented in thermal analyses of design, off-normal, and accident conditions. These analyses used the HANSF and FATE computer programs which contained models specifically written and validated to calculate chemical reactions, heat transfer, and fluid flow within an MCO. Stability analysis for early KOP CVD conceptual design was performed by [Plys and Lee, 2009]. Earlier examples are contained in [Plys and Duncan, 2000] and [Plys and Malinovic, 1999]. The current computer program used for this work, FATE, is described in [Plys and Lee, 2004], and changes to the model will be documented under Quality Assurance in follow-on work.

\subsection{Model Representation}

The FATE model representation for CVD of KOP material is shown in Figure 4-1. Since the copper block is nearly isothermal, by symmetry the KOP material is modeled as a layer with $1 / 2$ inch thickness insulated in what would be the middle of the 1 inch 
FAI $10-28$

Rev. 0

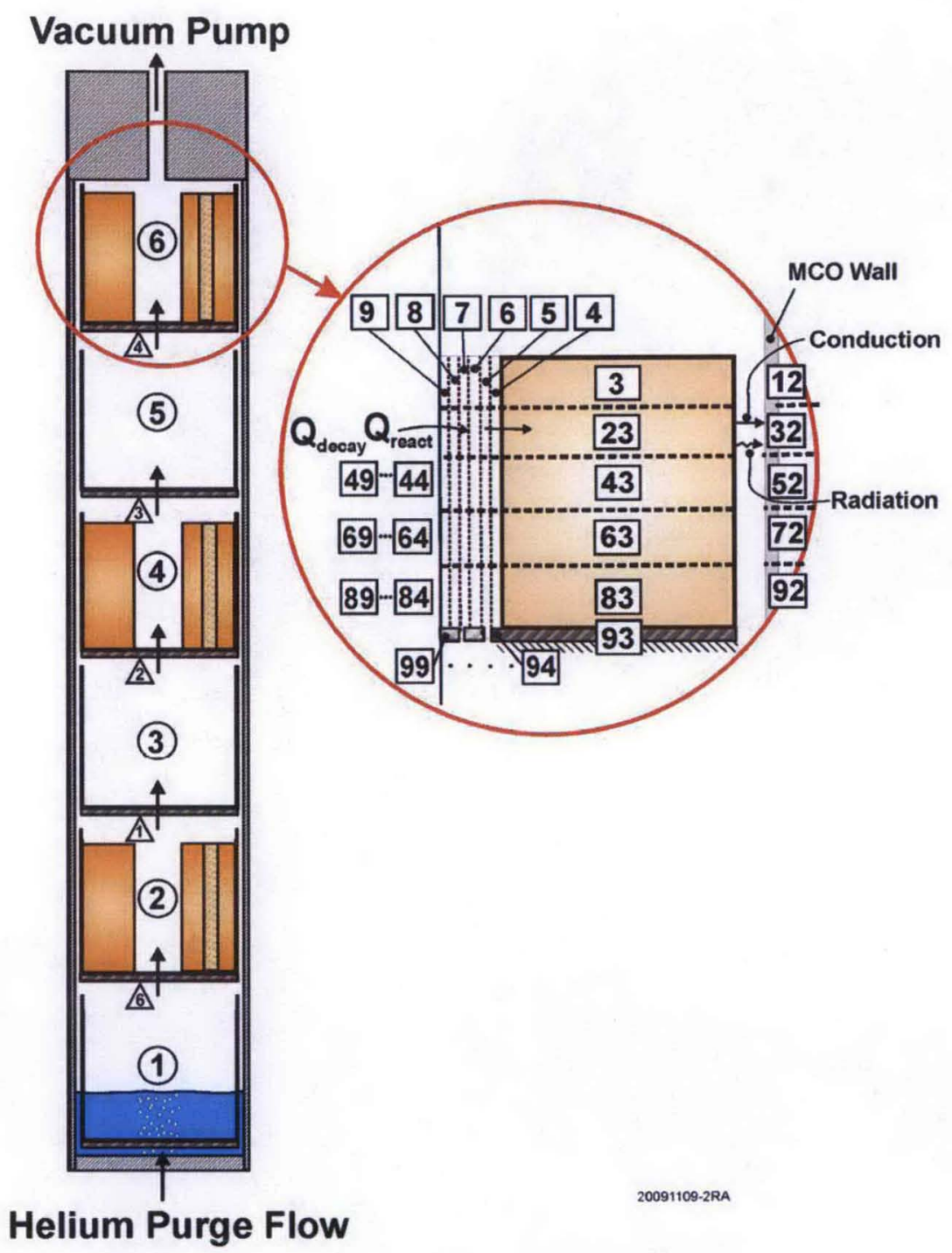

Figure 4-1: FATE model representation for CVD of KOP material in an insert block. 
thick fuel section. In the base analysis (Cases 1 and 5 ) and in both postulated accident scenarios (Cases 2, 3,6 and 7), the adjacent copper block is considered insulated on its opposite side, and no credit is taken for its ability to transfer heat to gas in the small surrounding gap, or across the gap to the scrap basket copper walls. In the cooldown scenario (Cases 4 and 8 ), credit is taken for heat transfer across the helium gap from the copper block to the scrap basket to the MCO wall, as described in Sections 5.4 and 6.4 .

Within the KOP material, six different average temperatures are used to for the reaction rate, and each average temperature is found from a three-point temperature distribution, so that the node thickness for heat conduction is less than $1 \mathrm{~mm}$. The KOP material and block are also axially divided into five levels.

Per the design, three baskets containing KOP material are separated by empty baskets with an empty basket in the bottom of the MCO. After draining, residual water remains in KOP material pores, and a heel of water remains on the MCO bottom, which can partially submerge KOP material if it is loaded in the bottom basket. Since the bottom basket is empty in the current design, submerged KOP material is not a concern in this analysis.

\subsection{Model Inputs}

Model inputs to FATE can be divided into five categories for the present purposes:

1. Regions. Control volume parameters are defined here, such as the free volume in each section of the MCO, elevation, and initial gas compositions.

2. Junctions. These are the flow path connections between MCO regions. A helium purge enters the MCO bottom, and a vacuum pump is modeled at the MCO top. The helium purge is allowed to evaporate water vapor from the MCO heel water pool when it exists, so the incoming gas flow is $100 \%$ relative humidity.

3. Heat Sinks. Solids with internal temperature distributions are specified here and include the MCO wall, bottom, and top, scrap basket structures, copper insert blocks, and KOP material. Dimensions, material properties, and boundary conditions are input. 
4. MCO models. Inputs that are specific to describing how MCO-specific phenomena are applied to regions, junctions, and heat sinks are provided here.

5. General calculation control. Items here include time step selection, plot parameter selection, and general overhead, and are of secondary importance.

The following input values are used for both the conservative and nominal calculations:

- $\quad 50^{\circ} \mathrm{C}$ initial temperature (all cases except MCO cooldown),

- $\quad 1.5 \mathrm{scfm}$ Helium purge rate (normal CVD only),

- 1 " effective KOP material thickness, (modeled as 1/2" KOP thickness with one side insulated boundary),

- $\quad 3 / 8$ " gap between copper insert and scrap basket copper shroud,

- 20 Liters free water heel at MCO bottom (all cases except MCO cooldown), and

- $10 \times$ reaction rate law multiplier (literature rate multiplied by 10 )

In the conservative case ( $25 \%$ void fraction), we use:

- $600 \mu \mathrm{m}$ particle diameter for reactive surface area,

- $11.77 \mathrm{~kg} /$ liter uranium loading in the block,

- $75 \%$ volume fraction of uranium ( $25 \%$ free volume),

- 12 vol\% residual free water in KOP material,

As mentioned previously, several values are used which are more conservative than those supplied by the SNF Databook, Volume 2 [Schmidt, 2006]. The free volume was reduced from $40 \%$ to $25 \%$ which tends to increase the surface area and thus increases the KOP material oxidation rate. The 600 micron particle size is less than half the safety basis size of 1500 microns, so it provides 2.5 times the reactive surface area per unit volume. This represents a bounding case so that results are not sensitive to variations of a separations process. The volume fraction of residual water was previously estimated at 7.5 vol\% in the nominal case (see [Epstein, 2008]), however in the conservative case it is assumed to be 12 vol\% pending further investigation. 
In the nominal safety-basis case ( $40 \%$ void fraction), we use:

- $1500 \mu \mathrm{m}$ particle diameter for reactive surface area,

- $9.42 \mathrm{~kg} /$ liter uranium loading in the block,

- $60 \%$ volume fraction of uranium ( $40 \%$ free volume),

- 7.5 vol\% residual free water in KOP material,

\subsection{Physical Models}

Thermal conductivity in the KOP material bed depends upon both gas composition and pressure, and a model for it is given and compared to data in [Plys and Lee, 2008]. The value of thermal conductivity at less than $10 \mathrm{mmHg}$ can be an order of magnitude or more less than the value at near-atmospheric pressure.

The reaction of uranium with MCO gases is evaluated using the rate law in the SNF databook, Volume 1. For practical purposes, this is the oxygen-free Pearce correlation for the reaction between uranium and water vapor. That is,

$$
R=10^{\star *}\left(4.33-2144 / T+0.5 * \log _{10}(P / 1000.0)\right)\left[\mathrm{mgO}_{2} / \mathrm{cm}^{2} / \mathrm{hr}\right] \text {, }
$$

where $\mathrm{T}$ is in $\mathrm{K}$ and $\mathrm{P}$ is in $\mathrm{Pa}$.

The reaction rate depends upon the square root of the water vapor pressure, so that at a given temperature, the reaction rate decreases with $\mathrm{MCO}$ pressure. Also, as water vapor attempts to enter a bed of KOP material, it will react, so its vapor pressure will decrease, and hence the reaction rate will decrease. In accord with bounding calculations for CVD, the literature rate is multiplied by a factor of 10 .

In addition, $12 \%$ of the KOP material is assumed to be coved by residual water in the conservative case. Because material is water-covered and below $100^{\circ} \mathrm{C}$, the rate law that is used by the code for the covered area, following the logic for the databook implementation, is:

$$
\mathrm{R}=10^{\star \star}(7.634-3016 / \mathrm{T})\left[\mathrm{mgO}_{2} / \mathrm{cm}^{2} / \mathrm{hr}\right]
$$

There is very little heat transfer resistance between the MCO bottom head and the water heel, per Section 2 of FAl/09-254, so most of the heat transfer resistance is due to conduction from circulating CVD water through the bottom head. This affects the 
evaporation rate of the heel. Comparing the normally-calculated FATE heat transfer coefficient with the value for a shallow pool, a multiplier of 10 is used in this case.

Helium entering the MCO can pass through a water pool when present, and due to the geometry, it can spread over considerable area as bubbles. This allows evaporation of water into the helium, which is therefore available for reaction with uranium. Based on Section 3 of FAI/09-254, evaporation is allowed to proceed to $100 \%$ relative humidity.

Water vapor available for reaction with KOP material is either residual water initially present in the pores, or it is water vapor that diffuses inward from the local gas surrounding a copper insert. As water vapor diffuses into the relatively long and narrow porous bed, reacting with uranium, the water vapor mass fraction decreases. As mentioned above, the reaction rate depends upon the square root of the water vapor partial pressure, which is proportional to the water vapor mass fraction. A model for this phenomenon is described in Section 6 of FAl/09-254, and it provides a step-by-step prescription to evaluate the "reaction efficiency," which is the reduction of the reaction rate compared to what it would be if all the KOP material were exposed to water vapor at the pressure outside the copper block.

Note that if residual water remains on the KOP material, then steam is produced locally and the reaction is not limited by diffusion. If the saturation pressure of wetted KOP material, evaluated at the KOP material temperature, is above the MCO total pressure, this corresponds to boiling of the residual water. If the saturation pressure is below the MCO total pressure, then evaporation occurs just at the rate required to supply the reaction with uranium. This conservatively supplies reactant. If residual water has vanished, then the diffusion limitation applies.

A transient analysis of the conceptual design was performed using the FATE ${ }^{\mathrm{TM}}$ 2.0 computer code modified per the discussion above. FATE (trademark symbol dropped for brevity) is the successor code to the HANSF computer code that was used for design and safety analysis of MCOs during the Spent Nuclear Fuel Project. The code and its capabilities are discussed in the references. 


\subsection{SIMULATION OF CVD OF 25\% VOID FRACTION KOP MATERIAL}

Four cases using $600 \mu \mathrm{m}$ diameter $25 \%$ void fraction KOP material are analyzed: a base CVD case, a degraded vacuum and loss of helium purge accident case, a loss of annulus cooling accident case, and a post-CVD cooldown case. The results of each analysis are discussed below.

\subsection{Case 1: KOPC19 - CVD of 25\% Void Fraction KOP Material}

The results of simulating CVD on $25 \%$ void fraction KOP material are shown in Figures 5-1A and B. The results demonstrate thermal stability. Each page has four separate history plots as follows:

Page 1, Upper Left: MCO pressure $(\mathrm{Pa})$. The pressure gradually decreases as residual water is evaporated from various scrap baskets, and it decreases suddenly when the bottom water heel dries out. The KOP material dries out in approximately 30 minutes and the bottom water heel has evaporated after about 9.7 hours.

Page 1, Lower Left: Reaction power per tier and decay power (W). Reaction power far exceeds decay power, while local surface water is available. After the KOP material dries out, the reaction rate is limited by diffusion of steam into the KOP material.

Page 1, Upper Right: KOP material temperature per tier, ${ }^{\circ} \mathrm{C}$. Temperatures stay within about 12 degrees of the initial temperature. "Noise" in the temperature and steam concentration early in the calculation is during the period when water is boiling inside the KOP material, and the end of the "noise" corresponds to dryout of the KOP material.

Page 1, Lower Right: Steam concentration per tier. Steam concentration shows the driving force for oxidant external to the KOP material, and it remains fairly steady until all water is evaporated. Since hydrogen is usually negligible compared to steam, the helium concentration is about one minus the steam concentration during drying.

Page 2, Upper Left: Tier 4 (middle basket) energy balance details. This is similar to the lower left plot of page 1 , but includes the total source and heat 
losses to the MCO wall. Losses increase steadily as the KOP material and inserts heat up.

Page 2, Lower Left: Reaction efficiency per tier. This illustrates the impact of the relative difficulty in supplying steam to KOP material, showing a reaction efficiency of about $30 \%$, consistent with expected values from hand calculations [Epstein, 2009].

Page 2, Upper Right: Gas temperature per tier $\left({ }^{\circ} \mathrm{C}\right)$. There is some minor instability due the small gas heat capacity compared to that of the solid structures.

Page 2, Lower Right: MCO water heel mass $(\mathrm{kg})$. The water heel steadily evaporates and is gone after about 9.7 hours.

Detailed investigation has shown the copper blocks are nearly isothermal, which is essential to their feature in providing heat capacity to suppress temperature increases. Residual water on fuel is gone after about $\mathbf{3 0}$ minutes, so that for most of the drying period, water is supplied by the bottom heel but a diffusion limitation occurs within KOP material. Results shown here are influenced in a conservative manner by the large residual water heel, and drying would be faster with a smaller heel. Also, this case is truly thermally stable, because heat losses are able eventually to equal heat sources (to observe this requires an alternate scenario with a considerably larger water heel, and a duration of about 24 hours).

\subsection{Case 2: KOP_VACXDG_19 - Degraded Vacuum Pumping with No Helium Purge}

The degraded vacuum pumping accident case considers a low vacuum pumping rate, $13 \mathrm{scfm}$ (compared to the normal rate of $30 \mathrm{scfm}$ ) and no helium injection flow. The degraded-vacuum case bounds all of the other vacuum cases in the original MCO accident calculations (HNF-SD-SNF-CN-023). Based upon this experience, if the degraded vacuum case for KOP material is benign, there is no reason to simulate the other vacuum cases.

Transient results histories for this case are shown in Figures 5-2A and 5-2B in the same format as described above for normal CVD. KOP material is thermally stable for this case. The pressure is lower compared to normal CVD with the helium purge, so water in the KOP material boils off faster. However, the water heel evaporates more 
PRC-STP-00187 REV 0

FAl/10-28

Page 21 of 99

Rev. 0

January, 2010

slowly without the helium purge, and dries out after about 18 hours. The KOP material temperature steadily rises while the heel evaporates, attaining about $88^{\circ} \mathrm{C}$ in the lower basket. The reaction efficiency decreases as KOP material heats up, as expected. The nature of the temperature and heat balance results indicates that this case is not truly thermally stable, and that an alternative scenario with a larger water heel would lead eventually to thermal runaway.

\subsection{Case 3: KOP_OVLOCXSP_19 - Open MCO with Loss of Annulus Water}

In the loss of annulus water case, the annulus water is assumed to be suddenly drained and replaced by air, which severely degrades the main mechanism for removing heat from the $M C O$. The $M C O$ is open to the vacuum pumping system at atmospheric pressure, but there is neither vacuum pumping nor helium injection, so the MCO atmosphere is stagnant. To eliminate the benefit of oxygen poisoning, no oxygen is included in the MCO atmosphere. Otherwise, initial and boundary conditions are the same as for normal CVD.

Transient results histories are shown in Figures 5-3A and -3B. Since the MCO is at a higher pressure than during normal CVD, there is no boiling. Residual water in KOP material evaporates and completely reacts with the uranium metal, leading to increased reaction power and temperature rise in the KOP material compared to normal CVD. The KOP material temperature stabilizes at $60^{\circ} \mathrm{C}$ shortly after the residual water in the material is consumed. The residual water heel remains intact.

\subsection{Case 4: KOP_COOLSPRS_19 - Cooling of MCO and KOP Sludge After Vacuum Drying}

The MCO cooldown case initial condition is an idealized state following vacuum drying and a final pressure rebound test. $200 \mathrm{~g}$ of free water are assumed to remain in the $\mathrm{MCO}$, and initial fuel and copper block temperatures are derived from the long-term results of the normal CVD case. The MCO is pressurized with helium to $4 \mathrm{psig}$, and all components of the $\mathrm{MCO}$ are initialized to $60^{\circ} \mathrm{C}$ corresponding to the end of vacuum drying. The annulus water is initially at $50^{\circ} \mathrm{C}$, and cooling water at $17^{\circ} \mathrm{C}$ is injected into the annulus at a rate of $15 \mathrm{gpm}$. The purpose of this case is to establish the maximum gas temperature after cooldown, so that the number of moles of helium can be separately compared to requirements for interim storage.

Transient results histories are shown in Figures 5-4A and 5-4B. After about 20 minutes, the KOP material has consumed all the residual water and quickly drops from 


\section{PRC-STP-00187 REV 0}

FAl/10-28

Page 22 of 99

Rev. 0

January, 2010

a peak temperature of about $72^{\circ} \mathrm{C}$ down to $60^{\circ} \mathrm{C}$ and thereafter slowly cools to about $30^{\circ} \mathrm{C}$ at the end of 10 hours.

\subsection{Transient Results Figures}

Results figures are given on the following pages. 
FAl/10-28

Rev. 0
Page 23 of 99

January, 2010

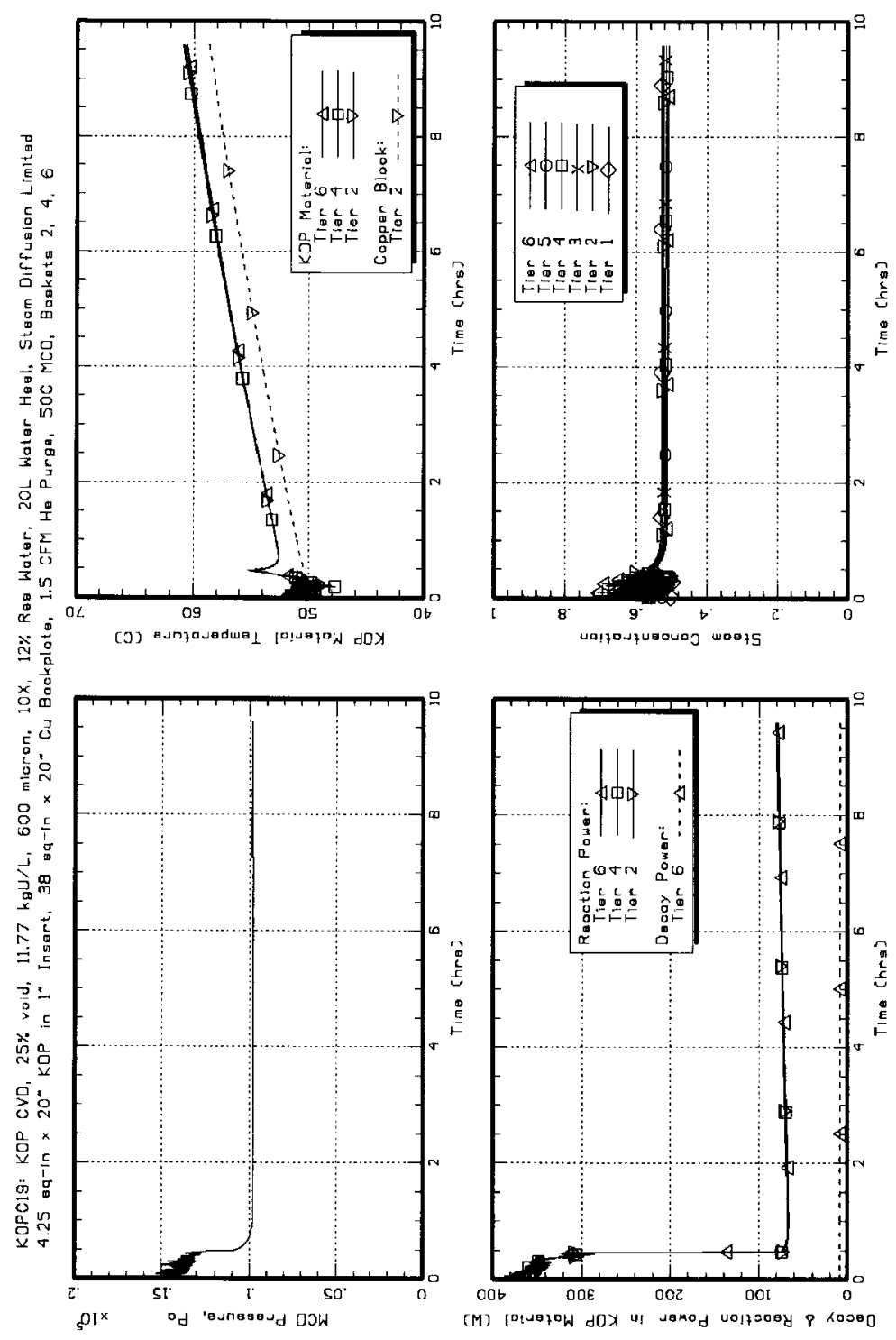

Figure 5-1A: Case 1: CVD of 25\% Void Fraction KOP Material (1 of 2). 
FAl/10-28

Rev. 0

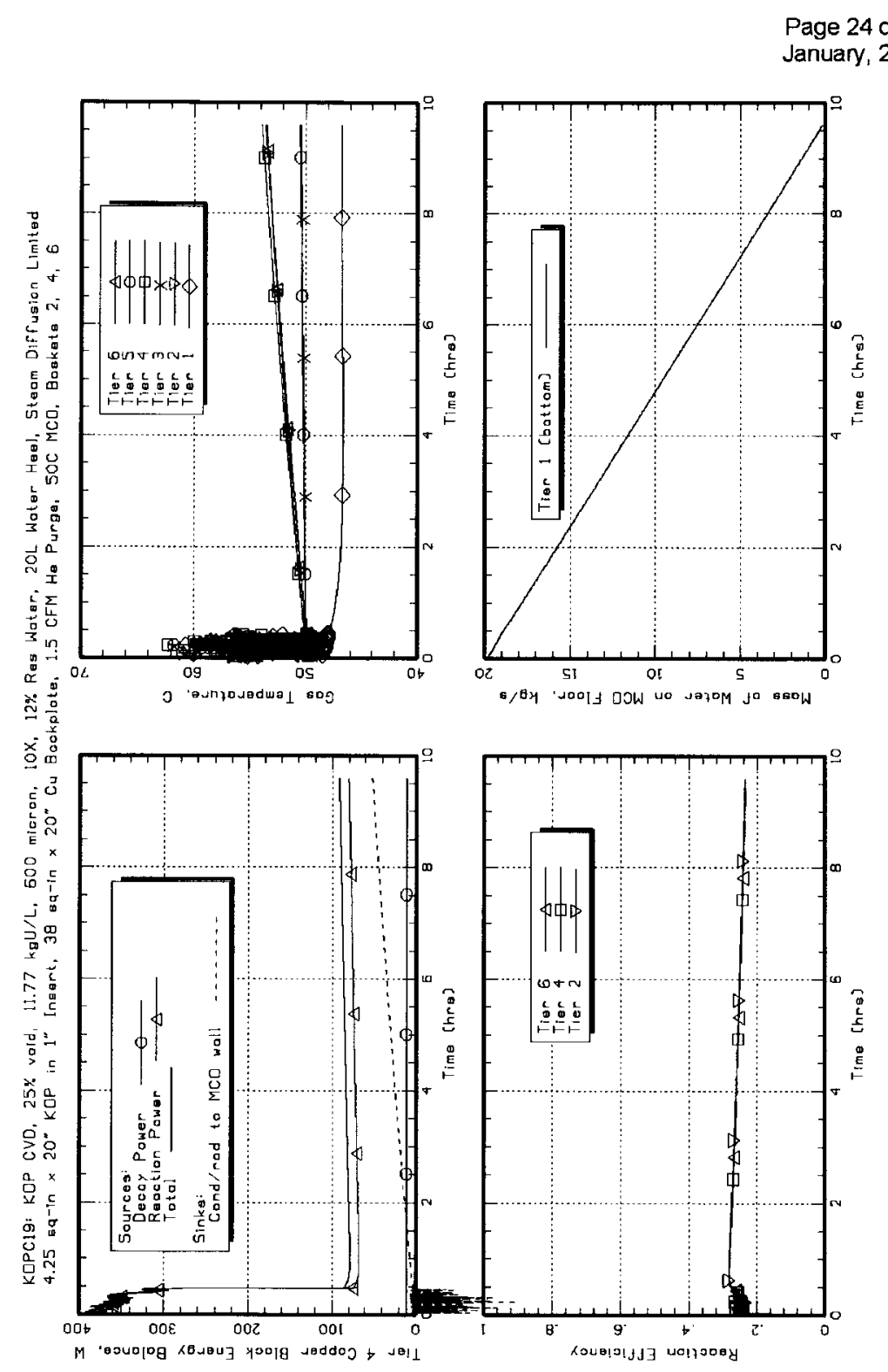

Figure 5-1B: Case 1: CVD of $25 \%$ Void Fraction KOP Material (2 of 2). 
FAl/10-28

Rev. 0
Page 25 of 99

January, 2010
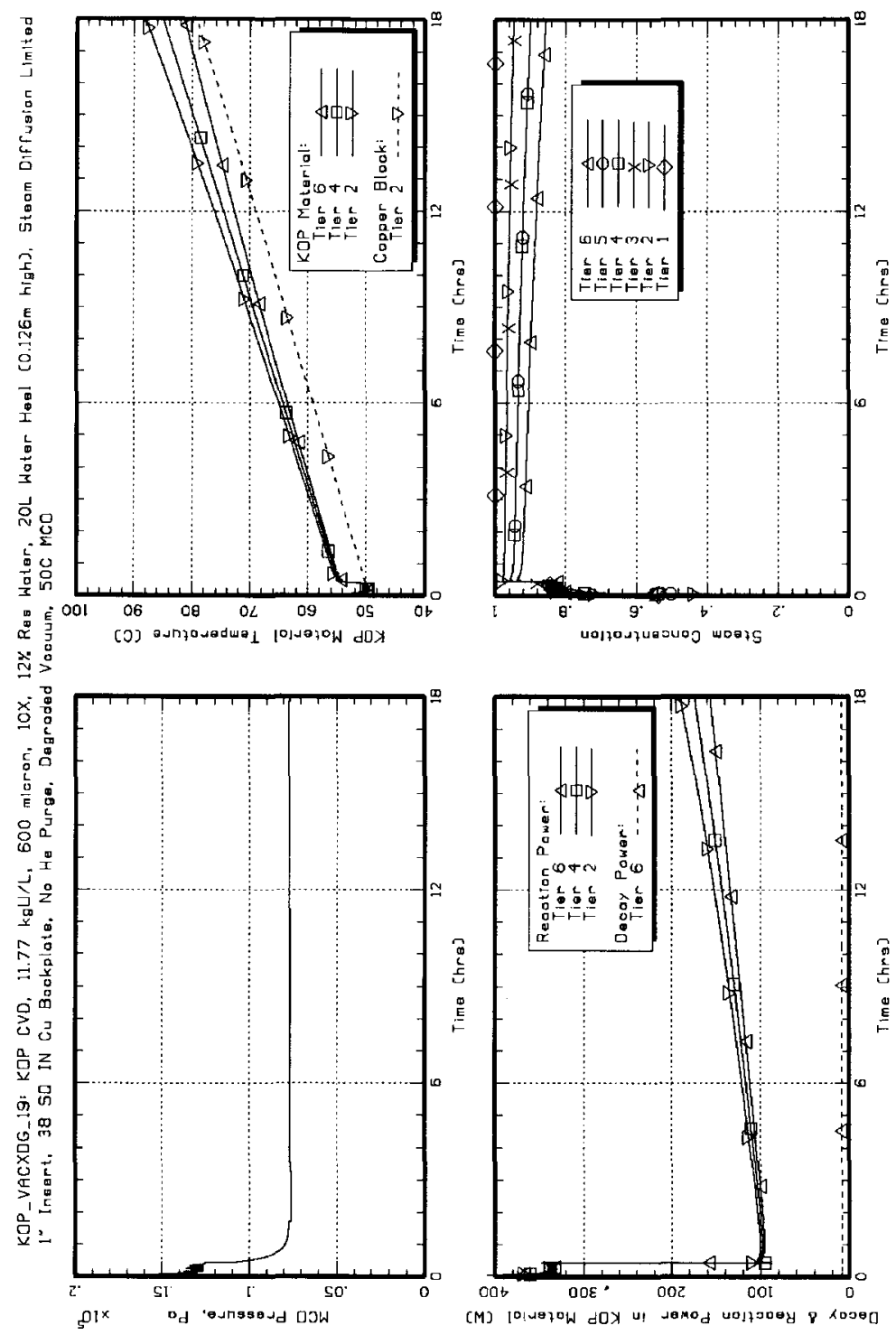

Figure 5-2A: Case 2: Degraded Vacuum Pumping With No Helium Purge (1 of 2). 
FAl/10-28

Rev. 0
Page 26 of 99

January, 2010
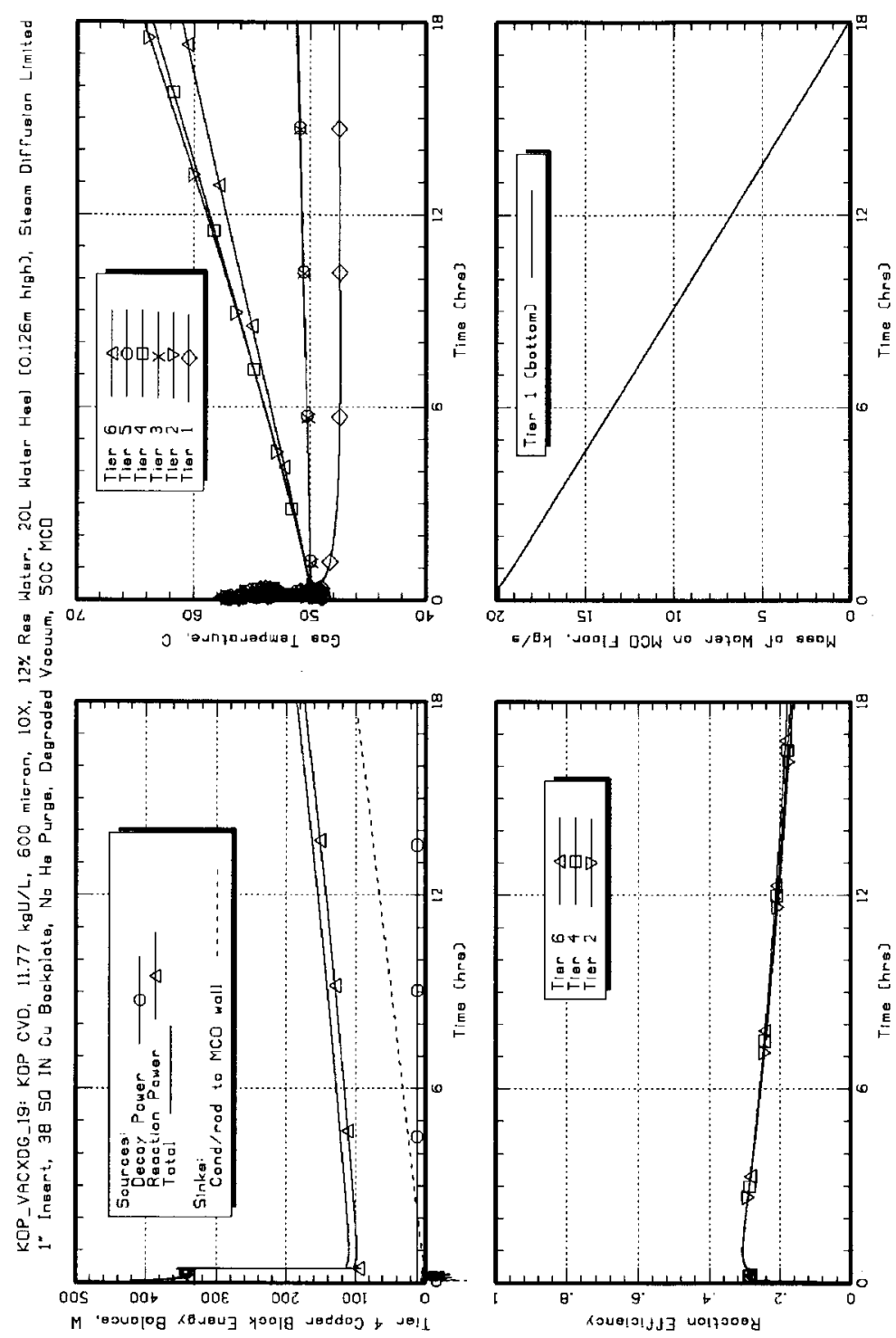

Figure 5-2B: Case 2: Degraded Vacuum Pumping With No Helium Purge (2 of 2). 

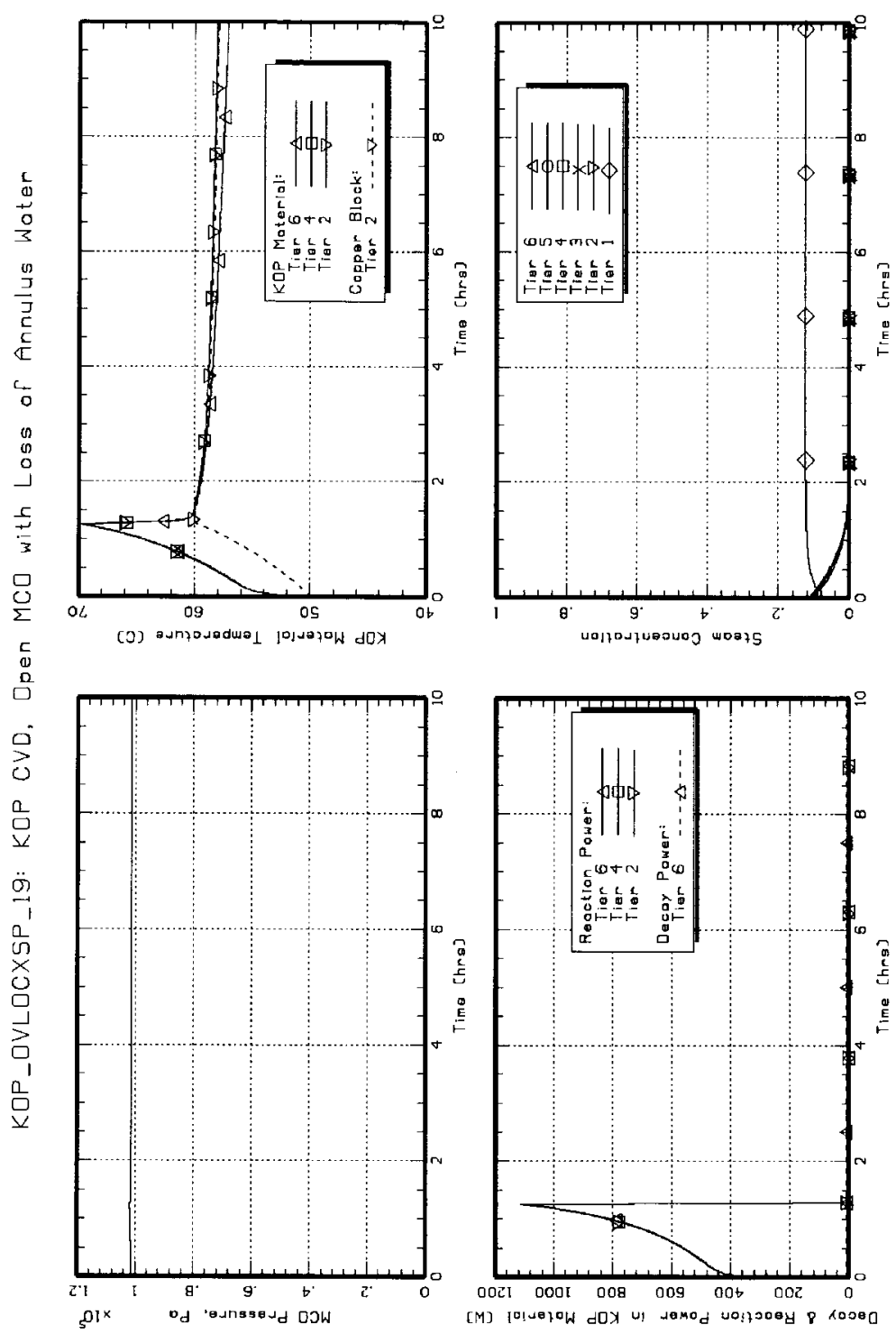

Figure 5-3A: Case 3: Open MCO With Loss of Annulus Water (1 of 2). 
FAl $/ 10-28$

Rev. 0

Page 28 of 99

January, 2010
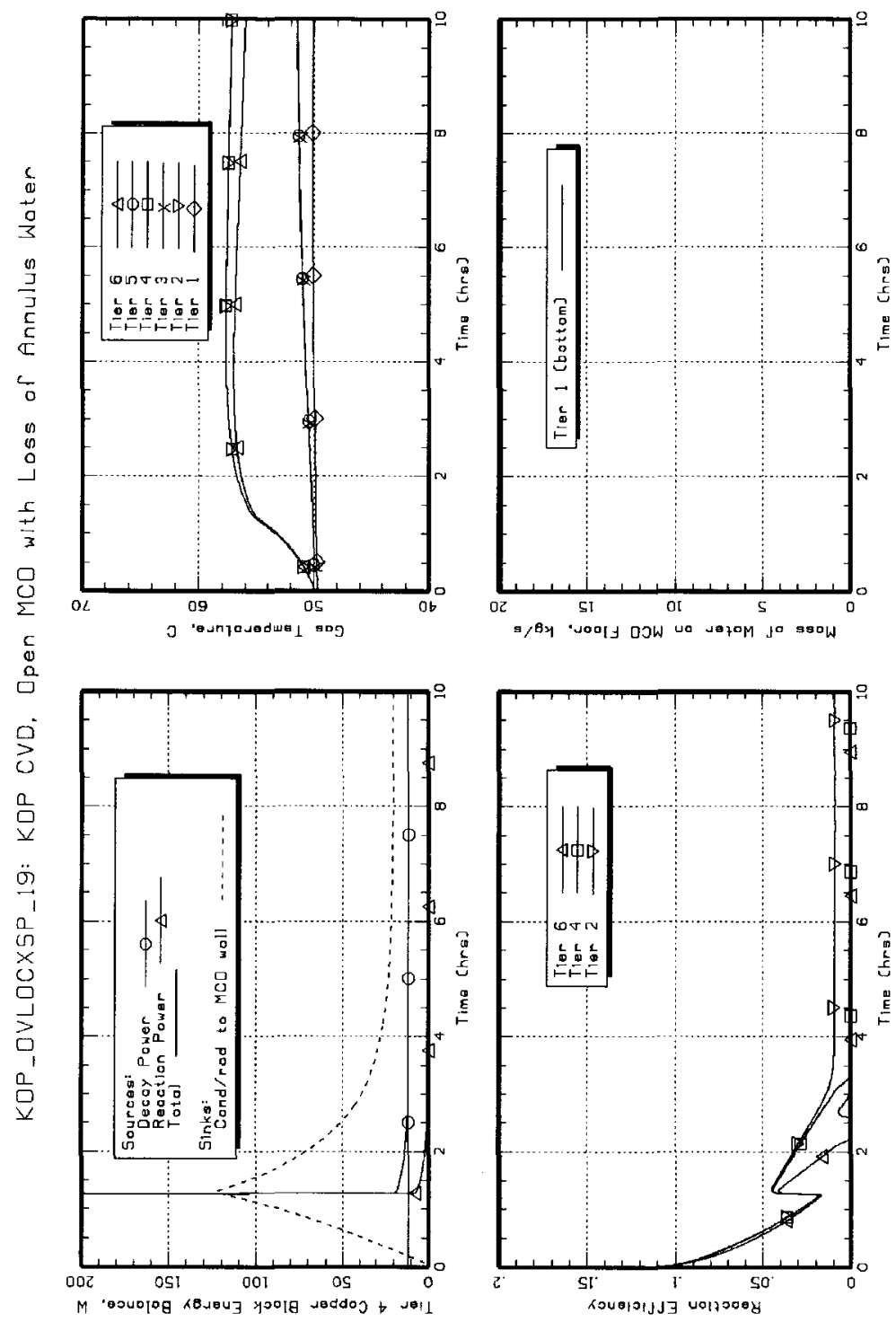

Figure 5-3B: Case 3: Open MCO With Loss of Annulus Water (2 of 2). 
FAl/10-28

Rev. 0

Page 29 of 99

January, 2010
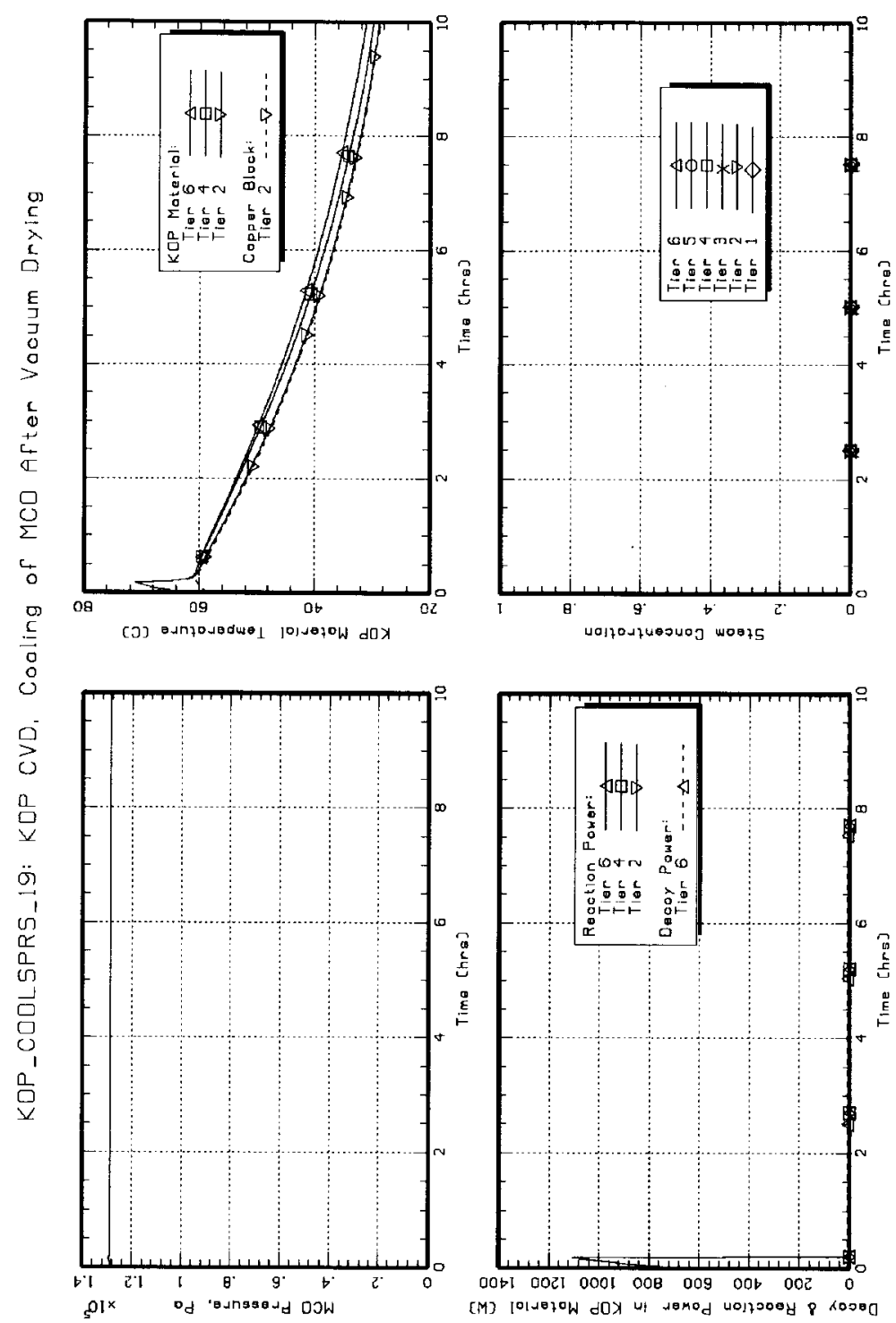

Figure 5-4A: Case 4: Cooling of MCO and KOP Sludge After Vacuum Drying (1 of 2). 
FAl/10-28

Page 30 of 99

Rev. 0

January, 2010
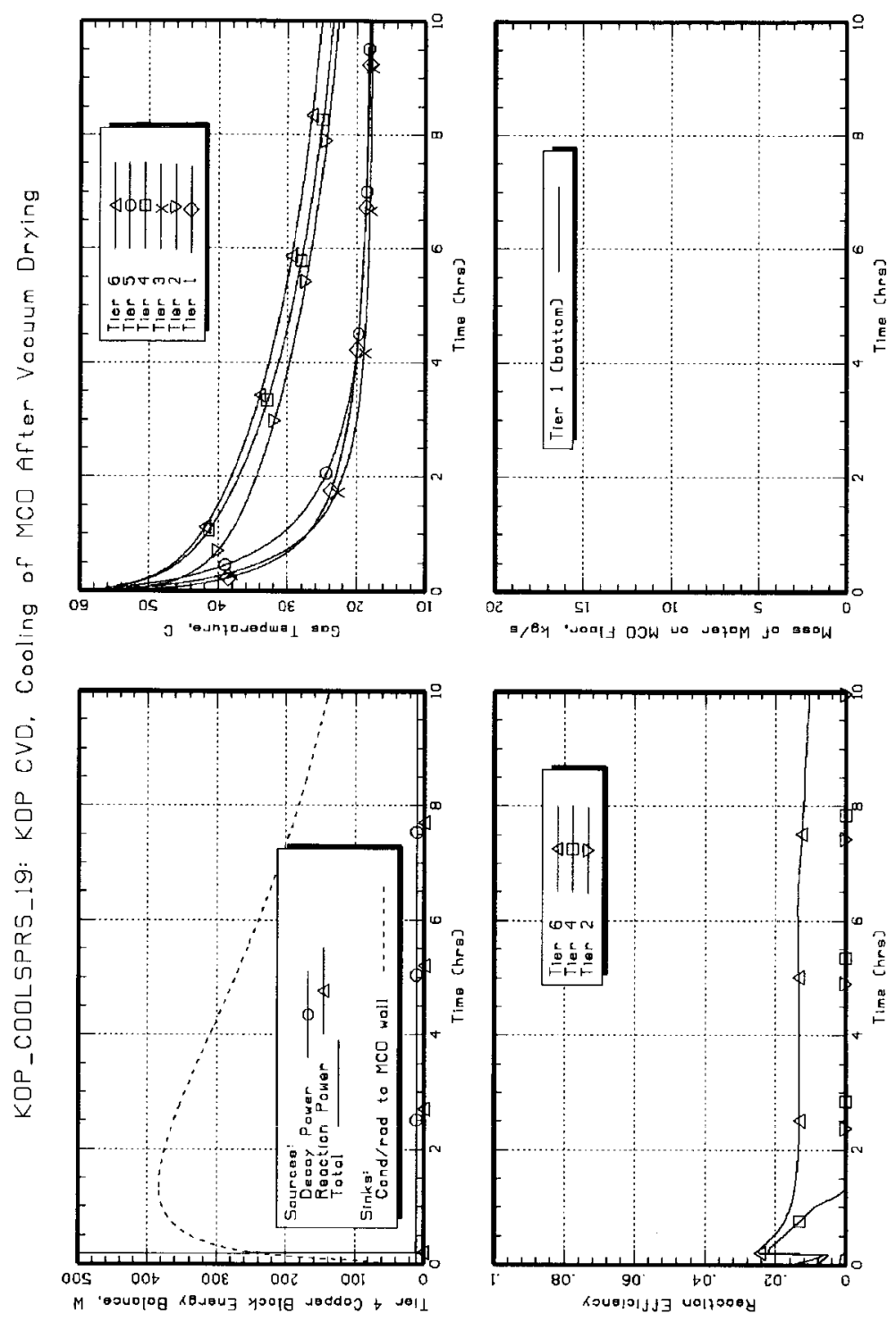

Figure 5-4B: Case 4: Cooling of MCO and KOP Sludge After Vacuum Drying (2 of 2). 


\subsection{SIMULATION OF CVD OF 40\% VOID FRACTION KOP MATERIAL}

The four cases described in Section 5.0 are re-analyzed here using safety basis KOP material properties ( $1500 \mu \mathrm{m}$ diameter and $40 \%$ void fraction). The purpose of the this analysis is to document the safety basis results. An additional purpose of the baseline CVD case is to document the amount of particulate generated. The results of each analysis are discussed below. Results figures for each case are organized the same as in Section 4, with the exception that for Case 5, normal CVD, a third figure with generated particulate is provided.

Because results are similar between analogous cases, only a brief description of results is required. While water is available, reaction power is about half the value found for analogous cases in Section 5, and KOP material temperatures are commensurately somewhat lower.

\subsection{Case 5: KOPC18 - CVD of Safety Basis KOP Material}

The results of simulating CVD safety basis KOP material are shown in Figures 6$1 \mathrm{~A}, \mathrm{~B}$, and $\mathrm{C}$. The results demonstrate thermal stability. Residual water in the scrap baskets boils away in slightly less than one hour, and the residual water heel evaporates in about 9.7 hours. Per Figure 6-1C, uranium dioxide is steadily produced with a maximum mass of $3.4 \mathrm{~kg}$ produced before the MCO is dry.

\subsection{Case 6: KOP_VACXDG - Degraded Vacuum Pumping with No Helium Purge}

Results for the safety basis degraded vacuum case are shown in Figures 6-2A and 6-2B KOP material is thermally stable, and the peak temperatures is $72{ }^{\circ} \mathrm{C}$, about 6 ${ }^{\circ} \mathrm{C}$ lower than for the case in Section 5.2. The time for water heel evaporation is 18 hours.

\subsection{Case 7: KOP_OVLOCXSP - Open MCO with Loss of Annulus Water}

Results for the safety basis loss of annulus water are shown in Figures 6-3A and 6-3B. The time period for evaporation of water on KOP material, and its complete local reaction with uranium metal, is about 5 hours. This process leads to increased reaction power and temperature rise in the KOP material compared to normal CVD. The KOP material temperature stabilizes near $60^{\circ} \mathrm{C}$ shortly after the residual water in the material is consumed. The residual water heel remains intact. 


\section{PRC-STP-00187 REV 0}

FAl/10-28

Page 32 of 99

Rev. 0

January, 2010

\subsection{Case 8: KOP_COOLSPRS - Cooling of MCO and KOP Sludge After Vacuum Drying}

Results for the safety basis cooldown case are shown in Figures 6-4A and 6-4B. These results are nearly identical to those presented in Section 5.4. After residual water is consumed in about 45 minutes, KOP material slowly cools to about $30^{\circ} \mathrm{C}$ at the end of 10 hours.

\subsection{Transient Results Figures}

Results figures are given on the following pages. 

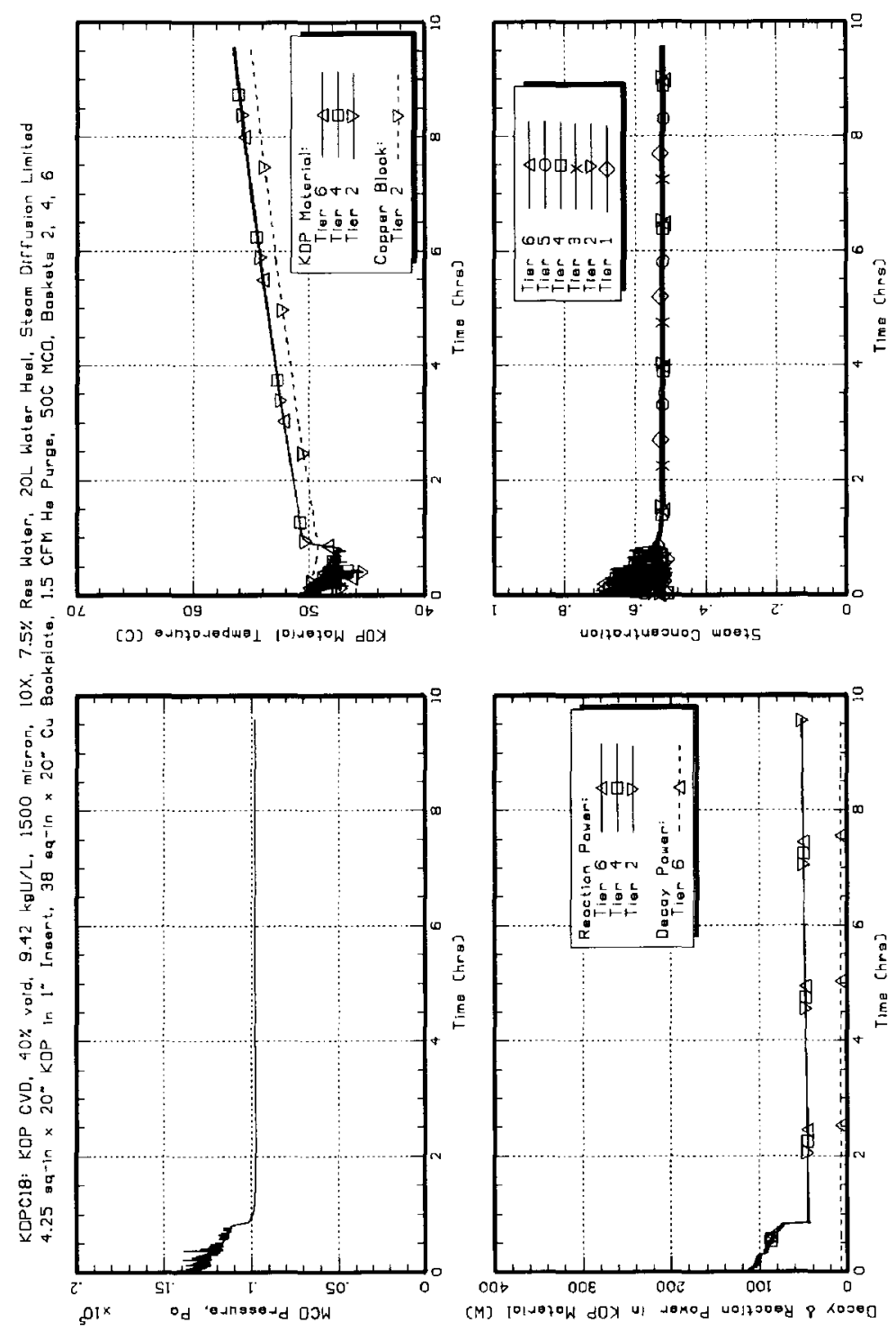

Figure 6-1A: Case 5: CVD of Safety Basis KOP Material (1 of 3). 

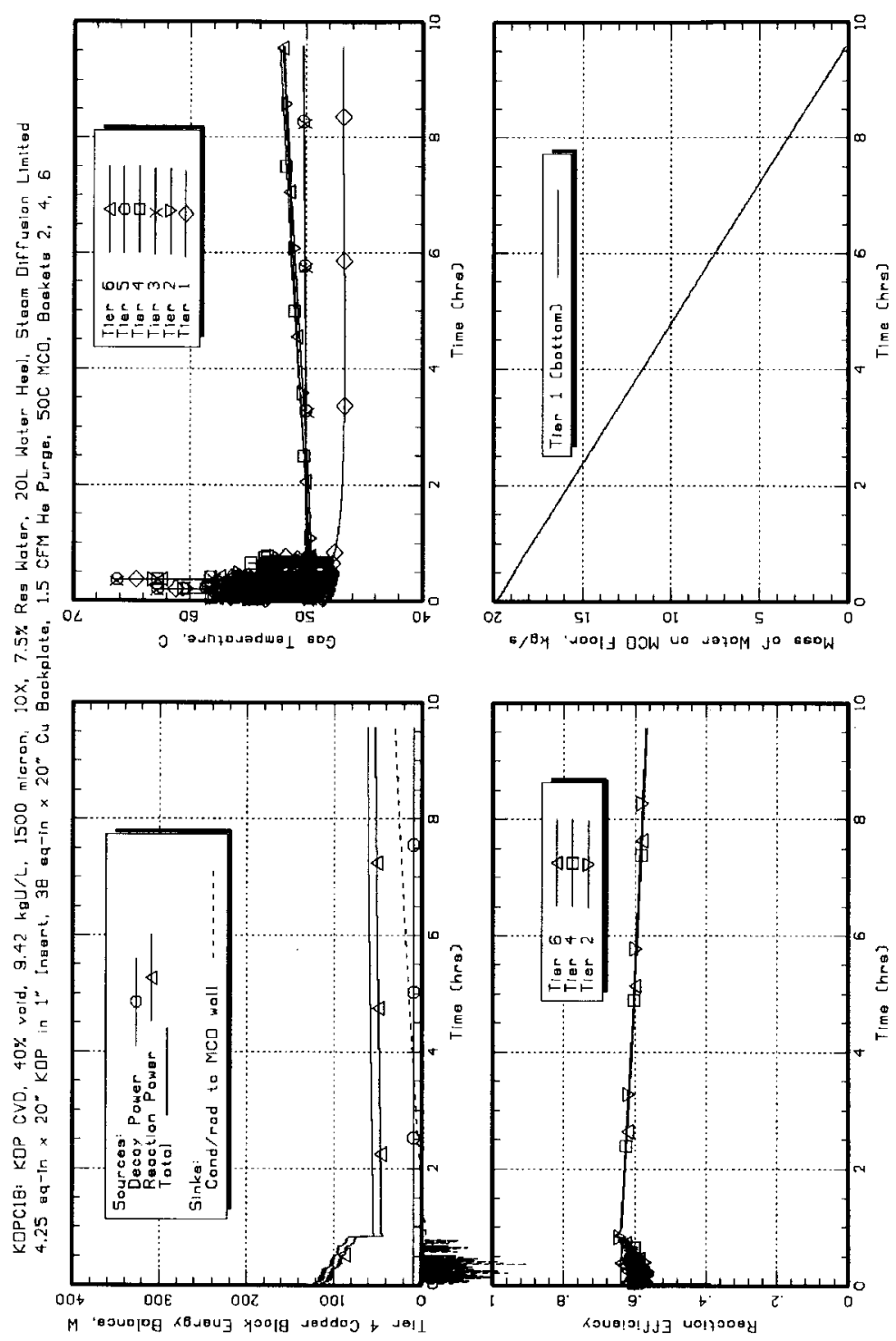

Figure 6-1B: Case 5: CVD of Safety Basis KOP Material (2 of 3). 


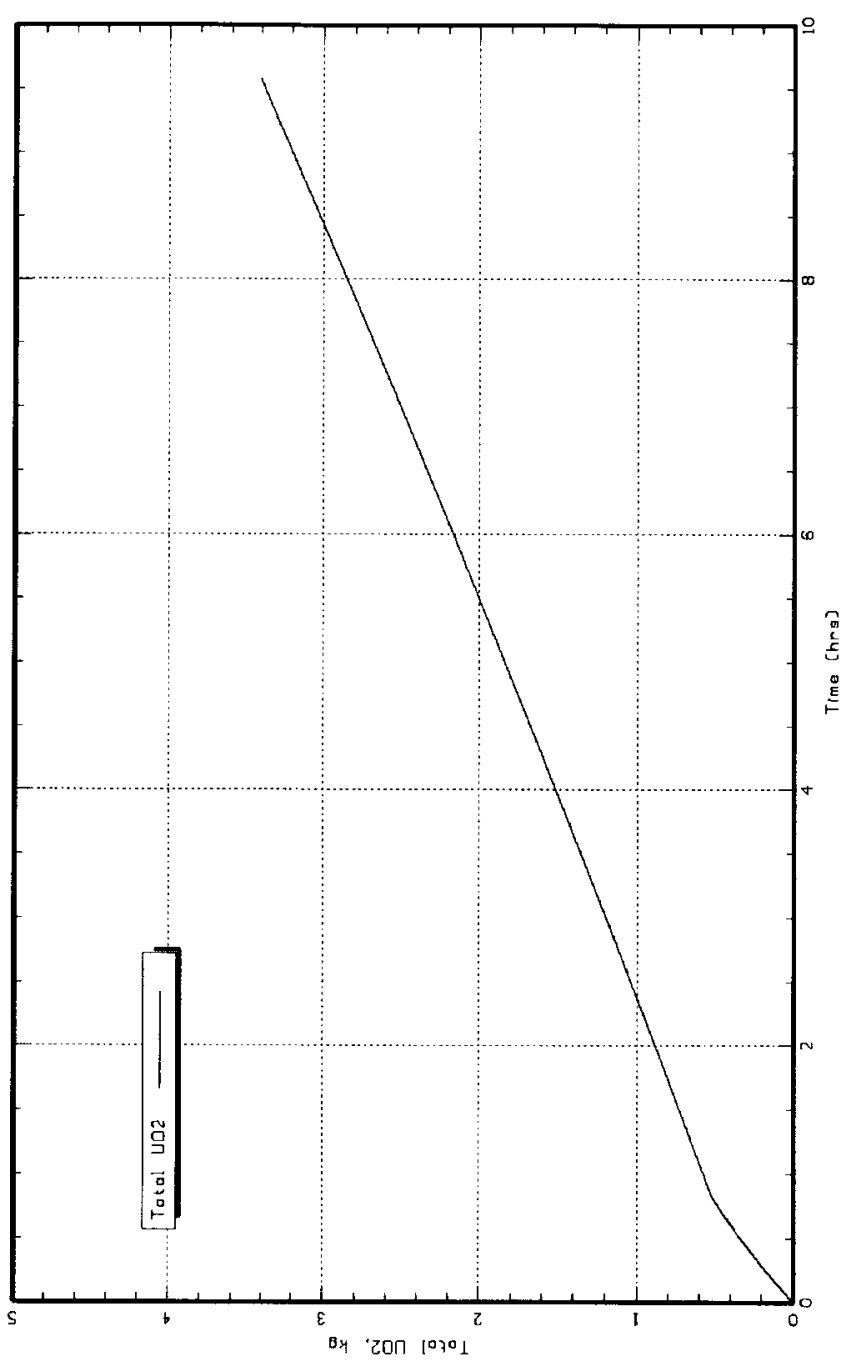

Figure 6-1C: Case 5: CVD of Safety Basis KOP Material (3 of 3). 
FAl/10-28

Rev. 0

Page 36 of 99

January, 2010
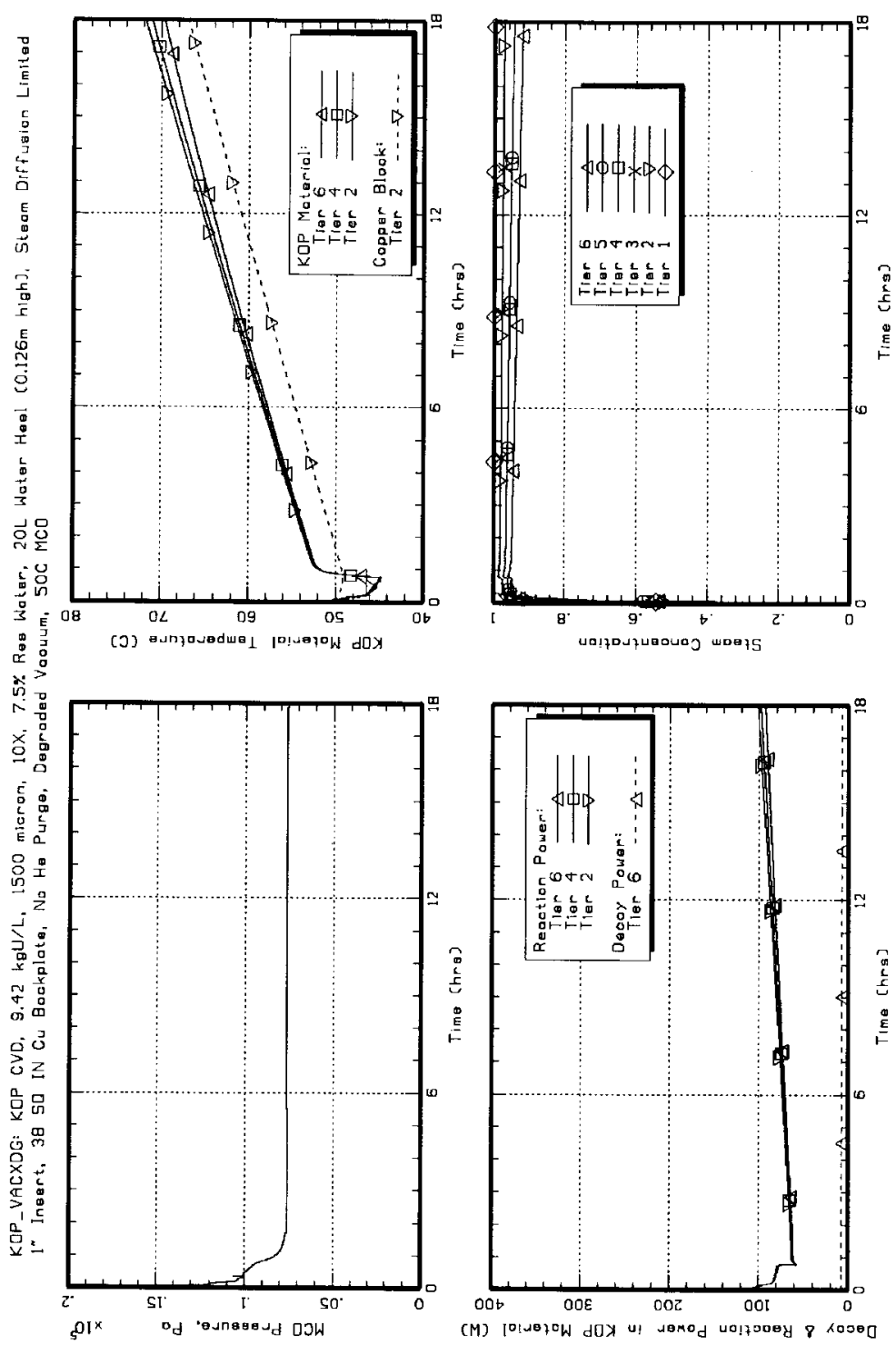

Figure 6-2A: Case 6: Degraded Vacuum Pumping With No Helium Purge (1 of 2). 
FAl/10-28

Rev. 0
Page 37 of 99

January, 2010
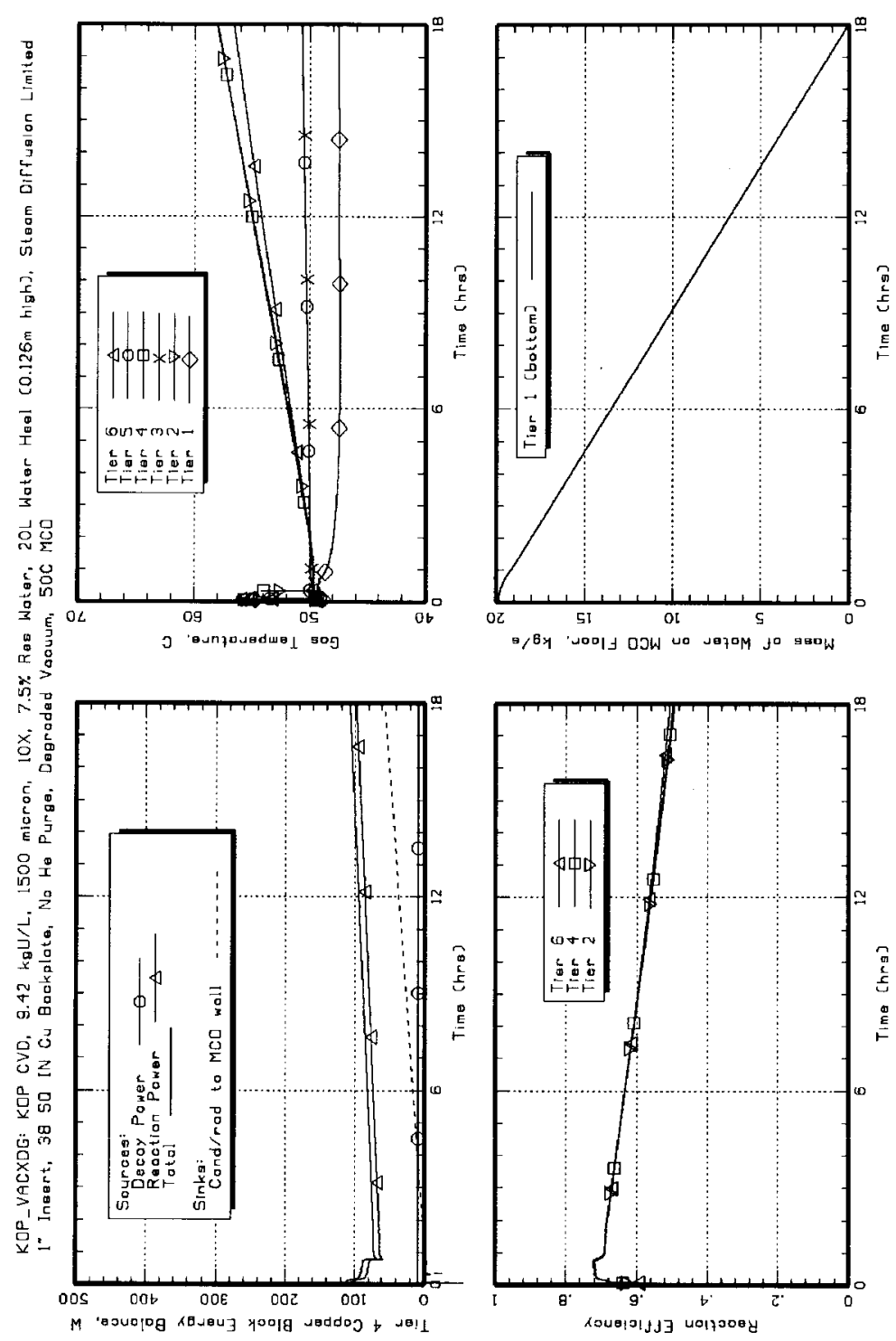

Figure 6-2B: Case 6: Degraded Vacuum Pumping With No Helium Purge (2 of 2). 

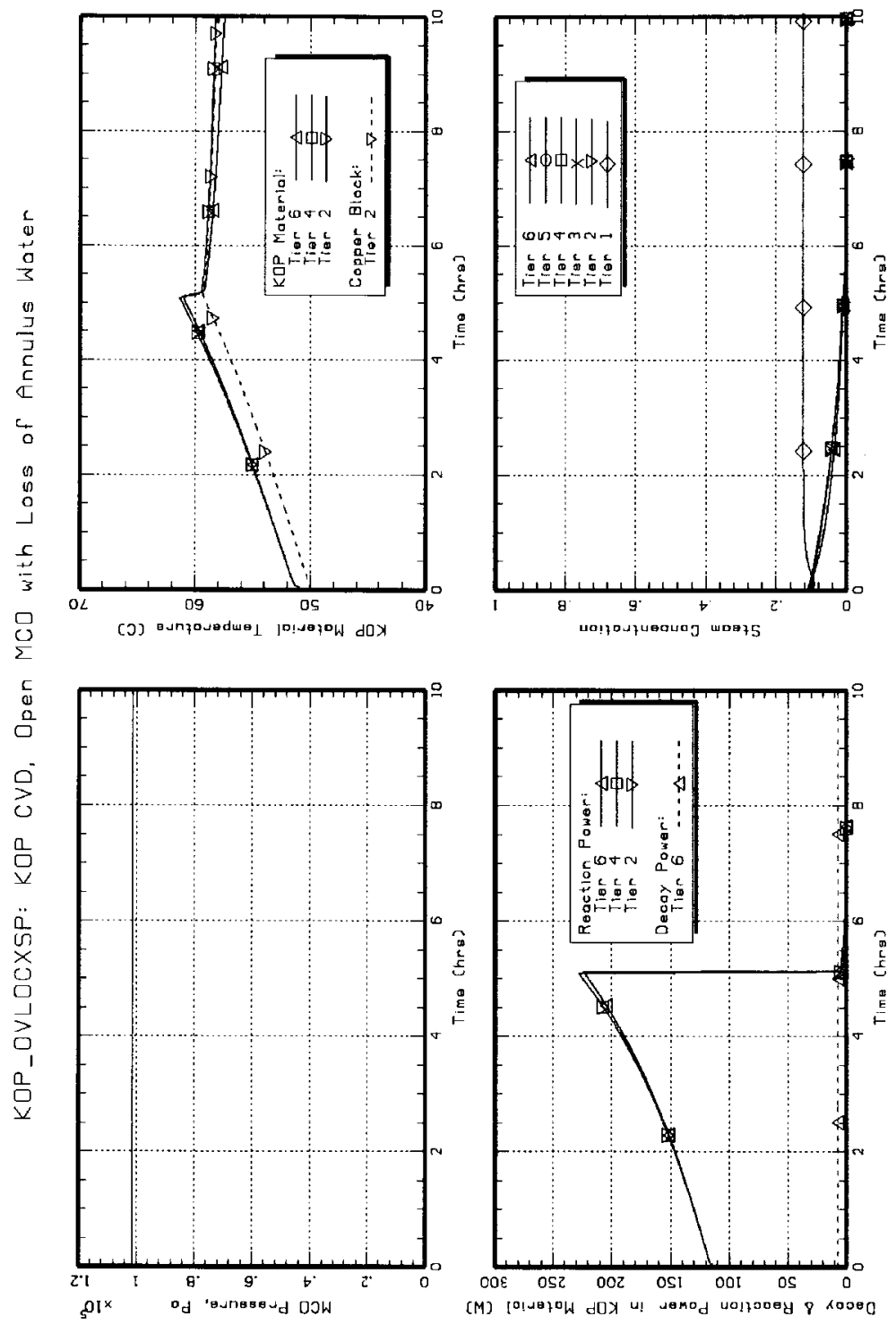

Figure 6-3A: Case 7: Open MCO With Loss of Annulus Water (1 of 2). 
FAl/10-28

Rev. 0
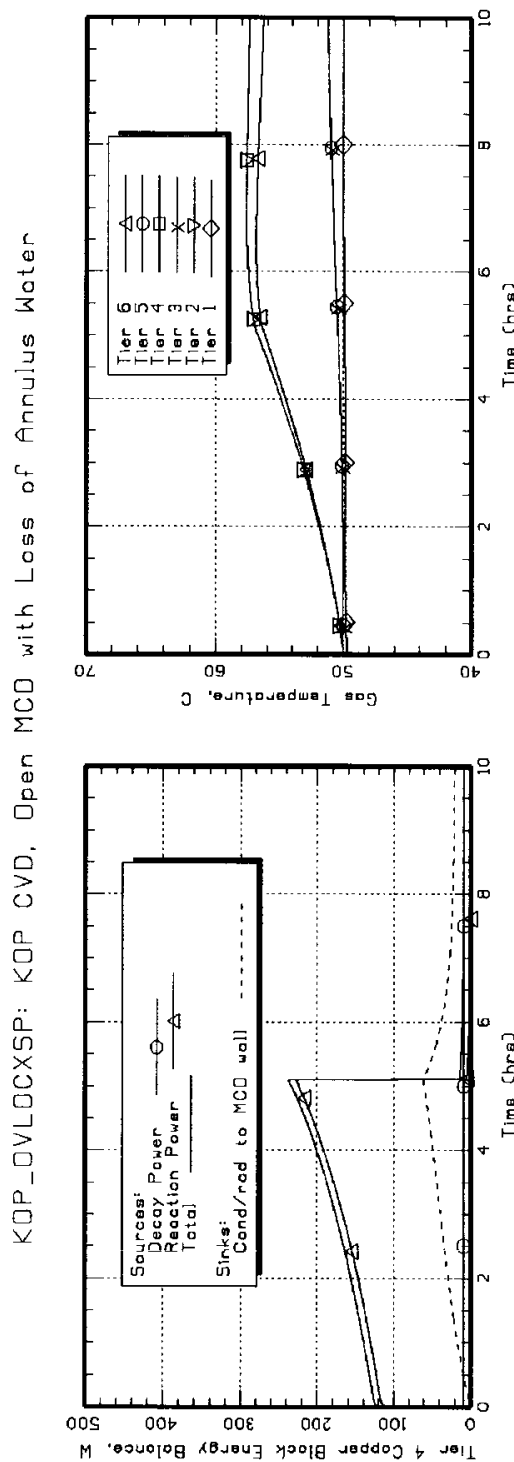

Page 39 of 99

January, 2010
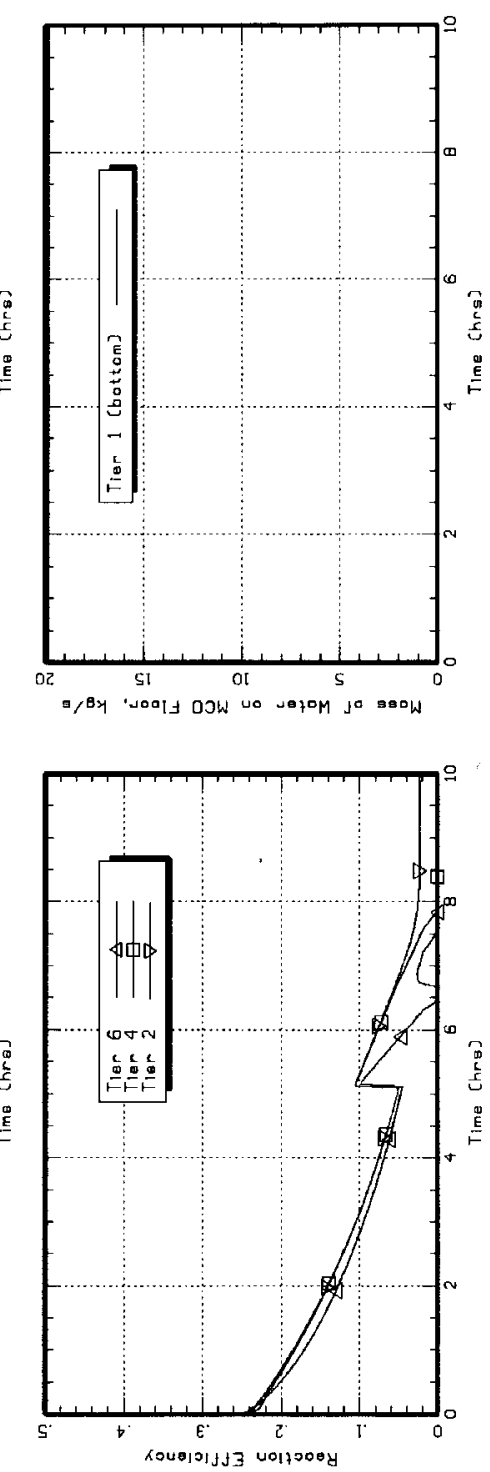

Figure 6-3B: Case 7: Open MCO With Loss of Annulus Water (2 of 2). 
FAl/10-28

Rev. 0
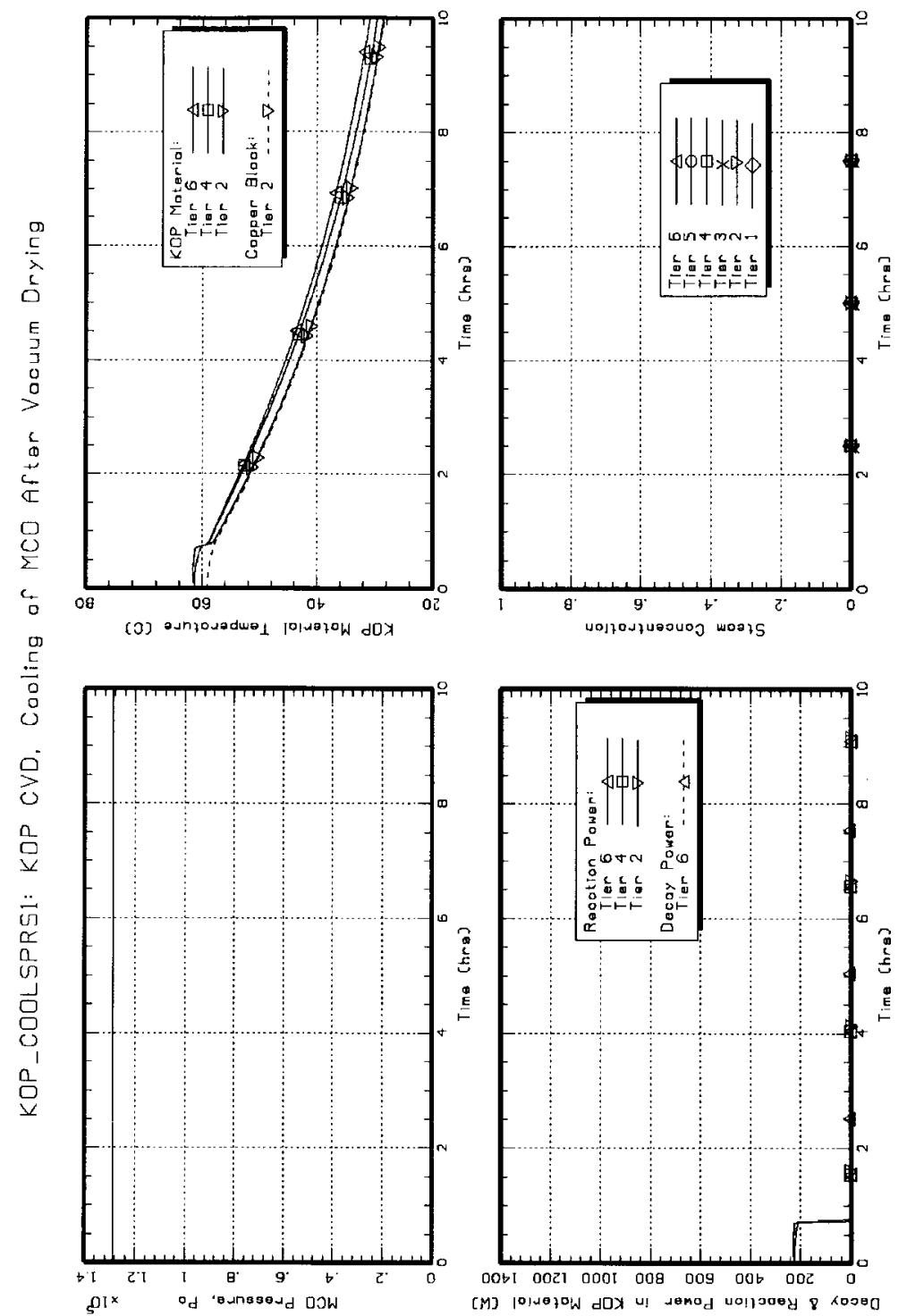

Figure 6-4A: Case 8: Cooling of MCO and KOP Sludge After Vacuum Drying (1 of 2). 

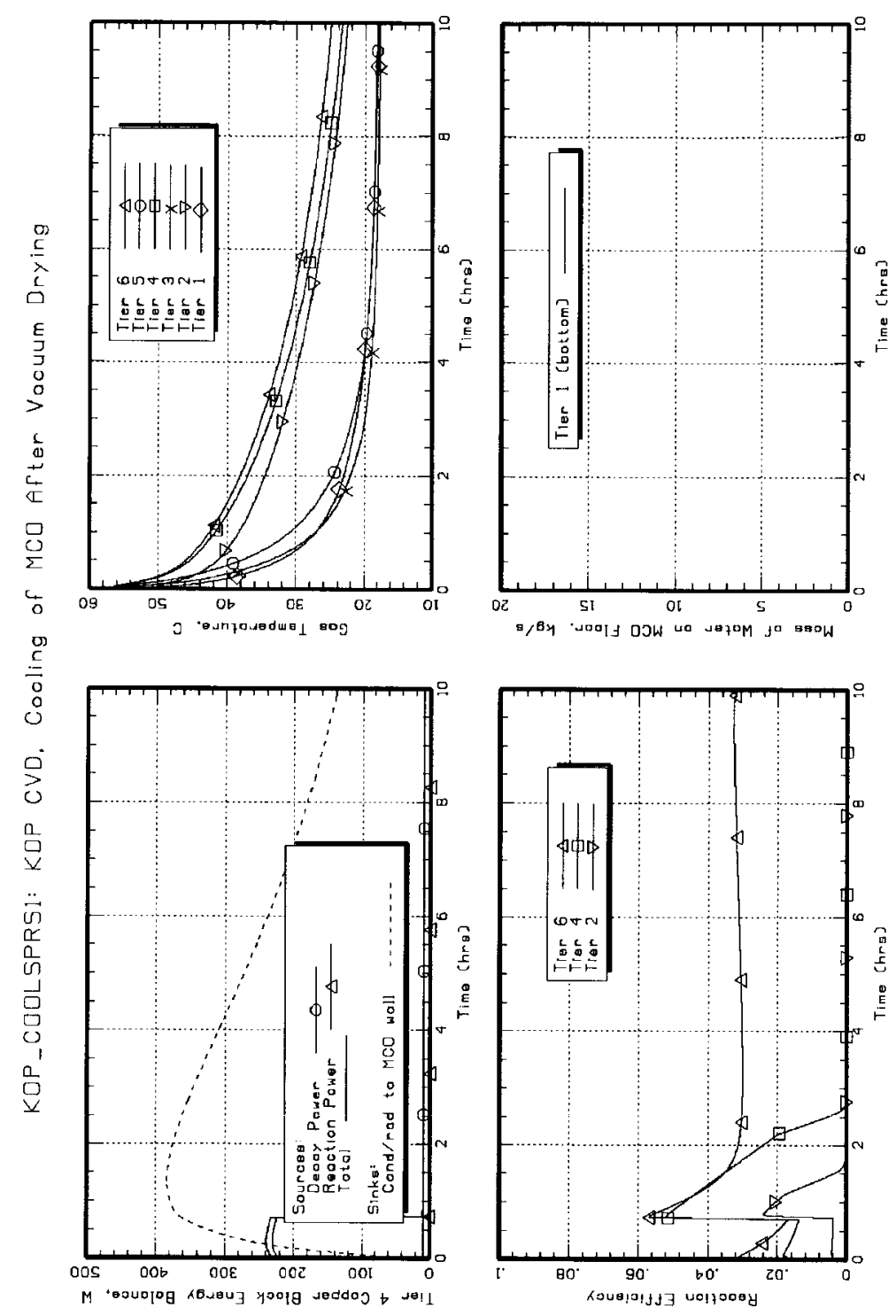

Figure 6-4B: Case 8: Cooling of MCO and KOP Sludge After Vacuum Drying (2 of 2). 


\subsection{REFERENCES}

Dwg. KOP-SK-510, Rev. 0, Sheet 4, KOP MCO Basket Insert Assembly, CHPRC Engineering Sketch, dated 8/14/09.

Epstein, M., 2008, "Residual Saturation Measurements," FAI Internal Memorandum to M.G. Plys, September 2, Fauske \& Associates, LLC.

Epstein, M., 2009, Correlations and Models in Support of FATE Computer Program Thermal Analyses of KOP Material During CVD and Shipping, FAl/09-254, Rev. 1, Fauske \& Associates, LLC, submitted to $\mathrm{CH} 2 \mathrm{M}$ Hill Plateau Remediation Company, Richland, WA, December.

Plys, M.G. and B. Malinovic, 1999, IWTS Metal-Water Reaction Rate Evaluation (Fauske \& Associates Report FAl/99-26), SNF-4266, Rev.0, Duke Engineering and Services Hanford, Inc., Richland, WA.

Plys, M.G. and D.R. Duncan, 2000, Uranium Pyrophoricity Phenomena and Prediction (FAl/00-39), SNF-6781, Rev. 0, EDT 629783, Fluor Hanford, Richland, WA, October.

Plys, M.G., and S.J. Lee, 2004, FATE 2.0: Facility Flow, Aerosol, Thermal, and Explosion Model (Improved and Combined HANSF and HADCRT Models), SNF23281, FAl/04-71, 2 volumes, Fluor Hanford, Inc., Richland, WA, November.

Plys, M.G., and S.J. Lee, 2008, "CVD of KOP Material in an MCO Insert Basket," FAI memorandum to J. Sloughter, C. Miska, and N. Sullivan, June 23, 2008.

Plys, M.G., and A.J. Schmidt, Supporting Basis for Spent Nuclear Fuel Project Sludge Technical Databook, SNF-7765, Revision 3B, released January, 2006.

Schmidt, A.J., 2006, Spent Nuclear Fuel Project Technical Databook, Vol. 2, Sludge, HNF-SD-SNF-TI-015, Revision 13A, Fluor Hanford, Richland, WA, June. 


\section{APPENDIX A: FATE INPUT DECKS}

\section{A.1 Case 1: KOPC19.DAT Simulation of CVD of $25 \%$ Void Fraction KOP Material}

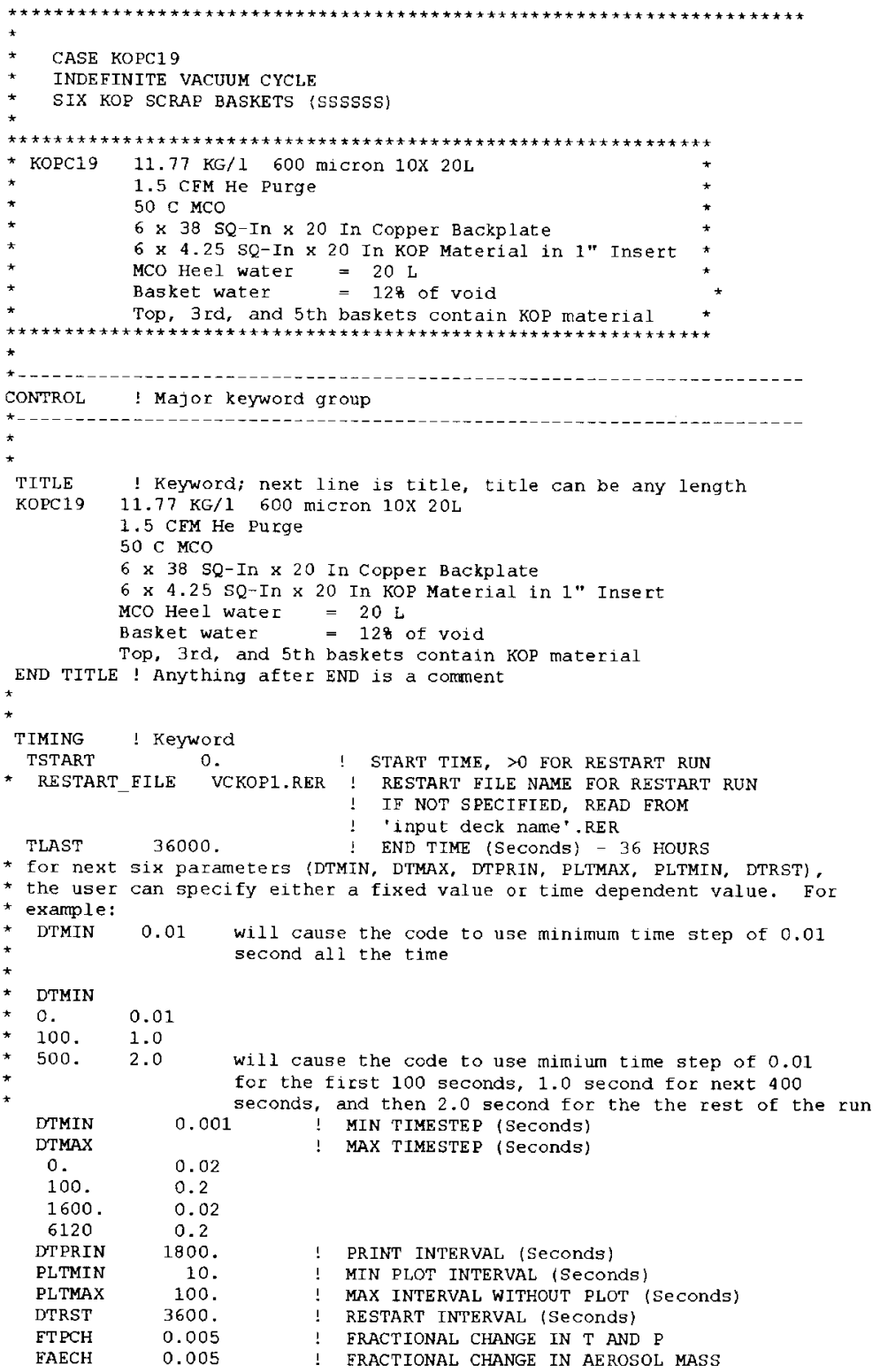




\section{PRC-STP-00187 REV 0}

FAl/10-28

Page 44 of 99

Rev. 0

$\begin{array}{llll}\text { FP PLCH } & 0.03 & ! & \text { FRACTIONAL CHANGE FOR PLOTTING } \\ \text { STARVTD } & 0.2 & ! & \text { MAXIMUM TIME STEP WHEN THE CORROSION IS } \\ & & ! & \text { STEAM STARVED }\end{array}$

END TIMING ! TIMING is a comment.

*

PRINT ! Keyword for printing section

* Printing syntax:

* HS n hlist - Heat Sink Temperatures, C

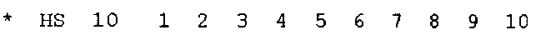

* HS $\begin{array}{lllllllllll}10 & 11 & 12 & 13 & 14 & 15 & 16 & 17 & 18 & 19 & 20\end{array}$

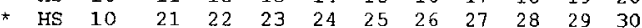

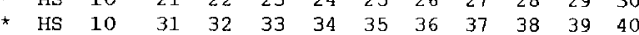

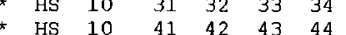

HS 1677

HS $\begin{array}{lllllll}5 & 3 & 23 & 34 & 43 & 63 & 83\end{array}$

HS $\begin{array}{lllllll}5 & 203 & 223 & 234 & 243 & 263 & 283\end{array}$

HS $5 \begin{array}{llllllll}5 & 403 & 423 & 434 & 443 & 463 & 483\end{array}$

HS $\begin{array}{llllll}5 & 12 & 32 & 52 & 72 & 92\end{array}$

HS $\begin{array}{llllll}5 & 212 & 232 & 252 & 272 & 292\end{array}$

HS $\begin{array}{lllllll}5 & 412 & 432 & 452 & 472 & 492\end{array}$

END RRINT ! PRINT is a comment

PLOT 1 ! Keyword for platting section

* Plotting syntax:

* PREsSuRe $n$ rlist - Pressure, Pa

* GAS-T n rlist - Gas Temperature, $K$

* HS-TI n hlist - Heat Sink Temperature - Inner surface, $K$

* HS-TO $n$ hlist - Heat Sink Temperature - outer Surface, K

* HS-TA $n$ hlist - Heat Sink Temperature - Average, K

* AEROSOl n rlist - Aerosol Mass (Total), kg

* GAS-W n jlist - Mass Flowrate, kg/s

* GAS-WX n jlist - CounterCurrent Mass Flowrate, $\mathrm{kg} / \mathrm{s}$

* GAS- $x$ GASNAME $n$ rlist - Gas Mole Fraction

* GAS-RH GASNAME n rlist - Gas Relative Humidity

* Gas-mass gasname n rlist - Gas Mass (Species), kg

* AER-MASS GaSNAME n rlist - Aerosol Mass (Species), kg

MASS GASNAME n rlist - Total Mass (Species), kg

* LIQ-MASS - GASNAME n rlist - Deposited Mass (Species), ko

* Pressure, Gas Temperature, and total aerosol mass require a region

* list

* Heat Sink Temperatures need a heat sink number list

* Flowrates need a junction number list

* Gas concentration, relative humidity, individual species gas mass,

* individual species aerosol mass, total (gastaerosol) individual

* species mass, and individual species deposited liquid mass require

* a region and gas name

* Note: plot routine can only accept 99 items; can't plot all things.

* Note: plot routine can only accept 99 items; can
* So plot all scrap T's but only 5 fuel (plus MCO)

PRESSURE 1111 ! Pressure in MCO

$\begin{array}{llllllllll}\text { GAS-T } & 6 & 1 & 2 & 3 & 4 & 5 & 6 & \text { ! Temperature in MCO }\end{array}$

LIQ-T $\quad 1 \frac{1}{6} \quad$ ! Liq Temperature in MCO

LIQ-MASS STEAM 1160 ! Liq MASS

$\begin{array}{llllllllll}\text { HS-TA } & 5 & 9 & 49 & 69 & 89 & 99 & \text { ! Tier } 6 \text { (top), vertical thru scrap }\end{array}$

$\begin{array}{llllllllllllll}\text { HS-TA } & 5 & 9 & 49 & 69 & 89 & 99 & & & & & & & \end{array}$

shroud, MCO

HS -TA

72 ! Tier 6, back-plate.

HS-TA

shroud, MCO

$\begin{array}{lllll}\text { HS-TA } & 5 & 409449469489499 & \text { ! Tier 2, vertical thru scrap }\end{array}$

$5 \quad 209249269289299$

! Tier 4 , vertical thru scrap

shroud, MCO

$5 \quad 409449469489499$

10463464465466467468469470471472 ! Tier 2, back-plate, scrap, spoke, 


\section{PRC-STP-00187 REV 0}

FAl/10-28

$\begin{aligned} & \text { HS-TA } \\ & \text { END PLOT }\end{aligned}$
$*$
PLOT 2

PLOT 3

QGAS-HSO $5 \quad 23,43,3,63,83$

QGAS-HSO $5 \quad 223,243,203,263,283$

QGAS-HSO $5 \quad 423,443,403,463,483$

QGAS-HSI $5 \quad 12 \quad 32 \quad 52 \quad 72 \quad 92$

QGAS-HSI $5 \begin{array}{llllll}512 & 232 & 252 & 272 & 292\end{array}$

OGAS-HST $5 \quad 412 \quad 432 \quad 452 \quad 472 \quad 492$

QRAD-HSO $523,43,3,63,83$

QRAD-H 5 23, 43, 3, 63, 83

QRAD- $50,5,223,243,203,263,283$

QRAD-HSO 5 423,443,403,463,483

QRAD-HSI 5 (12, $32,52,72 \quad 92$

QRAD-HSI $\begin{array}{llllll}5 & 212 & 232 & 252 & 272 & 292\end{array}$

$\begin{array}{llllllll}\text { QRAD-HSI } & 5 & 412 & 432 & 452 & 472 & 492\end{array}$

END PLOT ! PLO'T is a comment

ACTIVE MODELS ! Keyword; MODELS is a comment; $1=$ on, $0=$ off

IJUNC 1 ! Junction flow model

ICCFLW 1 : Counter-current flow model

IHSINK 1 ! Heat sinks

ICNDS 0 ! condensation

IHXPOL 1 Heat and Mass transfer on liquid pool

IASED 0 ! Aerosol Sedimentation

IALEAK 0 ! Aerosol Leakage

IFOG 0 ! Fog formation

ISRC 1 ! User-defined sources

IMCO 1 ! MCO models

ISENS 0 ! Sensitivity run

IPLTYP 2 1=wrap around, 2=no wrap (spreadsheet format)

END ACTIVE MODELS ! ACTIVE MODELS is a comment

MODEL ! keyword for model parameter

multipliers for region gas conductivities

*yntax:

FKGAS Ekgas1 fkgas2 £kgas $3 \ldots$

FLOWKBED 0.0066

FLANGM 0.1

* Multiplier to heat sink to liquid pool hx coefficient.

* There should be very little ho resistance between the rCo bottom

* and water heel because of He sparging and/or boiling during

vacuum drying.

FHHSL

END MODEL

SOURCE GROUP: GROUPS REPEATED FOR INPUT \# OF REGIONS

C END OF GROUP DESIGNATED BY 'REGION' OR 'END' KEYWORDS

C ENTER: TIME, TEMP, FLOWRATES, POWER

SYNTAX EXAMPLE:

$* 1.5 \mathrm{FT}^{\wedge} 3 / \mathrm{MIN} * 1 \mathrm{MIN} / 60 \mathrm{SEC} * 0.02832 \mathrm{M}^{\wedge} 3 / 1 \mathrm{FT}^{\wedge} 3=0.0007080 \mathrm{M}^{\wedge} 3 / \mathrm{SEC}$

* He density $\mathrm{e}$ stp is $0.16 \mathrm{~kg} / \mathrm{m}^{\wedge} 3$, hence $1.13 \mathrm{e}-4 \mathrm{~kg} / \mathrm{s}$

SOURCES 1 ! - KEYWORD AND \# SOURC

REGION 6 GASES 1 ! - REGION \#, \# GASES$$
\text { SPARGE } 0.00761 \quad 0.0
$$

HELIUM

! GaS SPARGE, RADIUS, ELEVATION

$0.0 \quad 45 \quad 1.13 \mathrm{E}-4 \quad 0 . \mathrm{EO}$ 


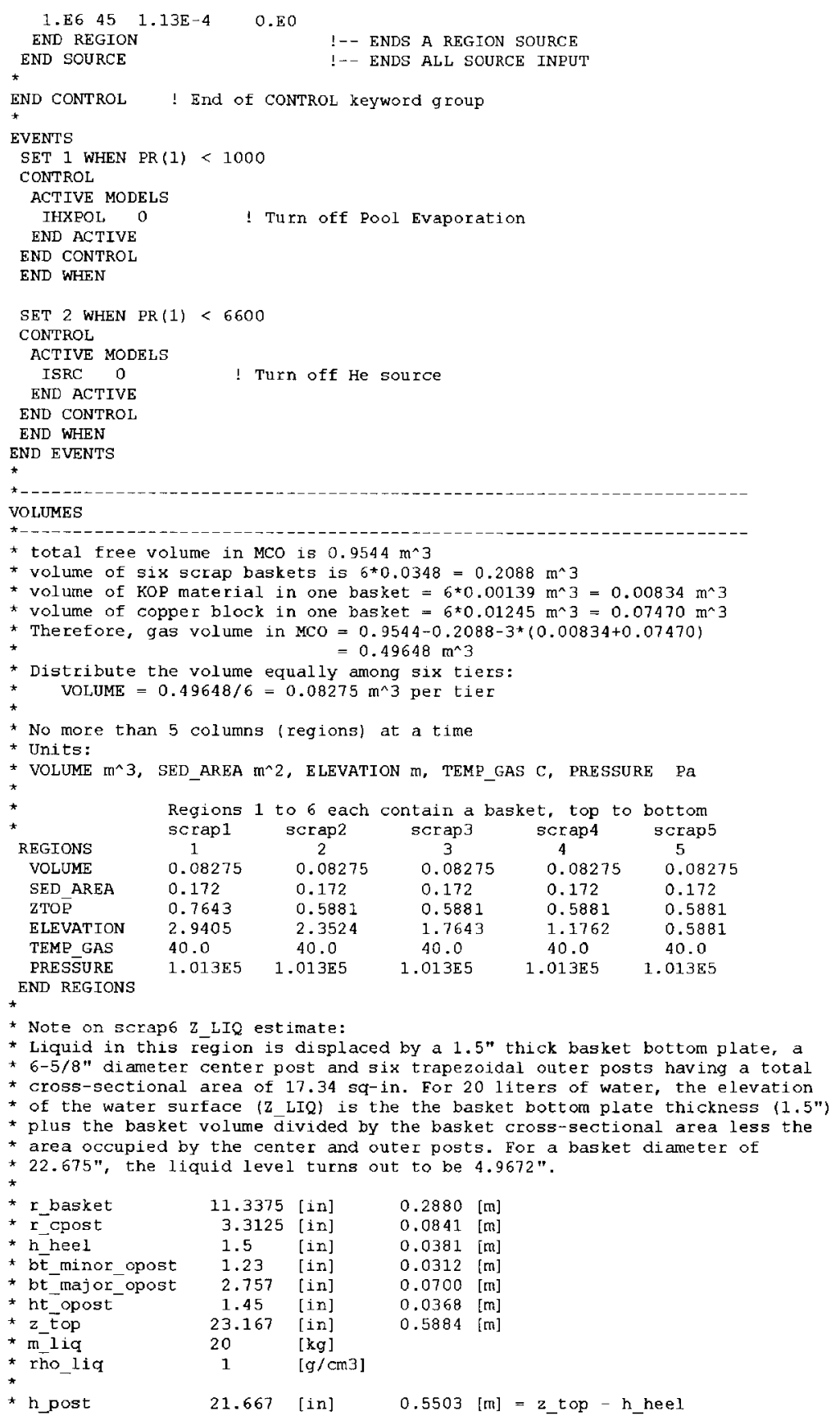




\begin{tabular}{|c|c|c|c|c|}
\hline & & & & \\
\hline ket & $\begin{array}{l}403.816 \\
34.471\end{array}$ & $69[\operatorname{in} 2]$ & 0.2605 & {$[\mathrm{~m} 2]$} \\
\hline A oposts & 17.343 & 35 [in2] & 0.0112 & $\begin{array}{l}{[\mathrm{m} 2]} \\
{[\mathrm{m} 2]}\end{array}$ \\
\hline$=6$ & * lbt_mino & or_opost $+\mathrm{b}$ & bt_major_o & \\
\hline Vheel & 605.73 & [in3] & 0.0099 & \\
\hline & 1220.4 & {$[$ in 3$]$} & 0.0200 & \\
\hline 2_liq_noposts & $s \quad 4.522$ & 23 [in] & 0.1149 & \\
\hline z_liq & $\begin{array}{r}=h \text { heel } 1 \\
4.967\end{array}$ & 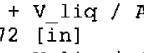 & $\begin{array}{l}\text { A_basket } \\
0.1262\end{array}$ & \\
\hline & $=h_{\text {L_heel }}$ & & & \\
\hline This also req & quires a ch & nange to & OLUME : & \\
\hline VOLUME $=V_{-} l i c$ & $\mathrm{Iq} * \mathrm{zTOP} /$ & $z_{-} L I Q=0$. & $0.0933\left[\mathrm{~m}^{\wedge} 3\right.$ & \\
\hline & scrap 6 & & environmen & \\
\hline & & 7 & 8 & \\
\hline VoLt & 0.0933 & 0.25 & $1 . \mathrm{Eg}$ & \\
\hline SED & 0.172 & 0.0 & 0 & \\
\hline & 5881 & 4.4069 & & \\
\hline ATION & 03048 & -0 . & & \\
\hline & & 40. & 40.0 & \\
\hline & 1262 & 0.0 & 0.0 & \\
\hline TEMP LIQ & 40.0 & 40.0 & 40.0 & \\
\hline & $1.013 \mathrm{E} 5$ & $1.013 \mathrm{E} 5$ & $1.013 \mathrm{E}$ & \\
\hline & & & & \\
\hline & & & & \\
\hline
\end{tabular}

*

* Gas composition of each region; specify mole fraction of each gas * No more than five columns at a time

HE L IUM

STEAM

${ }^{1}+89$

$0^{2} .89$

3

OXYGEN

0.11

0.11

0.89

NITROGEN

$0.0 \quad 0.0$

0.11

$\begin{array}{ll}0.11 & 0.0 \\ 0.0 & 0.0\end{array}$

4
0.89

0.89
0.11
0.0

5

END GASES

0.0

0.89

0.11

* If there are more than five regions, continue here.

* Gap is artificial here, MCO wall will be set to $40 \mathrm{C}$

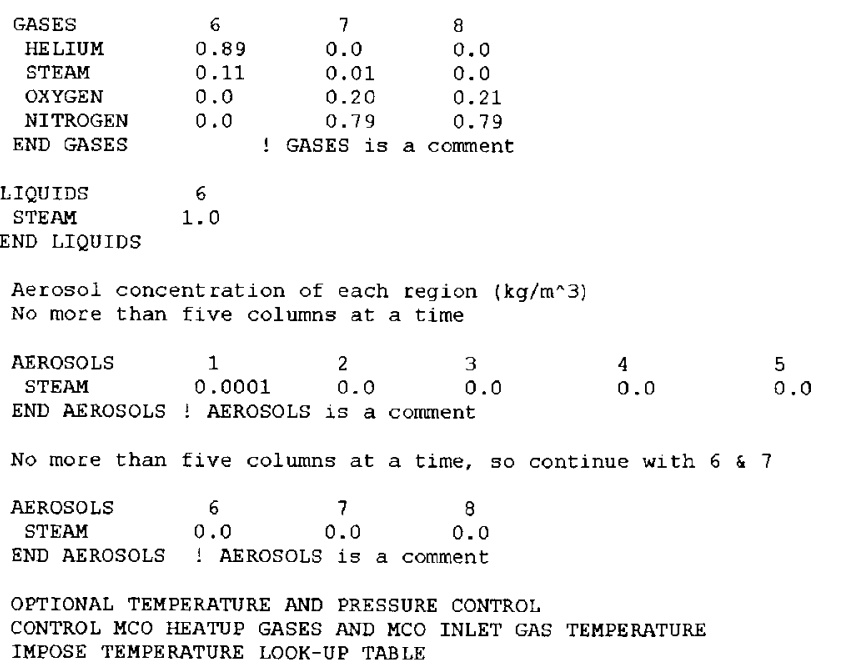




\section{PRC-STP-00187 REV 0}

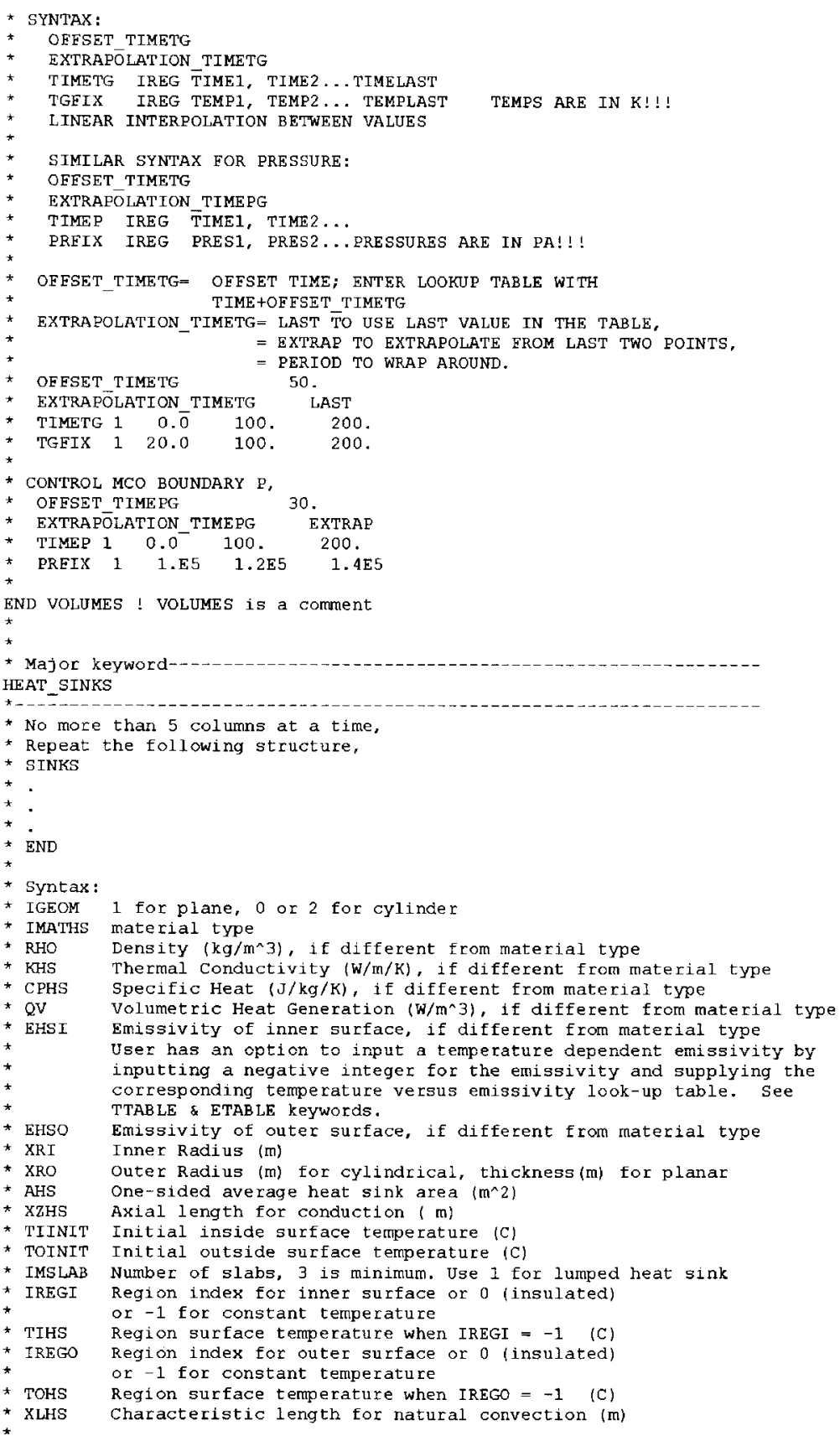




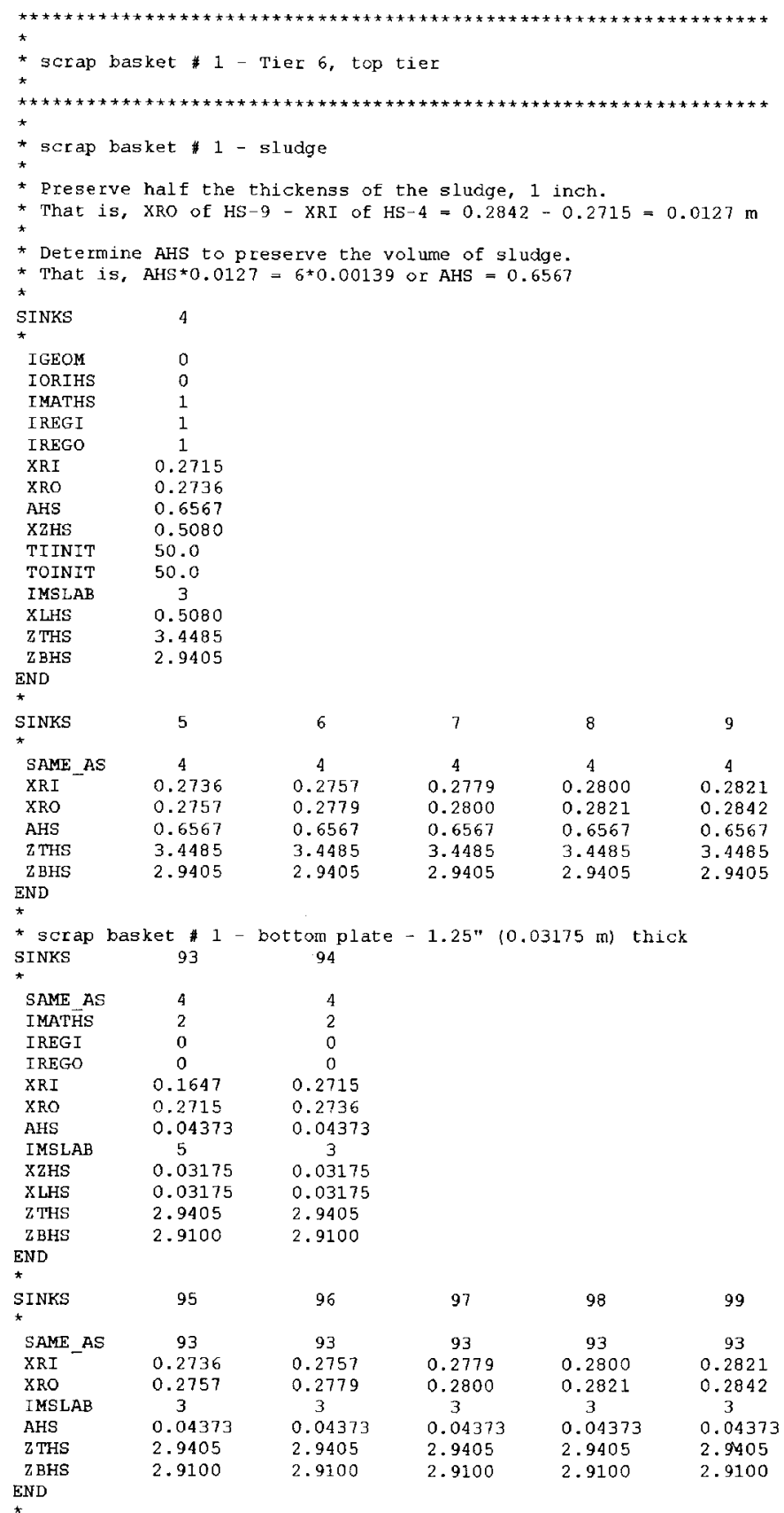




\section{PRC-STP-00187 REV 0}

FAl/10-28

Page 50 of 99

Rev. 0

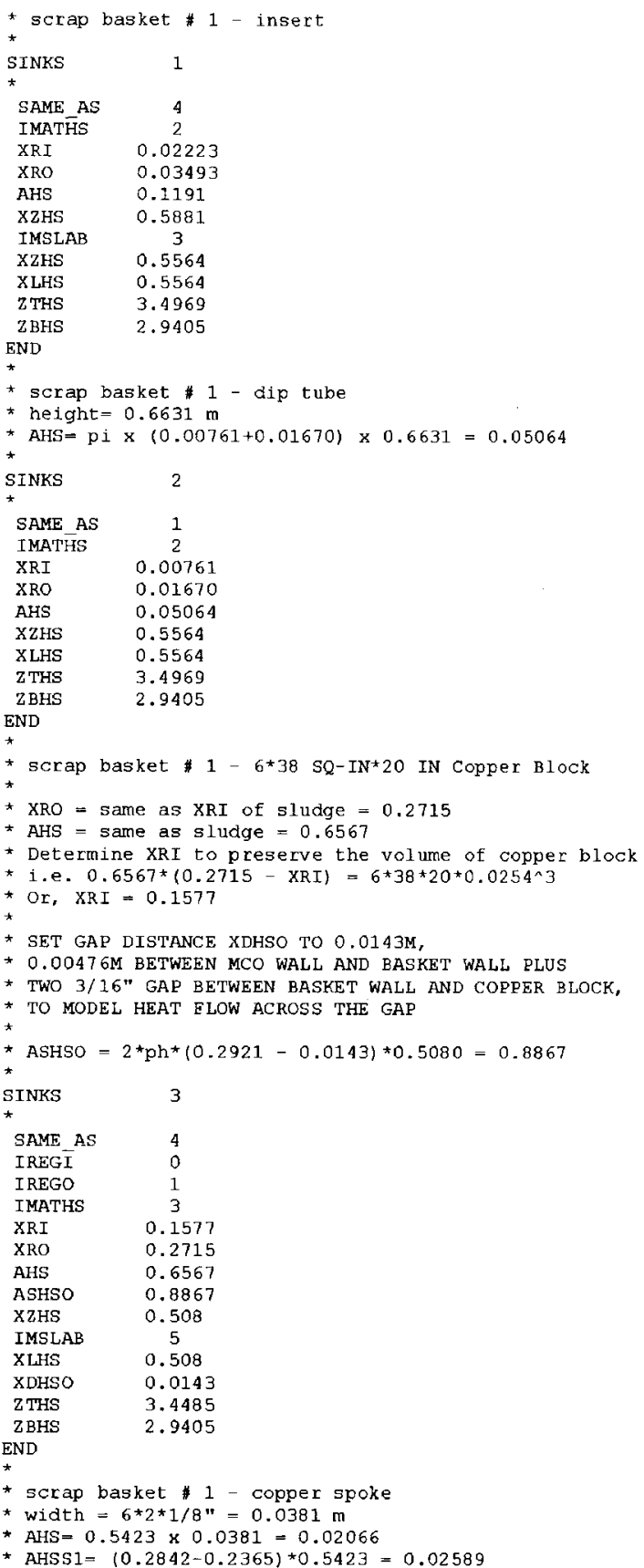


FAl/10-28

Page 51 of 99

Rev. 0

January, 2010

\begin{tabular}{ll}
$*$ & \\
SINKS & 10 \\
$*$ & \\
SAME_AS & 3 \\
IGEOM & 1 \\
IREGO & 1 \\
IMATHS & \multicolumn{1}{c}{3} \\
XRI & 0.0 \\
XRO & 0.169 \\
AHS & 0.02066 \\
IREGSI & 1 \\
AHSS1 & 0.02589 \\
IMSLAB & 20 \\
XLHS & 0.541 \\
XZHS & 0.541 \\
ZTHS & 3.4815 \\
ZBHS & 2.9405 \\
END &
\end{tabular}

* scrap basket \#1 - basket shroud

* Make EHSO very small to stop radiation to MCO wall

* Copper block to MCO wall ht across the gap

* is modeled separately

SINKS 11

SAME AS

IREG I

IREGO

IMATHS

EHSO

$X R I \quad 0.2842$

XRO 0.2874

AHS $\quad 0.9720$

$\begin{array}{lc}\text { AHS } & 0.972 \\ \text { IMS LAB } & 3\end{array}$

XLHS $\quad 0.541$

$\mathrm{XZHS} \quad 0.541$

ZTHS $\quad 3.4815$

ZBHS 2.9405

* scrap basket \#1-MCO wall

* SeT gaf Distance xDHsi to $0.0143 \mathrm{M}$,

* $0.00476 \mathrm{M}$ BETWEEN MCO WALl AND BASKET WALL PLUS

* TWO 3/16" GAP BETWEEN BASKET WALL AND COPPER BLOCK,

to MODEl heat FlOW aCross tHe GAP

SINKS

12

SAME AS 11

IREGT 11

IREGO ${ }^{7}$

wall temperature

IREGO -1

$\begin{array}{lc}\text { TOHS } & 50.0 \\ \text { IMATHS } & 2\end{array}$

XRI $\quad 0.2921$

XRO $\quad 0.3048$

AHS $\quad 1.1026$

XLHS $\quad 0.5881$

XZ10 0.0143

XZHS $\quad 0.588$

$\begin{array}{ll}\text { ZTHS } & 3.4981 \\ \text { ZBHS } & 2.9405\end{array}$

END

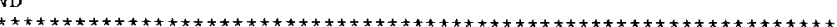

* scrap basket $\# 2$ - Tier 5 


\section{PRC-STP-00187 REV 0}

FAl/10-28

Page 52 of 99

Rev. 0

January, 2010

*

SINK

SAME AS

IREG $\overline{\mathrm{I}}$

IREGO

ZTHS

ZBHS

END

SINKS

193

195

196

0
0

94
0

2.352

2.3524
2.3207

2.320

95
0
0

.3524

SAME_AS

IREG $\bar{I}$

IREGO

ZTHS
ZBHS

ZBHS

197

2.3207

* scrap basket \#2 - insert

SINKS

101

SAME AS

IREG $\bar{I}$

I REGO

ZTHS

2

ZBHS

2.9088

END

2.3524

* scrap basket \#2 - dip tube

SINKS 102

SAME_AS

IREG $\vec{I}$

IREGO

$\mathrm{zTHS}$

ZBHS

97

0

2.3524

2.352

2.3524
2.3207

198

98
0
0

2. 3524

2.3524

2.3524

199

END

* scrap basket \#2-copper spoke

SINKS $\quad 110$

SAME AS

10

IREGI

IREGO

2.8934

ZBHS $\quad 2.3524$

* scrap basket \#2 - basket shroud

SINKS 111

SAME_AS

IREGI

IREGO

11

ZTHS 2.8934

2

HS 2.3524

END

* scrap basket *2 - MCO wall

SINKS

112

SAME_AS

12 


\section{PRC-STP-00187 REV 0}

FAl/10-28

Rev. 0

$\begin{array}{ll}\text { IREGI } & 2 \\ \text { ZTHS } & 2.9405 \\ \text { ZBHS } & 2.3524 \\ \text { END } & \end{array}$

* scrap basket \#3-Tier 4

$\star$

* scrap basket \#3 - sludge

SINKS

204

SAME_AS

IREGI

IREGO

$\mathrm{ZTHS}$

ZBHS

END

SINKS

206

4
3
3
2.2723
1.7643

2.2723
1.7643

205

SAME AS

IREG

IREGO

ZTHS

END

*

* scrap basket \#3-bottom plate

SINKS

293

294

94

SAME AS

ZTHS

ZBHS

93

1.7643
1.7326

1.7643

1.7326

END

SINKS

296

297

97

1.7643

1.7326

1.7643

1.7326

Z BHS

END

* scrap basket \#3 - insert

SINKS

201

SAMF AS

IREG $\overline{\mathrm{I}}$

IREGO

$\mathrm{Z}$ THS

$\frac{1}{3}$

$$
2.3207
$$

2.3207
1.7643

END

* scrap basket *3 - dip tube

INKS 20

SIN

SAME AS

IREGI

IREGO

IREGO

$\mathrm{ZTHS}$

END

$\star$

* scrap basket *3-copper back plate (block)
Page 53 of 99

January, 2010 
FAl/10-28

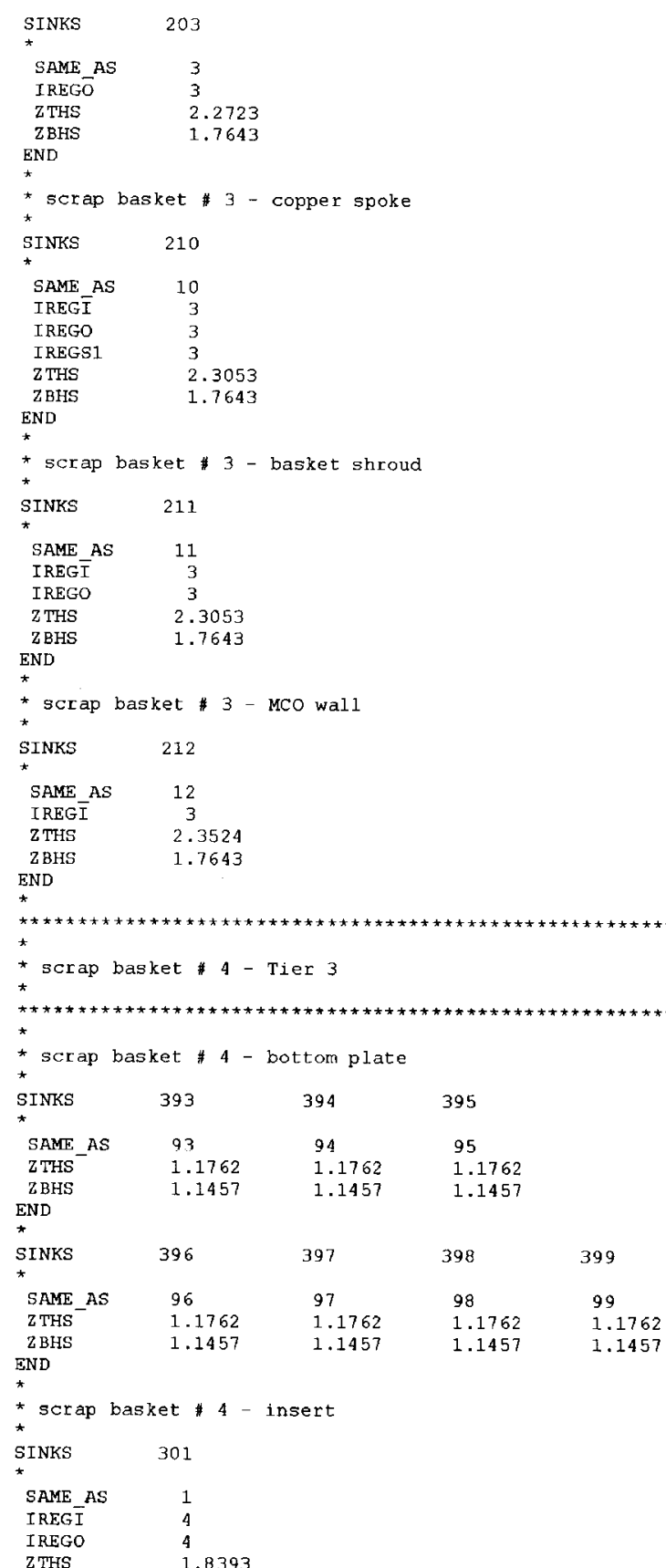


FAl/10-28

Page 55 of 99

Rev. 0

January, 2010

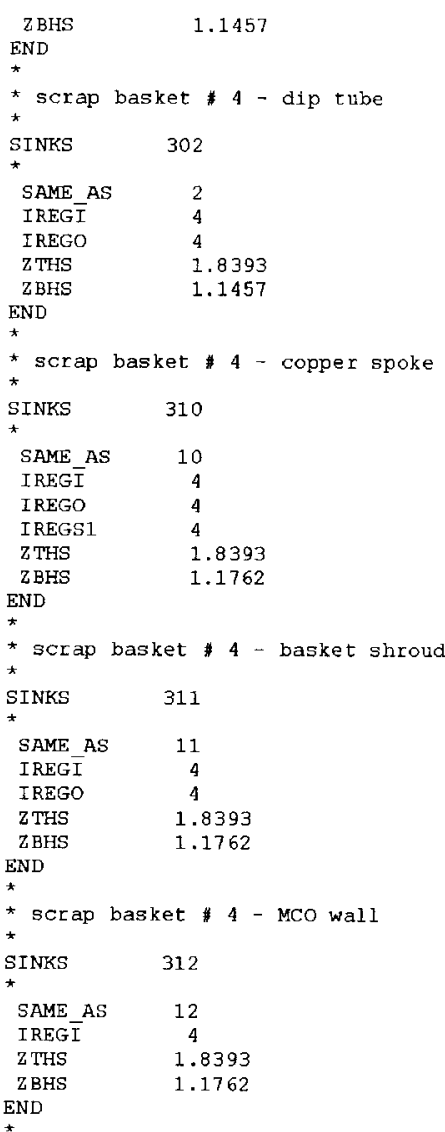

*

* scrap basket 5 - sludge

SINKS $\quad 404$

$\begin{array}{lll}\text { SAME_AS } & 4 & 5 \\ \text { IREGI } & 5 & 5\end{array}$

IREGO $\quad 5.0961$

$\begin{array}{lll}\text { Z THS } & 1.0961 & 1.0961 \\ \text { Z BHS } & 0.5881 & 0.5881\end{array}$

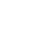

406

407

408

409

SAME_AS

IREGI

IREGO

ZTHS

6
5
5

5

1.0961
0.5881

7
5
5

5

1.0961
0.5881

8

5
5
1.0961

1.0961
0.5881

5
5
1.0961

1.0961
0.5881 
FAl/10-28

Page 56 of 99

Rev. 0

January, 2010

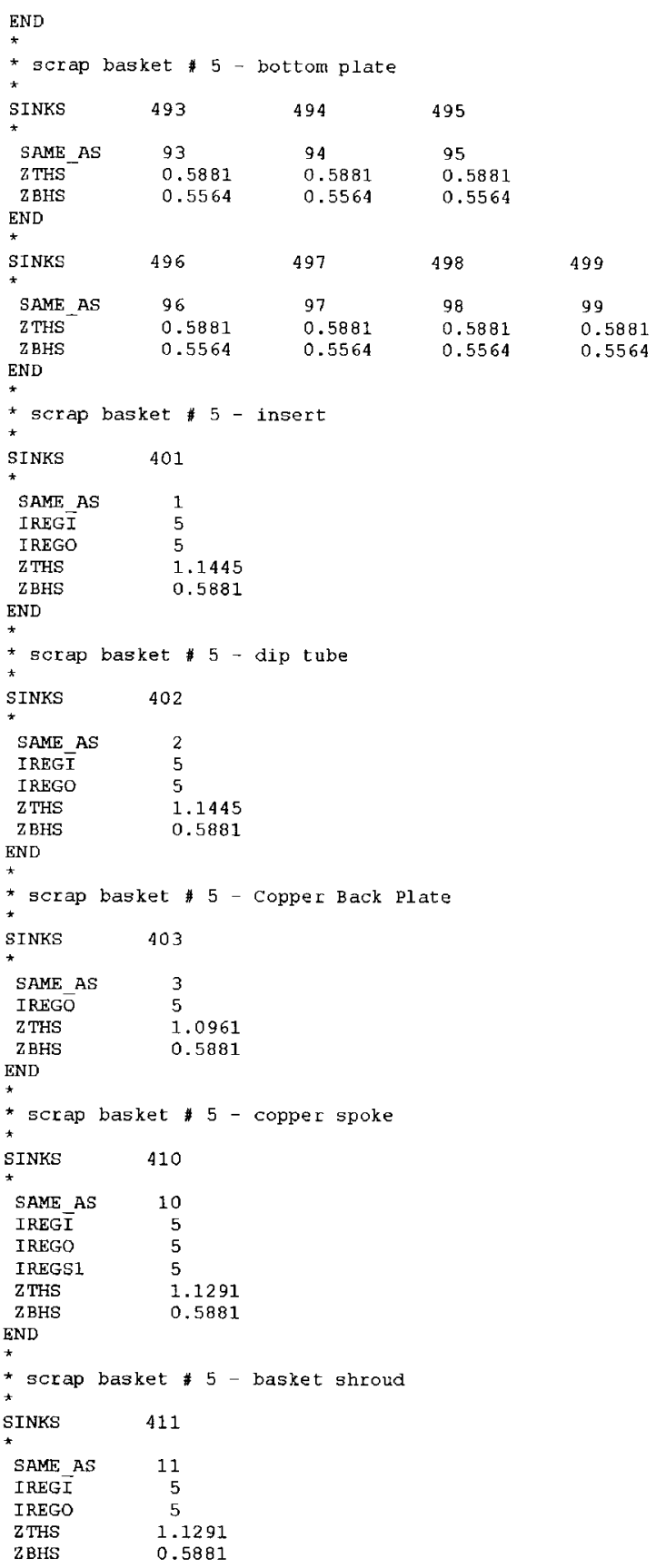


FAl/10-28

Rev. 0

END

* scrap basket \# 5 - MCO wall

SINKS 412

SAME AS 12

$\begin{array}{lr}\text { SAME AS } & 12 \\ \text { IREGI } & 5\end{array}$

ZTHS $\quad 1.1762$

ZBHS $\quad 0.5881$

END

* scrap basket \#6 - Tier 1, bottom tier

*

**

* Scrap basket $\# 6$ - bottom plate

SIN

$593 \quad 594 \quad 595$

SAME_AS $93 \quad 94 \quad 95$

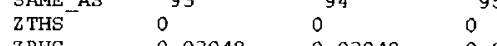

$\begin{array}{llll}\mathrm{ZBHS} & -0.03048 & -0.03048 & -0.03048\end{array}$

END

$\begin{array}{ll}\star & \\ \text { SINKS } & 596\end{array}$

ZTHS ${ }^{-1}$

Z THS

$0^{96}$

597

598

599

END

$0^{97}$

$0^{98}$

0
-0.03048

99

o 0.03048

* scrap basket \#6 - insert

SINKS

501

SAME AS

IREG $\overline{\mathrm{I}}$

IREGO

2 THS
ZBHS

END

$\star$

* scrap basket \#6 - dip tube

SINKS

SAME_AS

IREG $\bar{I}$
IREGO

ZTHS

ZBHS

END

* scrap basket \#6 - copper spoke

SIN

SAME_AS

IREG $\bar{I}$

IREGS 1

2 THS

ZBHS

END

* scrap basket \#6- basket shroud

SINKS

510

10

6

511 
FAl/10-28

Page 58 of 99

Rev. 0

I REG I

I REGO

TTHS

Z BHS

END

* scrap basket \#6 - MCO wall

SINKS

512

SAME AS 12

IREG $\overline{\mathrm{I}} \quad 12$

$\begin{array}{ll}\text { IREGI } & 6 \\ \text { ZTHS } & 0.5881\end{array}$

0

*

$\begin{array}{lccc}* & \text { CASK WALL } & \text { MCO BOT } & \text { MCO LID } \\ \text { SINKS } & 676 & 677 & 678\end{array}$

IGEOM

IORIHS

IMATHS

XRI

$X R O$

AHS

XZHS

TOINIT

IMSLAB

I REG I

I REGO

TOHS

$\mathrm{XIHS}$

$X$ LHS

0

1

1

0

0.3199

0.3199

10.24
3.95

$\begin{array}{ll}1 & 2 \\ 2 & 2\end{array}$

$0.0 \quad 0.0$

$0.0508 \quad 0.29$

$0.3 \quad 0.3$

$50.00 \quad 50.00 \quad 50.00$

$50.00 \quad 50.00$

10

7

0.0
8
0.0

0.0

0.02

3.95

EHSO

0.3

0.3

4.3924
-0.01452

5
6

0.0

$-1$

50.0

0.3

0.3
0.3

$-0.03048$

20
1
0.0

ZBHS

END

$-0.08128$

.0

0.0

0.02

0.3

1.0
0.3

3.9948

MATERIAL LIBRAY

* material library - SPEcify material properties for material 'imaths'

* UPTO 20 (INMAT) MATERIALS CAN BE SPECIFIED

* SYNTAX:

t

* OLD INPUTS:

* decay power per unit sludge volume for fuel piece sludge is $1100 \mathrm{~W} / \mathrm{m}^{\wedge} 3$

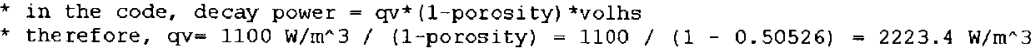

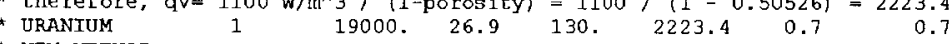

Will use 40 9 void for SB KOP material.

* True solid density $=16.8 \mathrm{MT} / \mathrm{m}^{\star * 3}$ is consistent

Preserve U metal khs, cp

Preserve SB decay power $\mathrm{Qm}=117 \mathrm{~W} / \mathrm{MTU}$

Q $Q v=Q m[W / M T U] * \pm u[M T U / M T]{ }^{\star}$ rho $\left[M T / m^{\star \star} * 3\right]$

$=117 * 0.825 * 15.667=1512.3$

* NEW METHOD FOR 258 VOID:

* KOP material solid particles are 82.638 uraninum and 17.378 zirconium by volume.

* E_void = 0.25; // vol-8

Emetal = 1.0-E_void:

$\mathrm{f} \bar{v}_{-} \mathrm{zr}=0.1737 ; / / \mathrm{vol}-\mathrm{z}$

* fv_u $=1-$ fv_zr $^{-}$

* rho zr $=0.8263$ \% 
FAI/10-28

Rev. 0

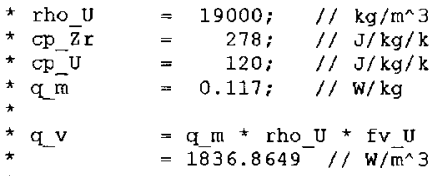

* rho_metal $=f v_{-} U *$ rho_U + fv_zr * rho_zr

$=16 \overline{8} 32.224 / / \mathrm{kg} / \overline{\mathrm{m}}^{\wedge} 3$

Cp_metal $=\left(f v_{-} U * \mathrm{rho} U * \mathrm{cp} U+\mathrm{fv}_{\mathrm{Z}} \mathrm{zr} *\right.$ rho $\mathrm{zr} * \mathrm{cp} \mathrm{zr}$ )/ rho metal

$=130.63073 \bar{T} / \mathrm{J} / \mathrm{kg} / \mathrm{k}$

name imaths rho khs cp gy ehsi $\begin{array}{lcllcccc} & \text { imaths } & \text { rho } & \text { khs } & \text { Cp } & \text { qV } & \text { ehsi } & \text { ehso } \\ \text { URANIUM } & 1 & 16832 & 26.9 & 131 . & 1837 . & 0.7 & 0.7\end{array}$

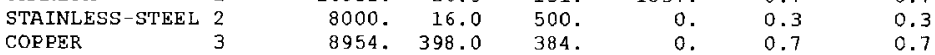
END

* USER CAN CONTROL hEAT SINK BOUNDARY TEMPERATURE

* SYNTAX:

* OFFsET TIMEHS

EXTRAPOLATION TIMEHS

EXIAPP THS ISD TIME 1 TIME 2 ...

THSFIX IHS ISD TEMP1, TEMP2.

* IHS = HEAT SINK NO.; ISD = SIDE NO. $(1$ OR 2) FOR IHS

* CONTROL HEAT SINK BOUNDARY $T$

* temperature DEPENDENT EMISSIVITY:

* USER CAN INPUT a TEMPERATURE DEPENDENT EMISSIVITY BY INPUTTING A

* NEGATIVE INTEGER FOR THE EMISSIVITY AND PROVIDING THE CORRESPONDING

* TEMPERATURE VERSUS EMISSIVITY LOOK-UP TABLE.

* SYNTAX:

* TTABLE $n$ temperature-ent $r y(C)$

* ETABle a temiserature-ent

* SANDWICh heat SINKS - STRING together NuMER of consecutive heat siNKS

* TO MIMIC a SANDWICH WALL. UPTO 100 SANDWICH WALLS CAN BE SPECIFIED, WITH

* UPTO 10 layers iN EACH WALl. THE SANDWICH HEAT SINK SERIES SHOUld BE

* ARRANGED SUCH THAT THE OUTER FACE OF THE FIRST HEAT SINK AND THE INNER FACE

* OF THE LAST hEAT SINK IN THE SERIES FACE THE GAS REgIONS (OR INSUlated).

* SYNTAX:

* SANDWICH hs1 hgap1 hs2 hgap2 hs3 hgap3 ... hsn

* WHERE 'hgap' is the gap conductance $\left(W / m^{\wedge} 2 / C\right)$ between the layers

* beTWEEN THE INSERT aND tHE DIP TUBE, THERE IS a AIR gaP oz THICKNESS

$\star 0.005524 \mathrm{M}$. THERE EORE, THE GAP CONDUCTANCE IS $0.03 / 0.005524=5.4 \mathrm{~W} / \mathrm{m}^{\wedge} 2 / \mathrm{C}$

* USER can DEFINE CONDUCtion NETWORKs

* sYNTAX

$\begin{array}{llllll}\text { COND_NETWORK } & \text { ihs1 } & \text { ihs2 } & \text { ihs3 } & \ldots \text { ihsn } & \text { upto } 100 \text { heat sinks } \\ \text { COND_NETWORK } & \text { ihs1 } & \text { ihs2 } & \text { ihs3 } \ldots . \text { ihsn } & \text { upto } 100 \text { heat sinks }\end{array}$

upto 5 networks

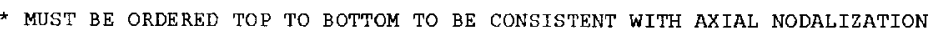

* MODEl CONTIGUOUS dip TUBE CONNECTEd TO THE SHIELd PLUG (HS \#278)

* COND_NETWORK NET $-1-278 \quad 22$

* 132

* $\begin{array}{r}132 \\ 187\end{array}$

* MODEL CONTIGUSOUS INSERT

* COND_NETWORK NET=2 $\quad 21$

242

131
186

* MODEl CONTIGUOUS MCO WAll CONNECTED TO THE SHIELD PLUG (HS \#278)

$\begin{array}{lllllll}\text { COND NETWORK NET }=3 & -278 & 51 & 106 & 161 & 216 & 271\end{array}$ 
* between the insert and the dip tUBe, there is a air gap of thickness

* $0.005524 \mathrm{M}$. THEREFORE, THE GAP CONDUCTANCE IS $0.03 / 0.005524=5.4 \mathrm{w} / \mathrm{m}^{\wedge} 2 / \mathrm{C}$ SANDWICH 15.42

SANDWICH 2015.4202

SANDWICH $4015.4 \quad 402$

* BETWEEN COPPER BLOCK AND SLUdGE

SANDWICH $3 \quad 1000 \quad 4$

SANDWICH $23 \quad 10002$

SANDWICH $43 \quad 1000 \quad 44$

SANDWICH $63 \quad 1000 \quad 64$

SANDWICH $83 \quad 1000 \quad 84$

SANDWICH $203 \quad 1000204$

SANDWICH $223 \quad 1000 \quad 224$

SANDWICH $243 \quad 1000244$

SANDWICH $263 \quad 1000264$

SANDWCH 2631000264

SANDTICH $403 \quad 1000284$

SANDWICH $403 \quad 1000404$

SANDWICH $423 \quad 1000 \quad 424$

SANDWICH $443 \quad 1000 \quad 444$

SANDWICH $463 \quad 1000464$

SANDWICH $483 \quad 1000484$

* NETWORKS

* basket 1 - FUel piece sLUdge

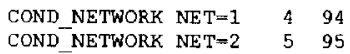

$\begin{array}{lll}\text { COND_NETWORK NET }=2 & 5 & 95 \\ \text { COND_NETWORK NET }=3 & 6 & 96\end{array}$

$\begin{array}{lll}\text { COND_NETWORK NET }=3 & 6 & 96 \\ \text { COND_NETWORK NET }=4 & 7 & 97\end{array}$

$\begin{array}{lll}\text { COND_NETWORK NET }=4 & 7 & 97 \\ \text { COND_NETWORK NET }=5 & 8 & 98\end{array}$

$\begin{array}{lll}\text { COND_NETWORK NET }=5 & 8 & 98 \\ \text { COND_NETWORK NET }=6 & 9 & 99\end{array}$

COND_NETWORK NET 6999
BASKET 1 - SS-BACK-PLATE

COND_NETWORK NET $=7 \quad 3 \quad 93$

BASKET 3 - FUEL PIECE SLUDGE

COND NETWORK NET $=8204294$

COND NETWORK NET=9 205295

CONDNETH NET=9 $205 \quad 295$

COND_NETWORK NET=10 $206 \quad 296$

CON_NETWONK NET=11 $207 \quad 297$

COND_NETWORK NET $=12 \quad 208298$

COND_NETWORK NET=13 $209 \quad 299$

* BASKET 3 - SS-BACK-PLATE

COND_NETWORK NET $=14 \quad 203 \quad 293$

* BASKET 5 - FUel PIECE SLUDGE

COND NETWORK NET $=15 \quad 404 \quad 494$

COND NETWORK NETT $=16 \quad 405 \quad 495$

COND-NTHORK $\mathrm{NET}=17$ 406 495

COND_NETWORK NET=17 $406 \quad 496$

COND_NETWRK NET=18 407497

COND_NETWORK NET $=19$ 408 498

COND NETWORK NET $=20 \quad 409 \quad 499$

* BASKÉT 5 - SS-BACK-PLATE

COND_NETWORK NET $=21 \quad 403 \quad 493$

END HEAT_SINKS ! HEAT_SINKS is a comment JUNCTIONS

$\begin{array}{lll}* & \text { 1) MCO fuel } 4 \text { to fuel } 3 & 5 \rightarrow>4 \\ \text { * 2) MCO fuel } 3 \text { to fuel } 2 & 4->3\end{array}$

* 3) MCO Euel 2 to fuel 1 a $3->2$

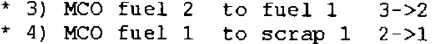

- 5) MCO top to outlet volume, $1 \rightarrow>7$ (deactivated)

* Syntax

* IJTYP Junction Type: 1 = Normal, 2 = HEPA, 3 = Cover, 4 = Failure,

5 = Check valve

* DP1 for faiure junction, it is the pressure differential required to fail from the upstream compartment to the downstream compt. 
PRC-STP-00187 REV 0

FAl/10-28

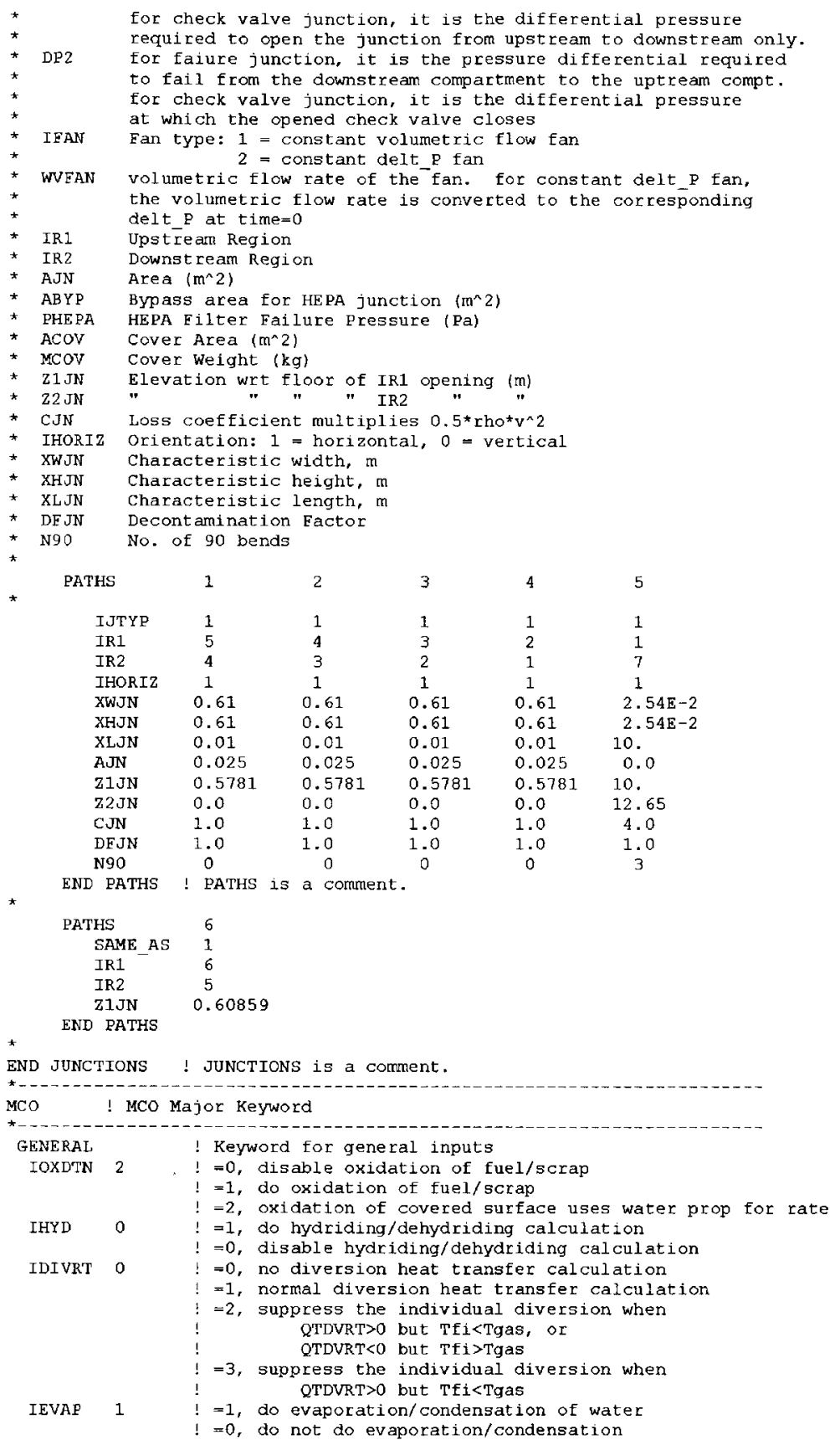




\section{PRC-STP-00187 REV 0}

FAl/10-28

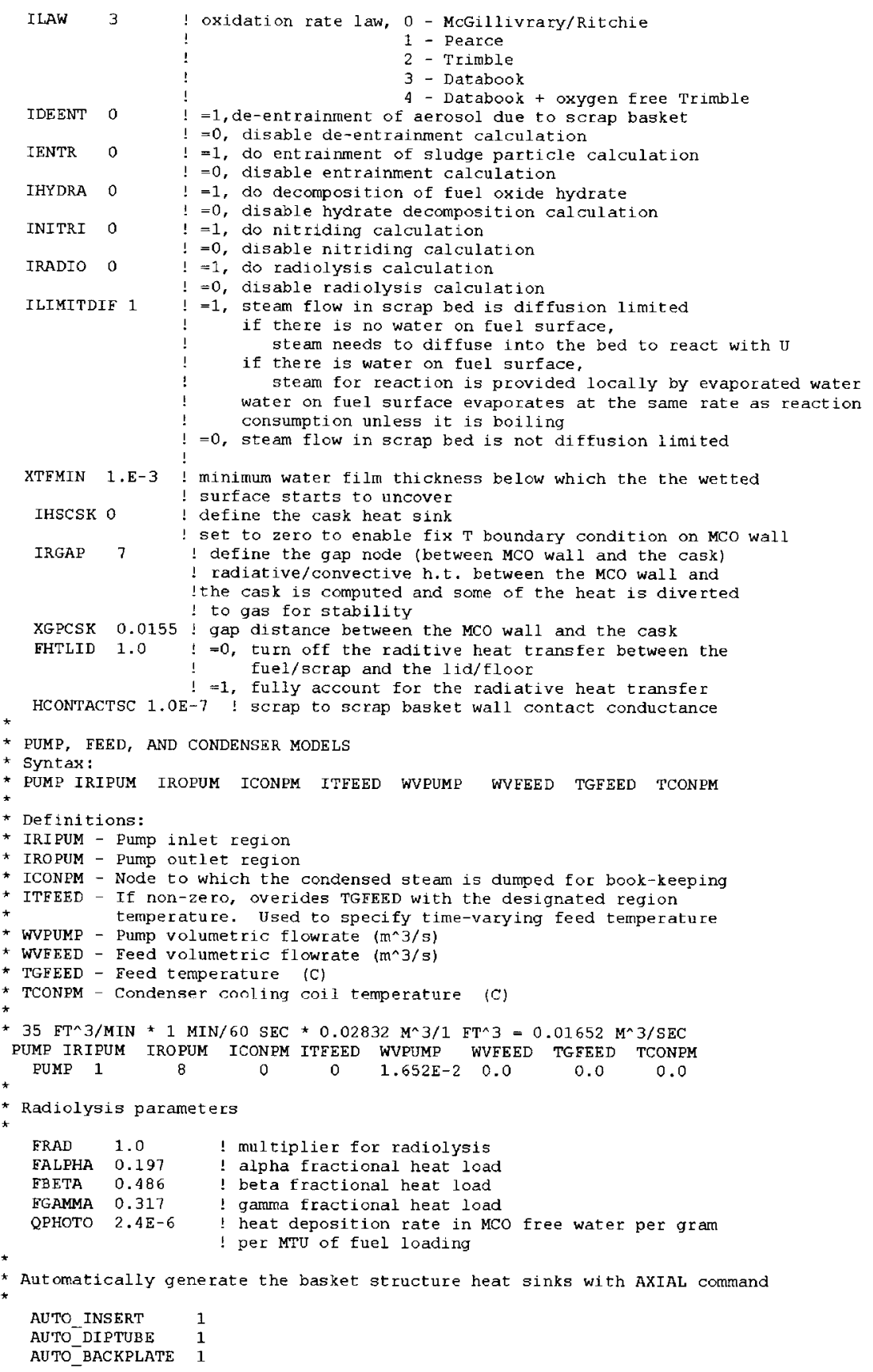




\section{PRC-STP-00187 REV 0}

FAl/10-28

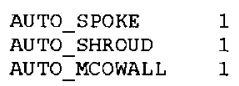

* Note: plot routine can only accept 99 items; can't plot all things. * So plot all scrap T's but only 5 fuel (plus MCO)

jlist - junction list

* hlist - heat sink list

* flist - fuel basket list

* slist - scrap basket list

CORRODH2

WH2TT

MH2T

DECSC $5 \begin{array}{llllll}5 & 1 & 2 & 3 & 4 & 5\end{array}$

QDECSC $5 \begin{array}{llllll}5 & 6 & 7 & 8 & 9 & 10\end{array}$

$\begin{array}{lllllll}Q D E C S C & 5 & 11 & 12 & 13 & 14 & 15\end{array}$

QDECTT

UDECT'T

gOXOTT

UOXOTT

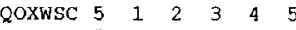

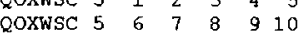

$\begin{array}{llllllll}\text { QOXWSC } & 5 & 11 & 12 & 13 & 14 & 15\end{array}$

QOXWTT

OXWT

QINTT

UINTT

QLIDT"

U LIDTT 
PRC-STP-00187 REV 0

FAl/ $10-28$

Page 64 of 99

Rev. 0

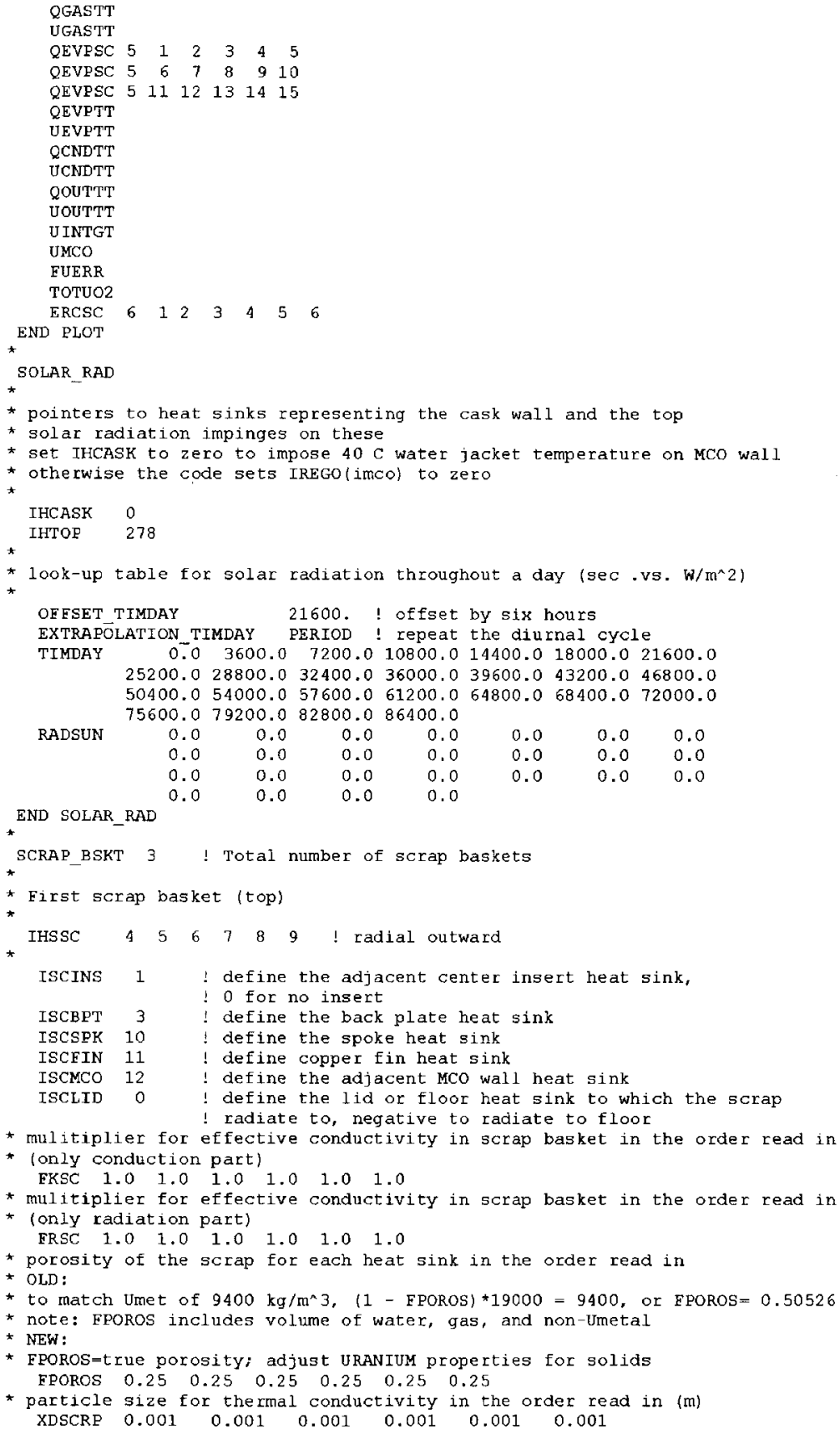

* to match Umet of $9400 \mathrm{~kg} / \mathrm{m}^{\wedge} 3,(1-$ FPOROS $) * 19000=9400$, or FPOROS $=0.50526$

* note: FPOROS includes volume of water, gas, and non-Umetal

FPOROS=true porosity; adjust URANIUM properties for solids

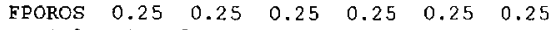

* particle size for themal conductivity in the order read in (m) $\begin{array}{lllllll}\text { XDSCRP } & 0.001 & 0.001 & 0.001 & 0.001 & 0.001 & 0.001\end{array}$ 
PRC-STP-00187 REV 0

FAl/10-28

XRSCBK 0.2842 ! radius of scrap basket (m)

XHSCBK 0.5413 ! height of scrap basket $(\mathrm{m})$

* exposed surface area available for oxidation

* per unit volume of scrap $(1 / \mathrm{m})$ for

* each scrap basket heat sink in the order read in.

* Émetal = 1 - E_void

* d_particle $=1500 . \mathrm{E}-6 ; \quad / 1 \mathrm{~m}$

* $\mathrm{fat}=0.08$

* rho w $=1000, / / \mathrm{kg} / \mathrm{m}^{\wedge} 3$

* for 258 void, Cumet $=(1-0.25) / 0.6 * 9400=11750 \mathrm{~kg} / \mathrm{mn}^{\wedge} 3$

$\star \mathrm{C}_{-} \mathrm{U}=\left(\mathrm{f}\right.$ metal $(0.6) * 9400 / / \mathrm{kg} / \mathrm{m}^{\wedge} 3$

${ }^{*} \mathrm{C}_{-} \mathrm{U}=1 \mathrm{f}$ met

* Hence, 6 curnet $/ \mathrm{D} / \mathrm{rhom}=6 * 11750 / 0.0006 / 19000=6184 / \mathrm{m}$

*AdV_ox $=6 * \mathrm{C}_{-} \mathrm{U} / \mathrm{d}$ _particle / rho_U $/ / \mathrm{m}^{\wedge}-1$

6 cumet $/ \mathrm{D} /$ rhom $=6 * 11750 / 0 . \overline{0} 006 / 19000=6184 / \mathrm{m}$

AVOXSC 6184.6184.6184.6184.6184.6184.

FOXSC $10 \quad 0 \quad$ ! multiplier for AVoxsC

* Sat * porosity * rhow $=0.12 * 0.25 * 1000=30 \mathrm{~kg} / \mathrm{m}^{\wedge} 3$

* mvw scrap $0=\mathrm{f}$ sat * $\mathrm{f}$ void * rhow $/ / \mathrm{kg} / \mathrm{m}^{\wedge} 3$

MVWSC 0 - 30.0 i initial amount $(\mathrm{kg})$ of water per unit bu $1 \mathrm{k}$ volume

Misco 30.0 ( $\left.\mathrm{m}^{\wedge} 3\right)$ of scrap

FWSCI0 0.0 ! on the outer surface of the insert

FWSCMO ! (per unit area, $m^{\wedge} 2$ )

- on the inner surface of the MCo wall

! (per unit area, $\mathrm{m}^{\wedge} 2$ )

! wetted fraction of surface area

AAWCM 1.0 ! wetted fraction of MCO wall

1.E3 disable insert to scrap micro-convection

* XSCMCO 0.00476 ! gap distance between scrap basket and MCo wall

XSCMCO 1.E3 ! disable hx between scrap basket and MCO wall

* axial conduction tracked in the scrap basket

top to bottom axial partition

$\begin{array}{lccccc}\text { AXIAL } & 0.2 & 0.2 & 0.2 & 0.2 & 0.2\end{array}$

$\begin{array}{lrrrrr}\text { AXIAL_INDEX } & 0 & 21 & 41 & 61 & 81 \\ \text { AXIAL_FUEL } & 1 & 1 & 1 & 1 & 1\end{array}$

* multipīier for fPoros (porosity of scrap) for each axial basket

FE POR $1.0 \quad 1.0 \quad 1.0 \quad 1.0 \quad 1.0$

* multiplier for Foxsc(multiplier for oxidation area) for each axial basket FFOXSC $1.0 \quad 1.0 \quad 1.0 \quad 1.0 \quad 1.0$

* multiplier for MWSCo(initial amount of water per unit volume) for each

* axial basket.

FMVWSC $1.0 \quad 1.0 \quad 1.0 \quad 1.0 \quad 1.0$

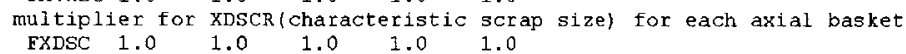

* multiplier for FKSC(multiplier for effective conductivity (conduction)

* in scrapl

FFKSC $1.0 \quad 1.0 \quad 1.0 \quad 1.0 \quad 1.0$

* multiplier for FRSC(multiplier for effective conductivity (radiation

* in scrap

FFRSC $1.0 \quad 1.0 \quad 1.0 \quad 1.01 .0$

END IHSSC for 1st scrap basket

* Third scrap basket (third from top)

SAME AS SCRAP BASKET 1

$\begin{array}{llllllll}\text { IHSSC } & 204 & 205 & 206 & 207 & 208 & 209 & \text { ! radial outward }\end{array}$

define the adjacent center insert heat sink,

$!$ o for no insert

ISCSPK 210 ! define the spoke heat sink

ISCEIN 211 ! define copper fin heat sink

ISCMCO 212 ! define the adjacent MCO wall heat sink 
$\mathrm{FAl} / 10-28$

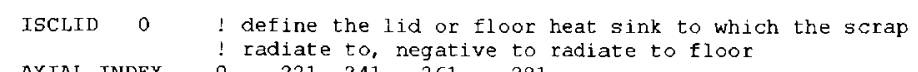

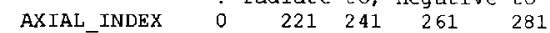
END IHS̄SC for 3 rd scrap basket

* Fifth scrap basket (fifth from top, second to bottom)

* SAME as scrap basket 1

* IHSSC $404 \quad 405406 \quad 407408 \quad 409 \quad$ ! radial outward

ISCINS 401 ! define the adjacent center insert heat sink,

! o for no insert

! define the back plate heat sink

ISCSPK 410 ! define the spoke heat sink

$\begin{array}{ll}\text { ISCFIN } 411 & \text { ! define copper fin heat sink } \\ \text { ISCMCO } 412 & \text { ! define the adjacent MCO wall heat sink }\end{array}$

ISCLID 0 ! define the lid or floor heat sink to which the scrap

AXIAL INDEX

$\begin{array}{lllll}10 & 421 & 441 & 461 & 481\end{array}$

END SCRA

END MCO 
FAl/10-28

\section{A.2 Case 2: KOP_VACXDG_19.DAT KOP with Degraded Vacuum Pumping and} No Helium Purge

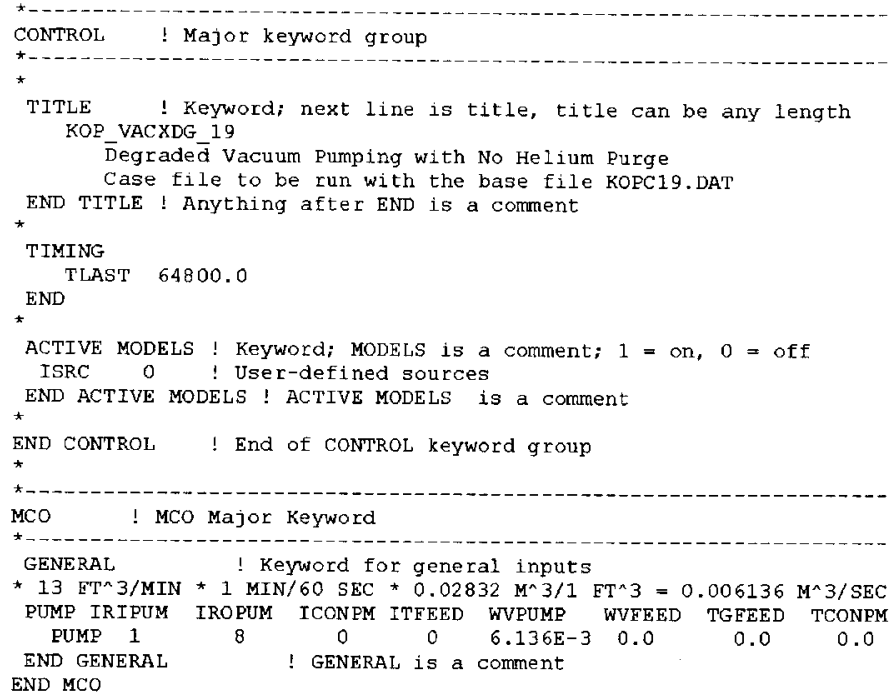


PRC-STP-00187 REV 0

FAl/10-28

Page 68 of 99

Rev. 0

January, 2010

\section{A.3 Case 3: KOP_OVLOCXSP_19.DAT Open MCO with Loss of Annulus Water}

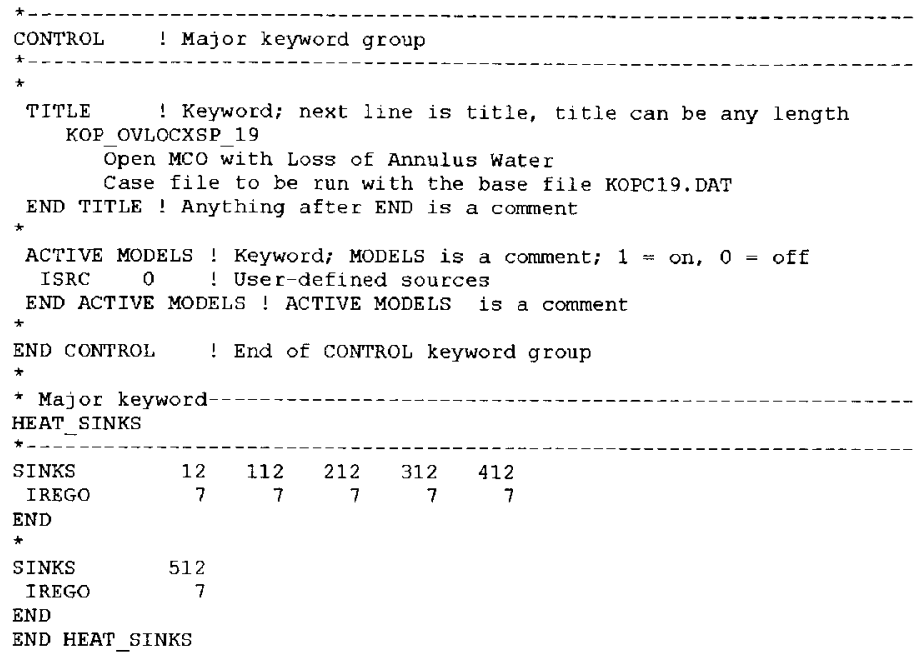




\section{A.4 Case 4: KOP_COOLSPRS_19.DAT Cooling of MCO and KOP Sludge After Vacuum Drying}

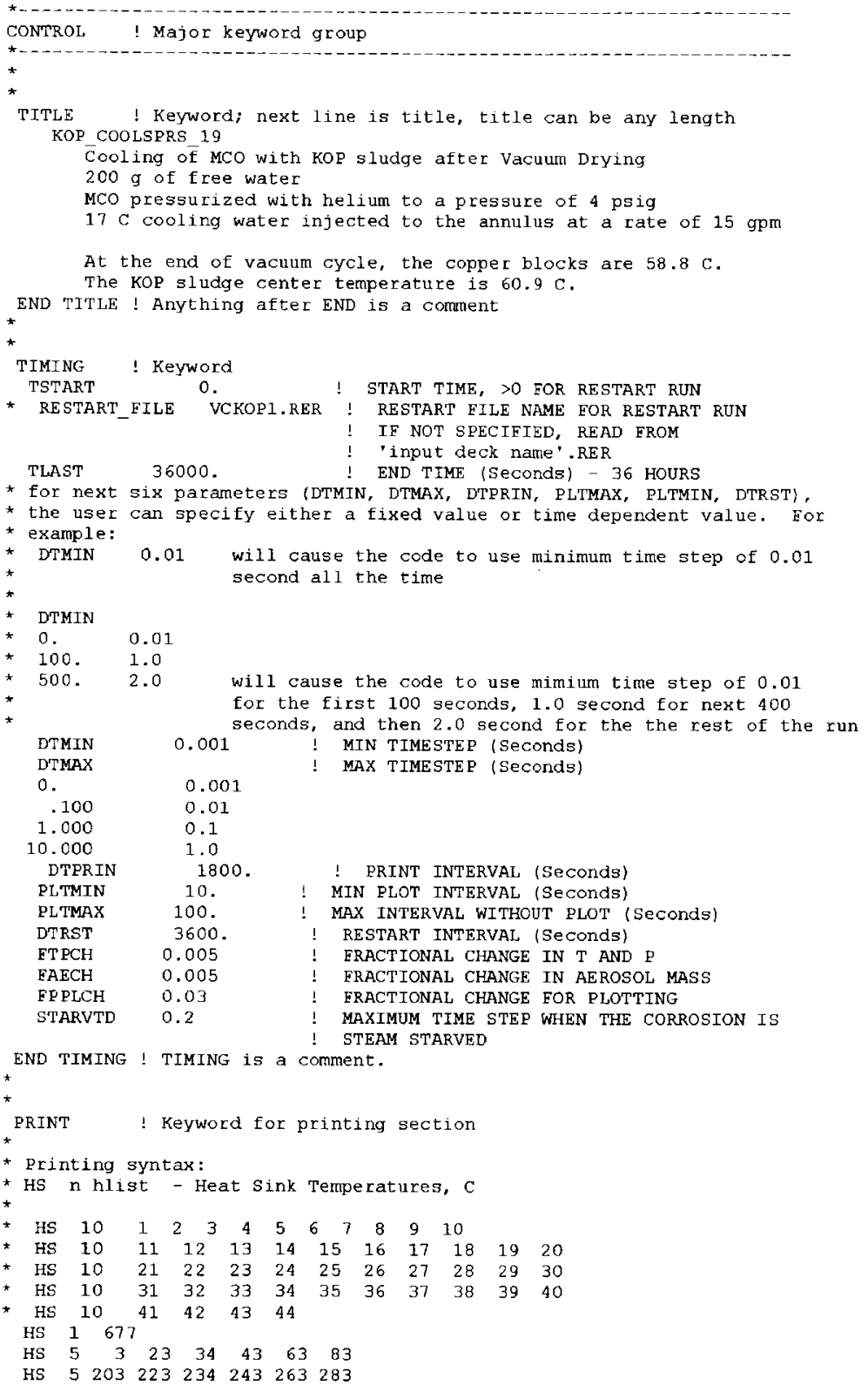


HS $\quad \begin{array}{lllllll}5 & 403 & 423 & 434 & 443 & 463 & 483\end{array}$

END PRINT ! PRINT is a comment.

PLOT 1 ! Keyword for plotting section

* Plotting syntax:

* Pressure n tlist - Pressure, Pa

* GAS-T n rlist - Gas Temperature, K

* HS-TI $n$ hlist - Heat Sink Temperature - Inner Surface, K

* HS-TO n hlist - Heat Sink Temperature - Outer Surface, K

* HS-TA n hlist - Heat Sink Temperature - Average, $K$

* AERosol n rlist - Aerosol Mass (Total), kg

* GAS-w n jlist - Mass Flowrate, $\mathrm{kg} / \mathrm{s}$

* GAS-WX n jlist - CounterCurrent Mass Flowrate, kg/s

* GAS-X GasNAME $\mathrm{n}$ rlist - Gas Mole fraction

* GAS-RH GASNAME n rlist - Gas Relative Humidity

* GAS-MASS GASNAME n rlist - Gas Mass (Species), kg

* GAS-MASS GASNAME n rlist - Gas Mass (Species), kg

* MAss GASNAME $n$ rlist - Total Mass (Species), k

* LIQ-MASS - GASNAME $n$ rlist - Deposited Mass (Species), kq

* Pressure, Gas Temperature, and total aerosol mass require a region * list

* Heat Sink Temperatures need a heat sink number list

* Flowrates need a junction number list

* Gas concentration, relative humidity, individual species gas mass,

* individual species aerosol mass, total (gastaerosol) individual

* species mass, and individual species deposited liquid mass require

* a region and gas name

* Note: plot routine can only accept 99 items; can't plot all things.

* So plot all scrap T's bit only 5 fuel (plus MCO)

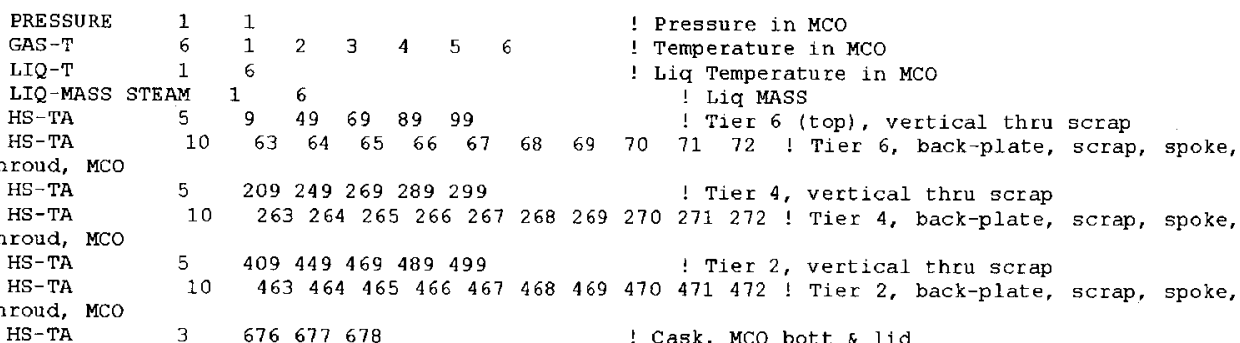

END PLOT

! Cask, MCO bott \& lid

PLOT 2

$\begin{array}{llllllllllll}\text { GAS -X NITROGEN } & 6 & 1 & 2 & 3 & 4 & 5 & 6 & \text { ! } & \text { N2 } & 8\end{array}$

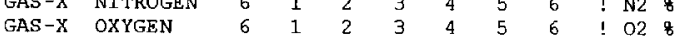

$\begin{array}{llllllllll}\text { GAS - X } & \text { STEAM } & 6 & 1 & 2 & 3 & 4 & 5 & 6 & 1 \mathrm{H} 2 \mathrm{O}\end{array}$

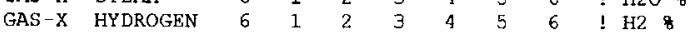

GAS-X HELIUM $\quad 6 \quad 1 \quad \begin{array}{llllllll}2 & 3 & 4 & 5 & 6 & \text { ! He } & 8\end{array}$

GAS-W

GAS-WV

GAS -WX

GAS-MASS HYDROGEN 118

Junc. flow

! Junc, ce flow

! H2 release

END PLOT

! $\mathrm{H} 2 \mathrm{O}$ release

PLOT 3

QGAS-HSO $5 \quad 23,43,3,63,83$

QGAS-HSO $5 \quad 223,243,203,263,283$

QGAS-HSO $5423,443,403,463,483$

$\begin{array}{lllllll}\text { QGAS-HSI } & 5 & 12 & 32 & 52 & 72 & 92\end{array}$

QGAS-HSI $\begin{array}{llllll}5 & 212 & 232 & 252 & 272 & 292\end{array}$ 
FAl/10-28

Rev. 0

QGAS-HSI $5 \quad 412 \quad 432 \quad 452 \quad 472 \quad 492$

QRAD -HSO $5 \quad 23,43,3,63,83$

QRAD-HSO $5 \quad 223,243,203,263,283$

QRAD-HSO $5 \quad 423,443,403,463,483$

QRAD-HSI $5 \quad \begin{array}{lllll}12 & 32 & 52 & 72 & 92\end{array}$

ORAD-HST $\begin{array}{llllll}5 & 212 & 232 & 252 & 272 & 292\end{array}$

QRAD-HST $5 \quad 412 \quad 432 \quad 452272 \quad 292$

END PLOT ! PLOT is a coment

* PLOT 4

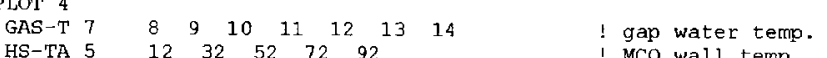

$\begin{array}{lllllllll}\text { HS-TA } & 5 & 12 & 32 & 52 & 72 & 92 & \text { ! MCO wall temp., tier } 6\end{array}$

! MCO wall temp., tier 5

HS-TA $5 \quad 212232252272292$ ! MCO wall temp. tier 4

HS-TA $5 \quad 412 \quad 432452472492 \quad$ ! MCO wall temp., tier 2

END PLOT ! PLOT is a comment

! MCO wall temp., tier

ACTIVE MODELS ! Keyword; MODELS is a comment; $1=$ on, $0=$ off

IJUNC 1 ! Junction flow model

ICCFLW 1. Counter-current flow model

IHSINK 1 ! Heat sinks

ICNDS 0 ! Condensation

IHXPOL 1 ! Heat and Mass transfer on liquid pool

IASED 0 ! Aerosol Sedimentation

IALEAK 0 ! Aerosol Leakage

IFOG 0 ! FOg formation

$\begin{array}{lll}\text { IFOG } & 0 & \text { IFOg formation } \\ \text { ISRC } & 1 & \text { ! User-defined sources }\end{array}$

ISRC 1 : User-defined

ISENS 0 ! Sensitivity runs

IPLTYP 2 ! 1=wrap around, 2=no wrap (spreadsheet format)

END ACTIVE MODELS ! ACTIVE MODELS is a comment

MODE L

! keyword for model parameters

* multipliers for region gas conductivities

* syntax:

FKGAS fkgas1 fkgas2 fkgas 3 ...

FLOWKBD 0.006

$\begin{array}{ll}\text { FLOWKBED } & 0.006 \\ \text { FLANGM } & 0.1\end{array}$

FLANGr D 0.1 or

* multiplier to heat sink to liquid pool hx coefficient
FHHSL 10.0

END MODEL

C SOURCE GROUP: GROUPS REPEATED FOR INPUT \# OF REGIONS

C END OF GROUP DESIGNATED BY 'REGION' OR 'END' KEYWORDS

C ENTER: TIME, TEMP, FLOWRATES, POWER

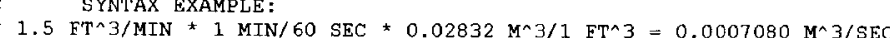

* He density a stp is $0.16 \mathrm{~kg} / \mathrm{m}^{\wedge} 3$, hence $1.13 \mathrm{e}-4 \mathrm{~kg} / \mathrm{s}$

SOURCES 1

!-- KEYWORD AND \# SOURCE GROUPS

* $17 \mathrm{C}$ cooling water injected to the annulus at a rate of $15 \mathrm{gpm}$

REGION 9 GASES 1 WATER

1-- REGION \#, \# GASES

$\begin{array}{llll}0 & 17.0 & 0.95 & 0 . E O\end{array}$

!- GAS NAMES MUST BE ON NEXT LINE

1.E6 $17.0 \quad 0.95 \quad 0 . \mathrm{E} 0$

END REGION

1-- ENDS A REGION SOURCE

END SOURCE

-- ENDS ALL SOURCE INPUT

END CONTROL ! End of CONTROL keyword group

EVENTS

SET 1 WHEN PR $(1)<1000$

CONTROL

ACTIVE MODELS

IHXPOL $O$

END ACTIVE

! Turn off Pool Evaporation 
FAl/10-28

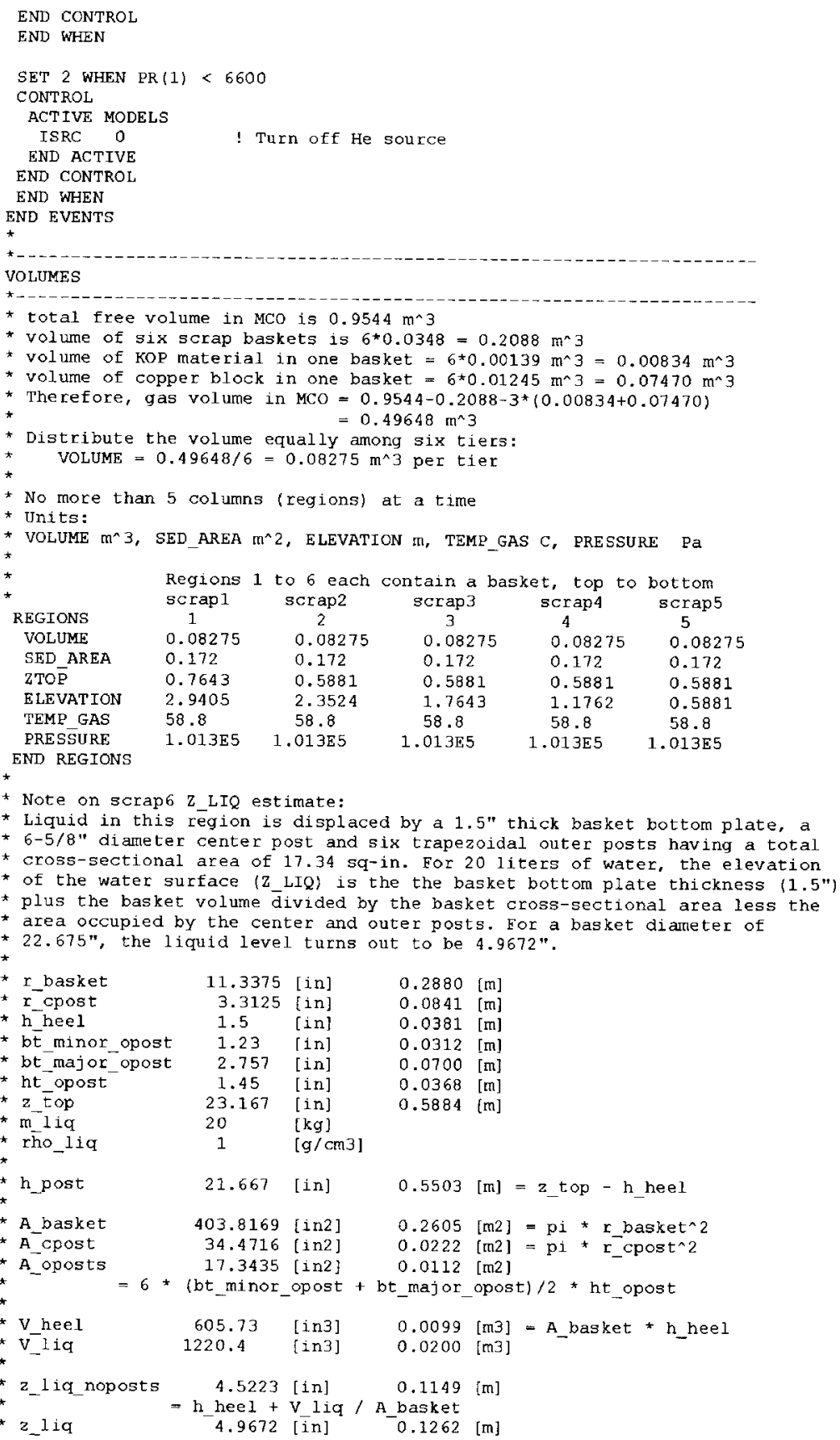




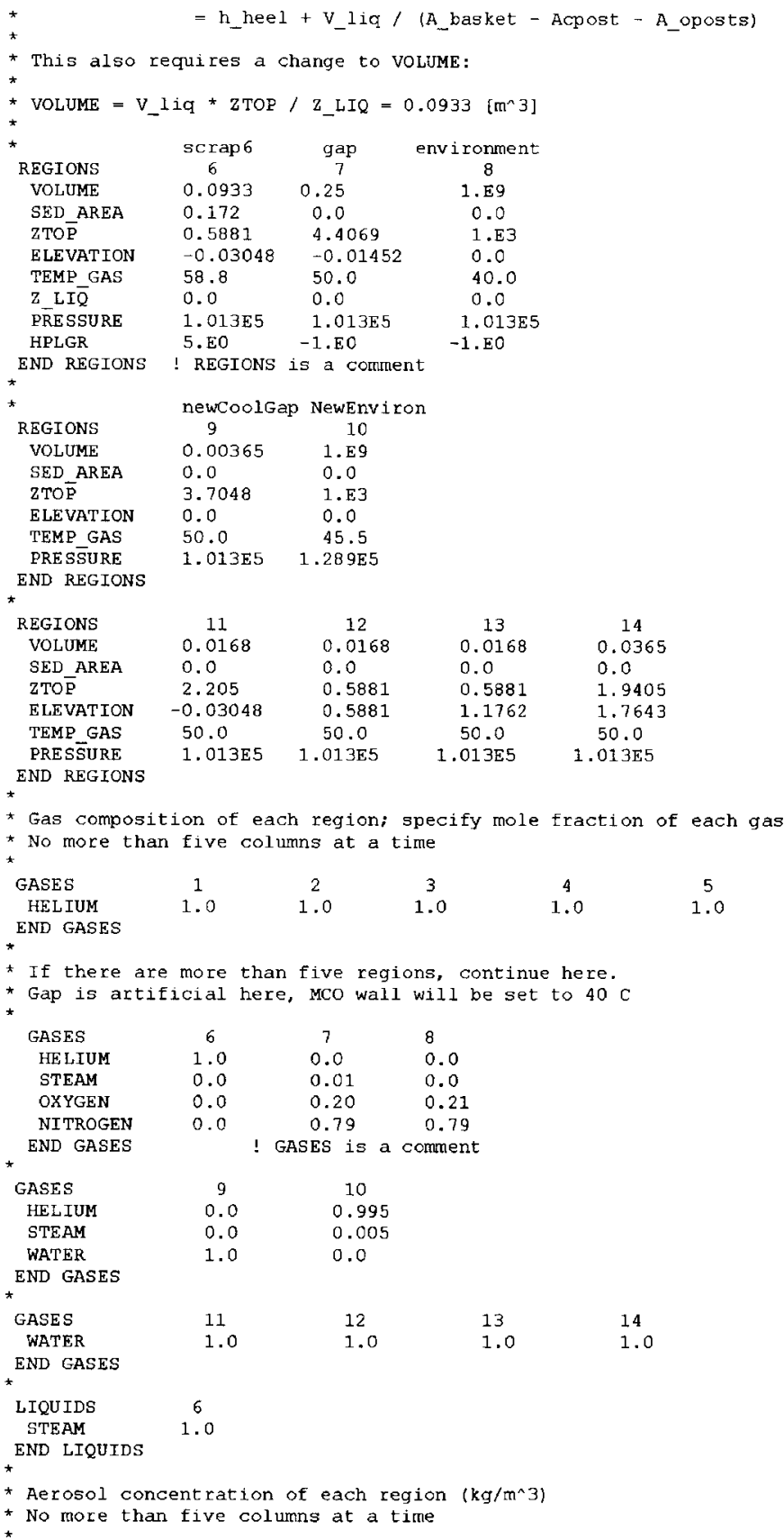


PRC-STP-00187 REV 0

FAl/10-28

Rev. 0

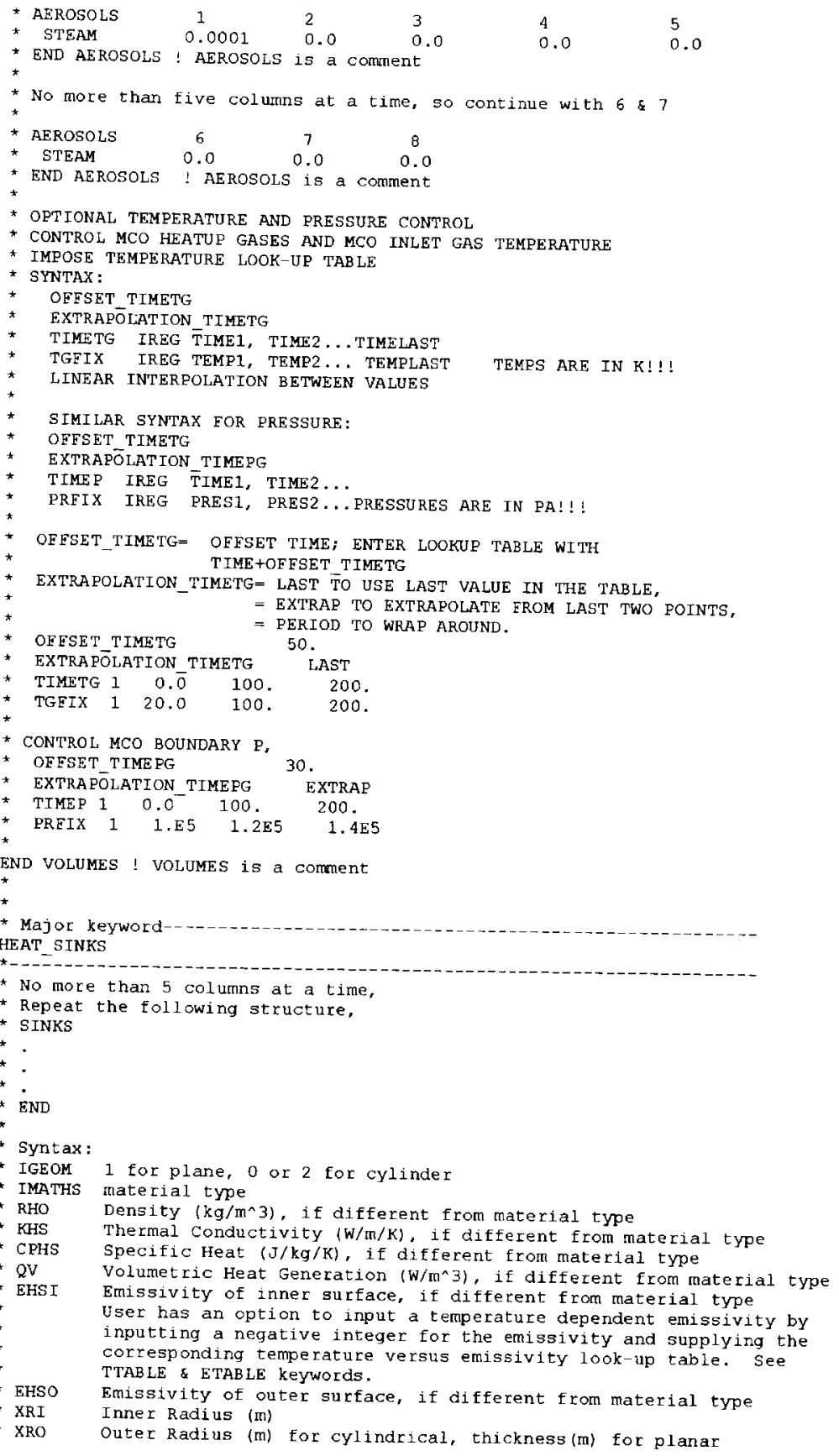




\section{PRC-STP-00187 REV 0}

FAl/10-28

Page 75 of 99

Rev. 0

* AHS One-sided average heat sink area $\left(\mathrm{m}^{\wedge} 2\right)$

* xzHS Axial length for conduction ( $\mathrm{m}$ )

* TIINIT Initial inside surface temperature (C)

* TOINIT Initial outside surface temperature (C)

* IMSLAB Number of slabs, 3 is minimum. Use 1 for lumped heat sink

* IREgI Region index for inner surface or 0 (insulated)

* or -1 for constant temperature

* TIHS Region surface temperature when IREGI $=-1 \quad$ (C)

* IREgO Region index for outer surface or 0 (insulated)

* or -1 for constant temperature

Region surface temperature when IREGO $=-1 \quad$ (C)

* XLHS Characteristic length for natural convection (m)

* Scrap basket \#1-Tier 6, top tier

$* \star *+*$

* scrap basket \#1- sludge

* Preserve half the thickenss of the sludge, 1 inch.

* That is, XRO of HS-9 - XRI of HS-4 $=0.2842-0.2715=0.0127 \mathrm{~m}$

* Determine AHS to preserve the volume of sludge.

* That is, AHS $\star 0.0127=6 \star 0.00139$ or AHS $=0.6567$

SINKS

4

IGEOM

IORIHS

IMATHS

IREGI

IREGO

XRI

XRO

AHS
XZHS

$X Z H S$
TIINIT

TOINIT

IMSLAB

$X$ LHS

ZTHS

ZBHS

END

*

SINKS

SAME_AS

$X R I$

$\begin{array}{ll}X R I & 0.2736 \\ X R O & 0.2757\end{array}$

AHS $\quad 0.5567$

3.4485

ZBHS $\quad 2.9405$

(1)

\begin{abstract}
6
\end{abstract}
4
0.275

0.2779

0.6567

0.6567
3.4485

3.4485

2.9405

scrap basket \#1-bottom plate

SINKS 93

SAME_AS

IMATḦS

IREG

$\mathrm{XRI}$

XRO

AHS

XZHS

XLHS

2THS

2BHS
93

4
2
0

0

0.1647

0.2715

0.04373

0.03175

0.03175

2.9405

2. 9100
94

4

2
0
0

0.2715

0.2736

0.04373

0.03175

0.03175

2.9405

2.9100

$\begin{array}{ccc}7 & 8 & 9 \\ 4 & & \\ 0.2779 & 0.2800 & 0.2821 \\ 0.2800 & 0.2821 & 0.2842 \\ 0.6567 & 0.6567 & 0.6567 \\ 3.4485 & 3.4485 & 3.4485 \\ 2.9405 & 2.9405 & 2.9405\end{array}$

$1.25 "(0.03175 \mathrm{~m})$ thick 
FAl/10-28

Page 76 of 99

Rev. 0

January, 2010

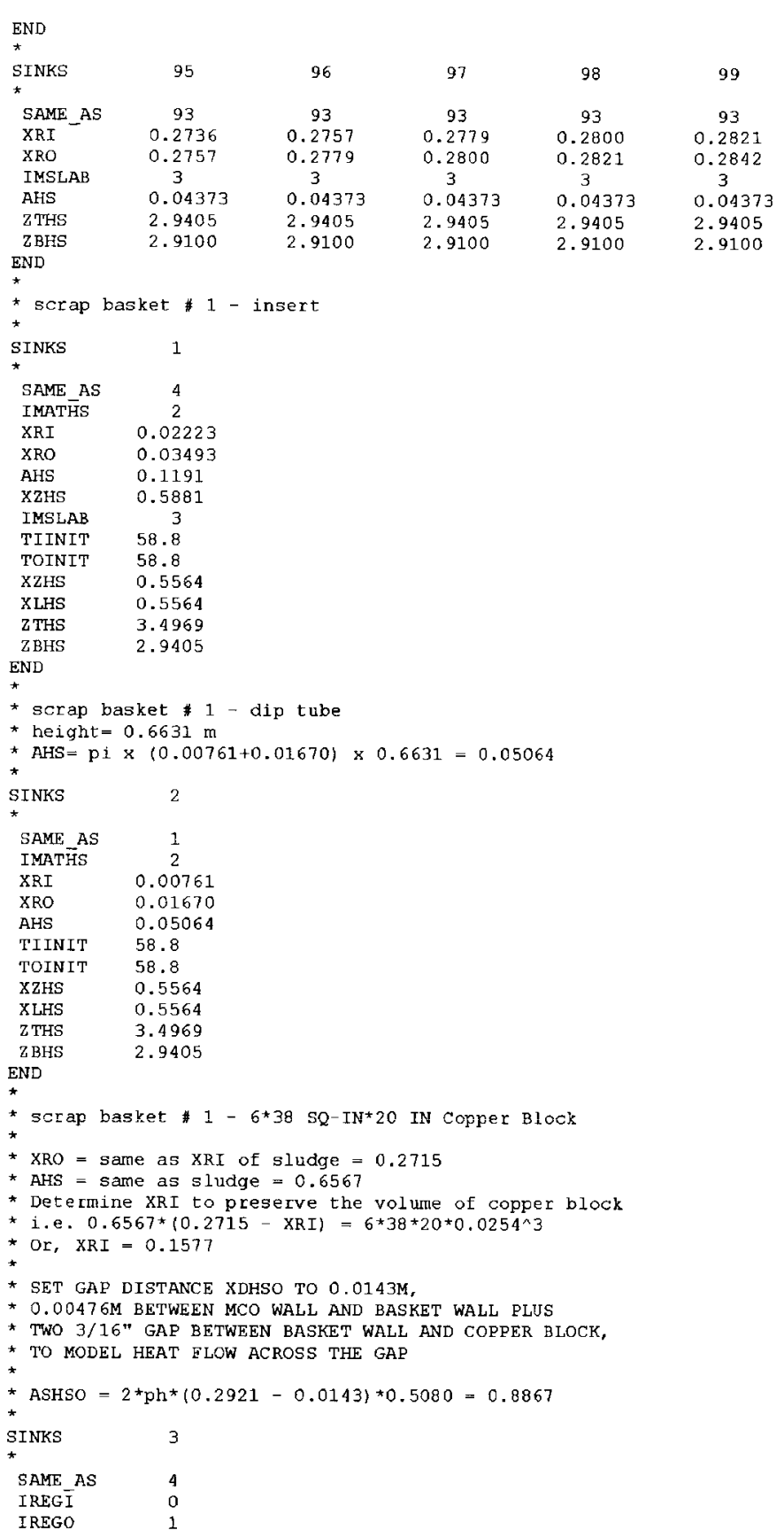




\section{PRC-STP-00187 REV 0}

FAl/10-28

Page 77 of 99

Rev. 0

\begin{tabular}{ll} 
IMATHS & \multicolumn{1}{c}{3} \\
XRI & 0.1577 \\
XRO & 0.2715 \\
AHS & 0.6567 \\
ASHSO & 0.8867 \\
XZHS & 0.508 \\
IMSLAB & \multicolumn{1}{c}{5} \\
TIINIT & 58.8 \\
TOINIT & 58.8 \\
XLHS & 0.508 \\
XDHSO & 0.0143 \\
ZTHS & 3.4485 \\
ZBHS & 2.9405 \\
END &
\end{tabular}

END

* scrap basket \# 1 - copper spoke

* width $=6 * 2 * 1 / 8 "=0.0381 \mathrm{~m}$

AHS $=0.5423 \times 0.0381=0.02066$

$*$ AHSS $1=(0.2842-0.2365) * 0.5423=0.02589$

SINKS $\quad 10$

SAME_AS

IGEOM

IREGO

IMATHS

$\begin{array}{ll}\text { XRI } & 0.0 \\ \text { XRO } & 0.169\end{array}$

AHS $\quad 0.02066$

$\begin{array}{ll}\text { IREGS1 } & 1 \\ \text { AHSS } 1 & 0.0258\end{array}$

IMSLAB 20

TIINIT $\quad 58.8$

TOINIT $\quad 58.8$

$X$ LHS $\quad 0.541$

X2FS -0.541

$\begin{array}{ll}\text { ZTHS } & 3.4815 \\ \text { ZBHS } & 2.9405\end{array}$

END

* scrap basket \#1 - basket shroud

* Make EHSO very small to stop radiation to MCO wall

* Copper block to MCO wall ht across the gap

* is modeled separately

SINKS

11

SAME

I REG $\bar{I}$

IREGO

IMATHS

THSO

XRI

AHS

IMSLAB

TIINI

TOIN I'

XZHS

0.541

3.4815

END

* scrap basket \#1-MCO wall

SET GaP Distance XDHSI TO $0.0143 \mathrm{M}$,

* $0.00476 \mathrm{M}$ BETWEEN MCO WALL AND BASKET WALL PLUS

* TWO 3/16" GAP BETWEEN BASKET WALL AND COPPER BLOCK,

* TO MODEL HEAT FLOW ACROSS THE GAP 
FAl/10-28

Rev. 0

$\begin{array}{lc}\text { SINKS } & 12 \\ \text { * SAME_AS } & 11 \\ \text { IREGI } & 1 \\ \text { IREGO } & 14 \\ \text { IMATHS } & 2 \\ \text { TIINIT } & 50.0 \\ \text { TOINIT } & 50.0 \\ \text { XRI } & 0.2921 \\ \text { XRO } & 0.3048 \\ \text { AHS } & 1.1026 \\ \text { XLHS } & 0.5881 \\ \text { XDHS I } & 0.0143 \\ \text { XZHS } & 0.5881 \\ \text { ZTHS } & 3.4981 \\ \text { ZBHS } & 2.9405 \\ \text { END } & \end{array}$

END
Page 78 of 99

January, 2010

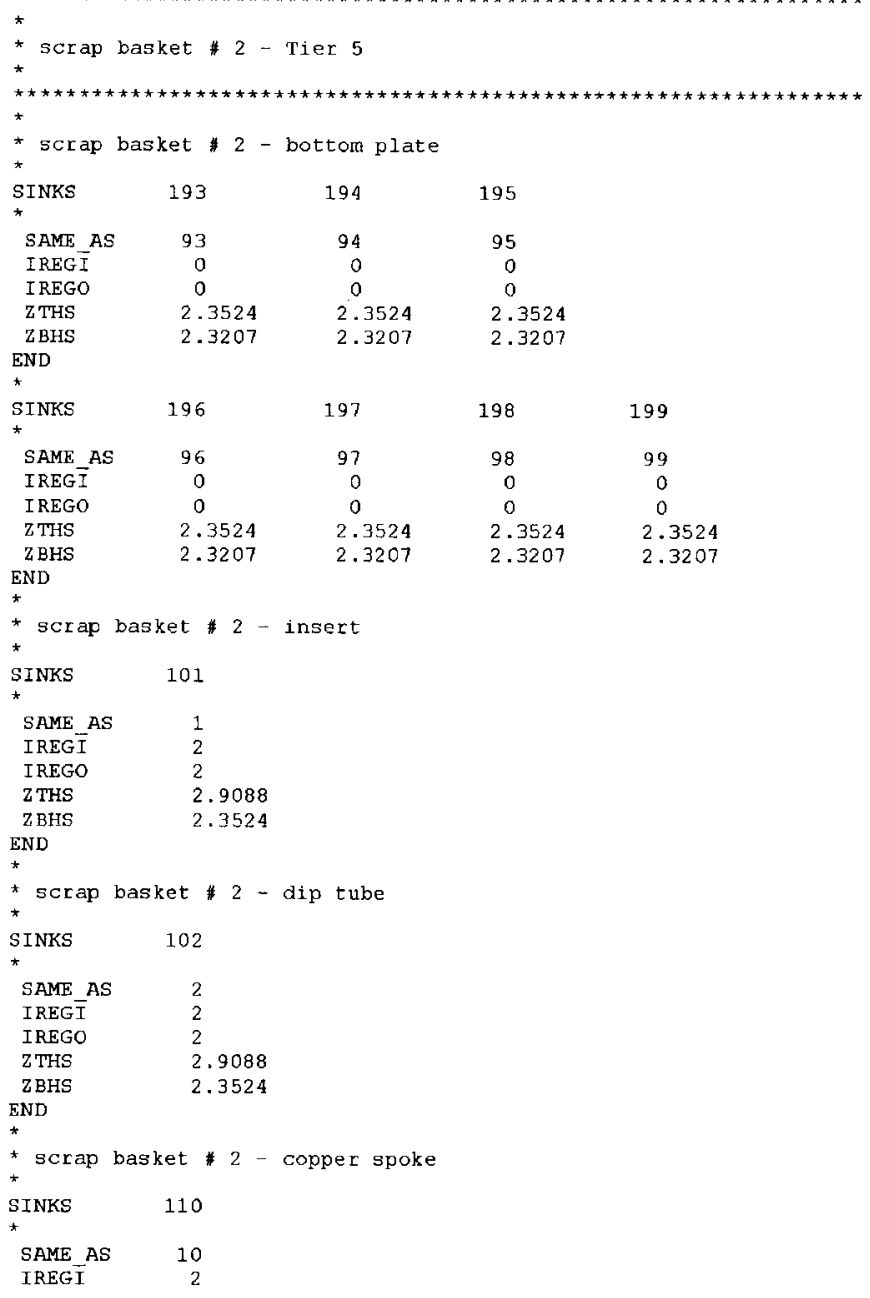




\section{PRC-STP-00187 REV 0}

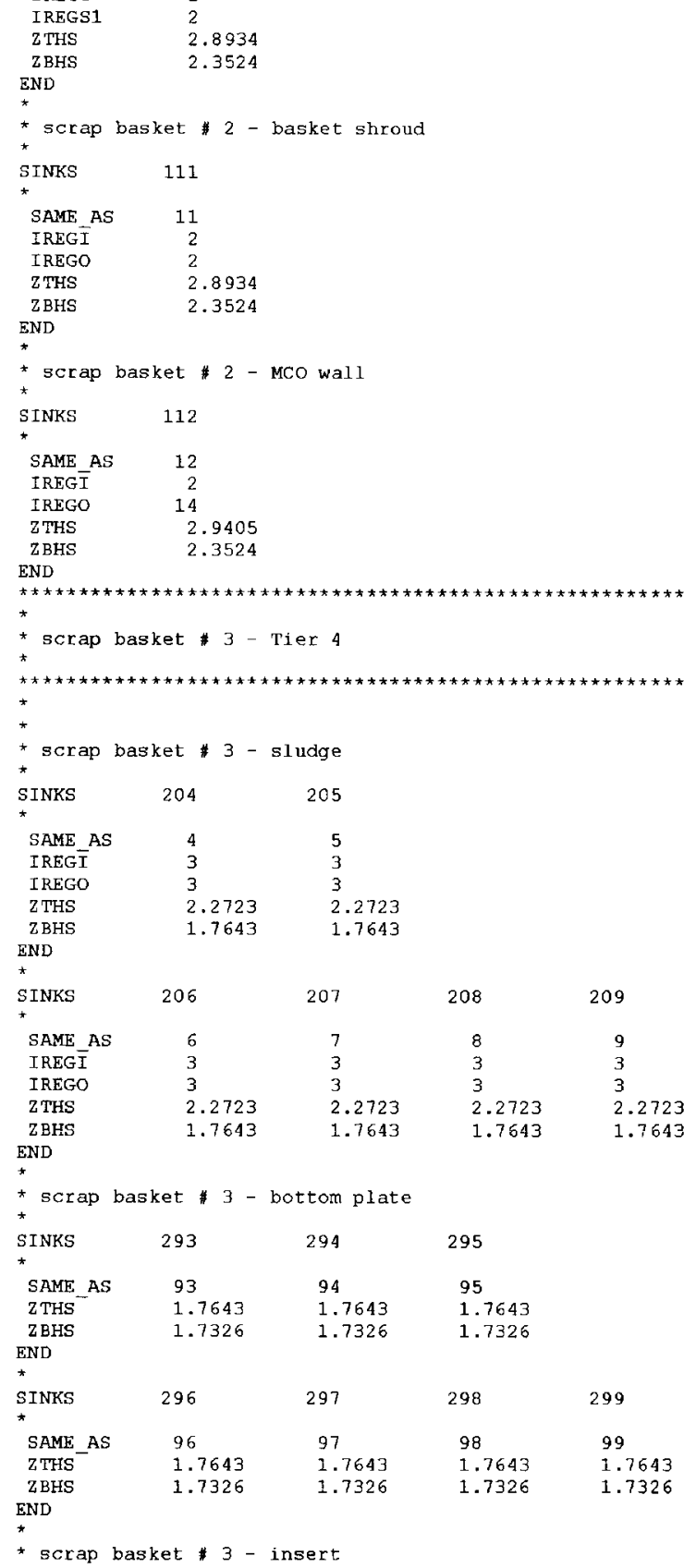


FAl/10-28

Page 80 of 99

Rev. 0

January, 2010

SINKS

201

IREG $\bar{I}$

IREGO

ZTHS

ZBHS

END

* scrap basket \#3- dip tube

SINKS 202

SAME, AS

IREG $\vec{I}$

IREGO

3

$\mathrm{ZTHS}$

2.3207

$\mathrm{ZBHS} \quad 1.7643$

END

* scrap basket \#3 - copper back plate (block)

SINKS 203

SAME AS

IREGO

THS 2.2723

ZBHS 1.7643

END

* scrap basket \# 3 - copper spoke

SINKS

210

SINKS

SAME AS

IREGI

IREGO

IREGSI

$\mathrm{ZTHS}$

END

1.7643

END

* scrap basket *3 - basket shroud

SINKS 211

$S A M E$ AS

IREG $\vec{I}$

IREGO

ZBHS

END

1.7643

* scrap basket *3- MCo wall

* scrap basket

SINKS

212

SAME_AS 12

$\begin{array}{lr}\text { IREG } \bar{I} & 3 \\ \text { IREGO } & 14\end{array}$

ZTHS 2.3524

ZBHS $\quad 1.7643$

END

scrap basket \#4-Tier 3 


\section{PRC-STP-00187 REV 0}

FAl/10-28

Page 81 of 99

Rev. 0

* scrap basket \#4-bottom plate

SINKS

SAME AS 93

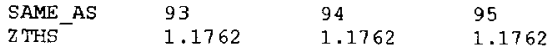

$\begin{array}{llll}\mathrm{ZBHS} & 1.1457 & 1.1457 & 1.1457\end{array}$

END

SINKS $396 \quad 397$

SAME_AS $96 \quad 97 \quad 98$

$\begin{array}{lllll}\text { SAME_AS } & 96 & 97 & 98 & 99 \\ \text { ZTHS }^{\text {TTHS }} & 1.1762 & 1.1762 & 1.1762 & 1.1762 \\ \text { ZBHS } & 1.1457 & 1.1457 & 1.1457 & 1.1457\end{array}$

तND

$1.1457-1.1457$

1.2457

1. 1457

* scrap basket \#4-insert

SINKS 301

SAME AS

IREG

IREG

ZTHS

4

END

1.8393
1.1457

* scrap basket \#4-dip tube

SINKS

302

* SAME AS

2

IREG

IREG

$Z$ THS $\quad 1.8393$

ZBHS

1.8393
1.1457

END

1.1457

* scrap basket \#4 - copper spoke

SINKS $\quad 310$

10

SAME AS

IREG $\bar{I}$

IREGO

IREGS1

ZTHS

4
4

z BHS

ND

1.1762

* scrap basket \#4-basket shroud

SINKS 311

SINKS

SAME_AS

IREG $\bar{I}$

11

ZBHS 1.1762

END

* scrap basket *4-MCo wall

* scrap basket

SINKS

312

SAME_AS 12

IREG $\bar{I}$

ZTHS 13

ZBHS $\quad 1.1762$

END 


\section{PRC-STP-00187 REV 0}

FAl/10-28

Page 82 of 99

Rev. 0

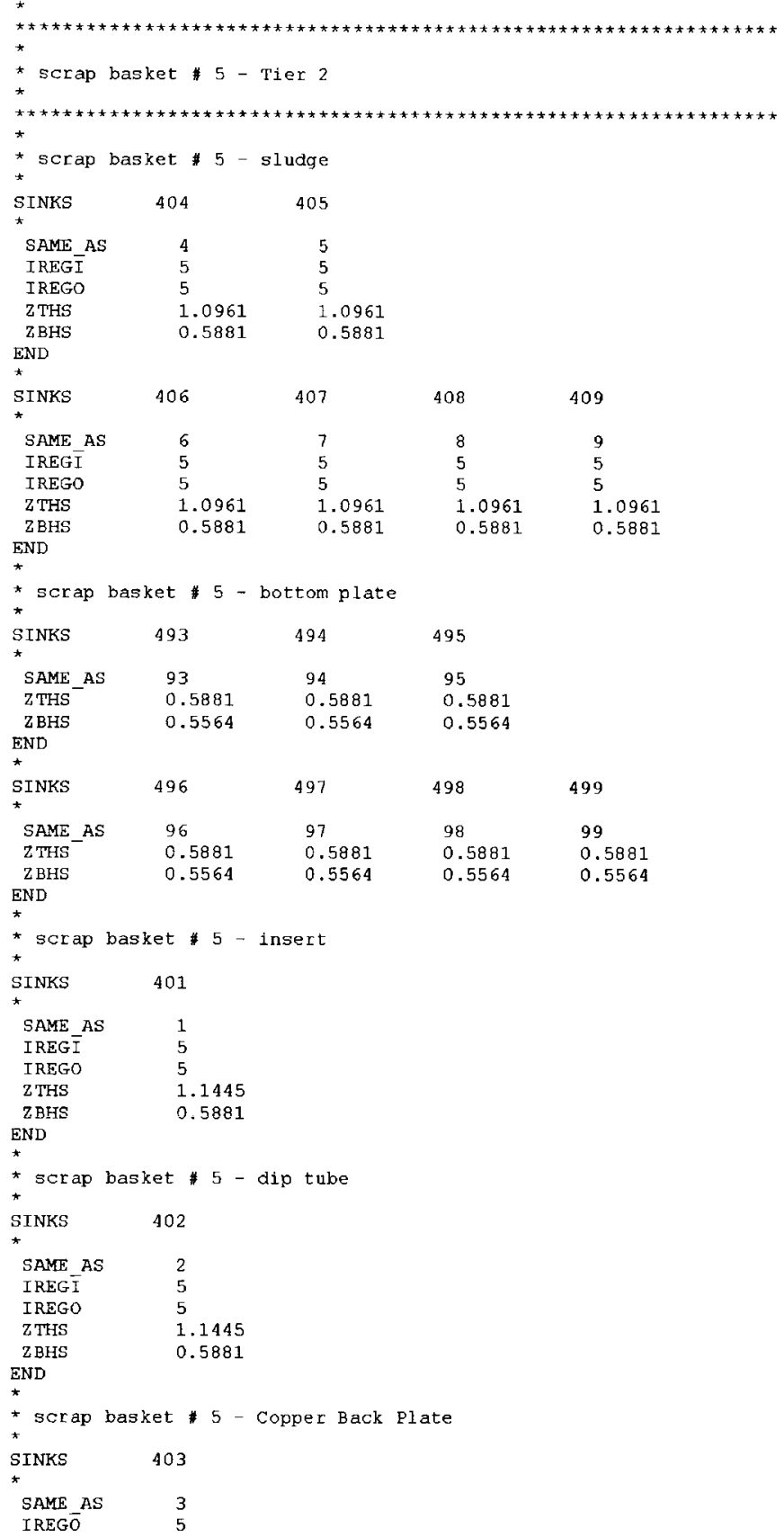


FAl/10-28

Page 83 of 99

Rev. 0

$\begin{array}{ll}\text { ZTHS } & 1.0961 \\ \text { Z BHS } & 0.5881 \\ \text { END } & \end{array}$

END

* scrap basket *5 - copper spoke

SInKS 410

$*$

SAME_AS 10

IREG $\overrightarrow{\mathrm{I}}$

I REGO

I REGS1

IREG

Z BHS

10
5
5
5

1.1291

END

* scrap basket \#5- basket shroud

SINKS

411

11
5

IREG $\bar{I}$

$\begin{array}{lc}\text { IREGO } & 5 \\ \text { ZTHS } & 1.1291\end{array}$

$\begin{array}{ll}\text { ZTHS } & 1.1291 \\ \text { ZBHS } & 0.5881\end{array}$

$2 \mathrm{BH}$

0.5881

* scrap basket \#5 - MCo wall

SINKS $\quad 412$

* SAME AS 12

IREG $\bar{I} \quad 5$

IREGO 12

$\begin{array}{ll}\text { ZTHS } & 12 \\ \text { ZBHS } & 1.1762\end{array}$

$\begin{array}{ll}\text { ZTHS } & 1.1762 \\ \mathrm{ZBHS} & 0.5881\end{array}$

END

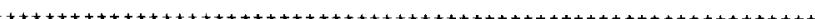

* scrap basket \#6-Tier 1 , bottom tier

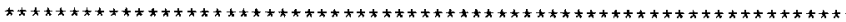

* scrap basket 6 - bottom plate

*

$\begin{array}{llll}\text { SAME_AS } & 0^{93} & 0^{94} & 0^{95}\end{array}$

$\begin{array}{lrrr}\text { ZBHS } & -0.03048 & -0.03048 & -0.03048\end{array}$

END

$\begin{array}{lllll}* & 596 & 597 & 598 & 599\end{array}$

*

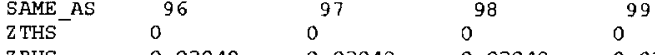

$\begin{array}{lllll}\text { ZBHS } & -0.03048 & -0.03048 & -0.03048 & -0.03048\end{array}$

END

scrap basket \#6 - insert

SINKS $\quad 501$

SAME AS

IREGI

IREGO

ZTHS

ZBHS
END

6

6
0.5564 
FAl/10-28

Page 84 of 99

Rev. 0

January, 2010

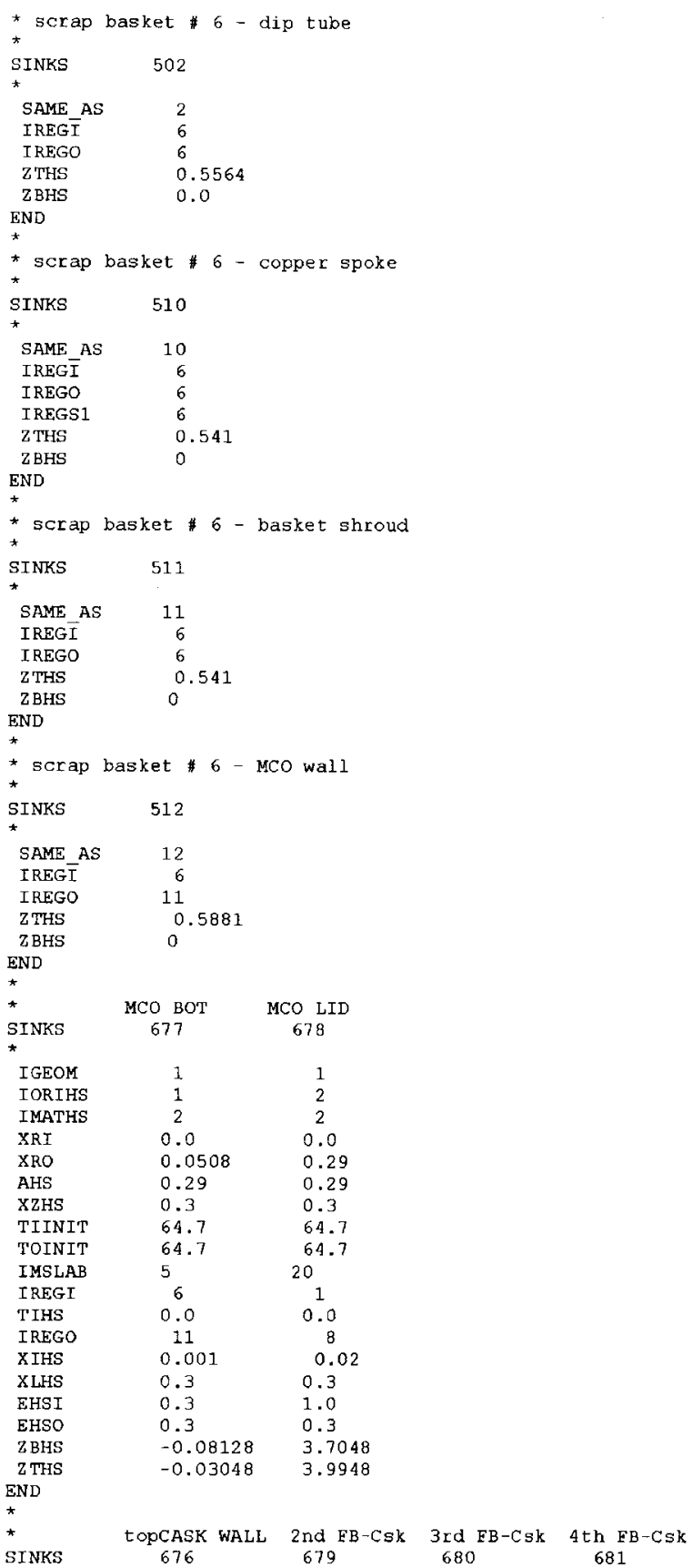




$\begin{array}{lllll}\text { IGEOM } & 0 & 0 & 0 & 0 \\ \text { IORIHS } & 0 & 0 & 0 & 0 \\ \text { IMATHS } & 2 & 2 & 2 & 2 \\ \text { XRI } & 0.3199 & 0.3199 & 0.3199 & 0.3199 \\ \text { XRO } & 0.5056 & 0.5056 & 0.5056 & 0.5056 \\ \text { AHS } & 4.36 & 1.944 & 1.944 & 1.944 \\ \text { XZHS } & 1.88522 & 0.84057 & 0.84057 & 0.84057 \\ \text { TIINIT } & 67.7 & 67.7 & 67.7 & 67.7 \\ \text { TOINIT } & 67.7 & 67.7 & 67.7 & 67.7 \\ \text { IMSLAB } & 10 & 10 & 10 & 10 \\ \text { IREGI } & 14 & 13 & 12 & 11 \\ \text { IREGO } & 10 & 10 & 10 & 10 \\ \text { XLHS } & 3.95 & 3.95 & 3.95 & 3.95 \\ \text { ZTHS } & 4.3924 & 2.50718 & 1.66662 & 0.82605 \\ \text { ZBHS } & 2.50718 & 1.66662 & 0.82605 & -0.01452\end{array}$

END

$2.50718-1.66662$

MATERIAL LIBRAY

$*$

* material library - specify material properties for matertal, 'imaths'

* UPTO 20 (INMAT) MATERIALS CAN BE SPECIFIED

* SYNTAX:

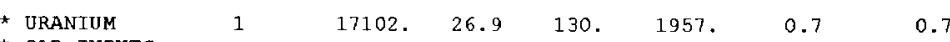

* OLD INPUTS:

* decay power per unit sludge volume for fuel piece sludge is $1100 \mathrm{~W} / \mathrm{m}^{\wedge} 3$

* in the code, decay power $=\mathrm{qv}^{*}(1-\text { porosity })^{*} \mathrm{volhs}$

* therefore, $q v=1100 \mathrm{~W} / \mathrm{m}^{\wedge} 3 /(1$-porosity $)=1100 /(1-0.50526)=2223.4 \mathrm{~W} / \mathrm{m}^{\wedge} 3$

* URANIUM

19000.26 .92130

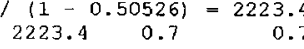

* Will use 408 void for SB kOP material.

* True solid density $=16.8 \mathrm{MT} / \mathrm{m}^{* *} 3$ is consistent

* Preserve U metal khs, cp

* Preserve SB decay power $\mathrm{Om}=117 \mathrm{~W} / \mathrm{MTTU}$

${ }^{*} \mathrm{QV}=\mathrm{Qm}[\mathrm{W} / \mathrm{MTU}]{ }^{\star} \mathrm{fu}[\mathrm{HTU} / \mathrm{MT}]{ }^{\star} \mathrm{rho}\left[\mathrm{MT} / \mathrm{m}^{\star \star}+3\right]$

$\star \quad=117 * 0.825 * 15.667=1512.3$

* NEW METHOD FOR 258 VOID:

* KOP material solid particles are 82.638 uraninum and 17.37 zirconium by volume.

* E_void = $0.25 ; / /$ vol-8

E_metal $=1.0-$ f_void;

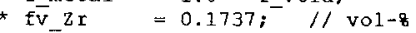

* $\mathrm{IV}_{-} \mathrm{U}=1-\mathrm{fv}_{-} \mathrm{Zr}$

$=0.8263$

* rho_zr $=6520 ; / / \mathrm{kg} / \mathrm{m}^{\wedge} 3$

$\star$ rho $^{-} \mathrm{U}=19000 ; / / \mathrm{kg} / \mathrm{m}^{\wedge} 3$

$* \mathrm{cp} \overline{\mathrm{z}} \mathrm{r}=278 ; / / \mathrm{J} / \mathrm{kg} / \mathrm{k}$

$+\mathrm{Cp}^{-} \mathrm{U}=120 . / / \mathrm{J} / \mathrm{kg} / \mathrm{k}$

$\star q \mathrm{~m} \quad=0.117 ; \quad / / \mathrm{W} / \mathrm{kg}$

* q v $\quad=q_{-} m *$ rho $U *$ fv U

$=1 \overline{8} 36.8649^{-} / / \mathrm{W} / \overline{\mathrm{m}}^{\wedge} 3$

* rho_metal $=\mathrm{fv} U$ * rho U + fv $\mathrm{zr}$ * rho $2 \mathrm{r}$

$=16 \overline{8} 32.224-/ / \mathrm{kg} / \overline{\mathrm{m}}^{\wedge} 3$

* $c p_{-}$metal $=\left(f v_{-} U *\right.$ rho $U * c p_{-} U+f v_{-} z r *$ rho_zr $\left.2 \mathrm{cp}_{-} z r\right) /$ rho_metal

$\begin{array}{lcrrrrrr}\text { * name } & \text { imaths } & \text { rho } & \text { khs } & \text { cp } & \text { qv } & \text { ehsi } & \text { ehso } \\ \text { URRANIUM } & 1 & 16832 . & 26.9 & 131 . & 1837 . & 0.7 & 0.7 \\ \text { STA INLESS-STEEL } & 2 & 8000 . & 16.0 & 500 . & 0 . & 0.3 & 0.3 \\ \text { COPPER } & 3 & 8954 . & 398.0 & 384 . & 0 . & 0.7 & 0.7\end{array}$ END

* USER can control heat sink boundary temperature

* SYNTAX:

* ofFSET TIMEHS

* EXTRAPŌLATION TIMEHS

TIMTHS IHS ISD TIME1, TIME2... 
PRC-STP-00187 REV 0

FAl/10-28

* THSFIX IHS ISD TEMP1, TEMP2.

* IHS = HEAT SINK NO.; ISD = SIDE NO. (1 OR 2) FOR IHS

* CONTROL HEAT SINK BOUNDARY T

TEMPERATURE DEPENDENT EMISSIVITY :

* USER CAN INPUT A TEMPERATURE DEPENDENT EMISSIVITY BY INPUTTING A

* NEGATIVE INTEGER FOR THE EMISSIVITY AND PROVIDING THE CORRESPONDINC

* TEMPERA'TURE VERSUS EMISSIVITY LOOK-UP TABLE.

* SYNTAX:

* TTABLE $n$ temperature entry(C)

* etable n emissivity-entry

$n$ is the table designator

* SANDWICH HEAT SINKS - STRING TOGETHER NUMER of CONSECUTIVE heat SINKS * TO MIMIC A SANDWTCH WALL. UPTO 100 SANDWICH WALLS CAN BE SPECIFIED, WITH * UPTO 10 LAYERS IN EACH WALL. THE SANDWICH HEAT SINK SERIES SHOULD BE

* arRanged such that the oUter face of the First heat SiNK and tHE INNER face

* OE THE LAST HEAT SINK IN THE SERIES FACE THE GAS REgIONS (OR INSUlated).

* SYNTAX:

* SANDWICH hs1 hgap1 hs2 hgap2 hs3 hgap3 ... hsn

* WHERE ' $h g a p$ " is the $g$ ap conductance $\left(w / m^{\wedge} 2 / C\right)$ between the layers

* BETWEen THE INSERT AND THE DIP TUBE, THERE is a AIR GAP OF THICKNESS

* $0.005524 \mathrm{M}$. THEREFORE, THE GAP CONDUCTANCE IS $0.03 / 0.005524=5.4 \mathrm{w} / \mathrm{m}^{\wedge} 2 / \mathrm{C}$

* USER CAN DEFINE CONDUCTION NETWORKS

* SYNTAX:

* COND_NETWORK ihs1 ihs2 ihs3 .... ihsn upto 100 heat sinks

* COND NETWORK ihs1 ins2 ihs3 .... insn upto 100 heat sinks

*

* upto 5 networks

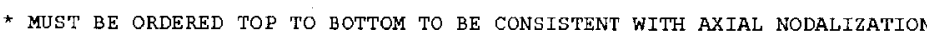

* MODEl CONTIGUOUS DIP TUBE CONNECTED TO THE SHIELD PLUG(HS \#278)

* COND_NETWORK NET $=1-278 \quad 22$

$\begin{array}{rr}* & 22 \\ * & 77 \\ * & 132\end{array}$

$\begin{array}{ll}+ & 132 \\ + & 187\end{array}$

* MODEL CONTIGUOUS INSERT

* COND NETWORK NET $=2$

$\star$

*

18

* MODEL CONTIGUOUS MCO WALL CONNECTED TO THE SHIELD PLUG (HS \#278)

BETWEEN THE INSERT AND THE DIP TUBE, THERE IS A AIR GAP OF THICKNESS

$0.005524 \mathrm{M}$. THEREFORE, THE GAP CONDUCTANCE IS $0.03 / 0.005524=5.4 \mathrm{~W} / \mathrm{m}^{\wedge} 2 / \mathrm{C}$ SANDWICH 1 5.4 2

SANDWTCH $201 \quad 5,4202$

bETWEEN COPPER bLOCK and SLUDge

SANDWICH $3 \quad 1000 \quad 4$

SANDWICH $23 \quad 100024$

SANDWICH $43 \quad 1000 \quad 44$

ANDWICH $63 \quad 100064$

SANDWICH $83 \quad 100084$

SANDWICH $203 \quad 1000204$

SANDWICH $223 \quad 1000224$

SANDWICH $243 \quad 1000244$

SANDWICH $263 \quad 100026$

SANDWICH $283 \quad 100028$

SANDWICH $403 \quad 1000 \quad 404$

SANDWTCH $423 \quad 1000 \quad 424$

SANDWICH $443 \quad 1000 \quad 444$

SANDW $463 \quad 1000464$

SANDWTCH 4631000464

SANDWICH $483 \quad 1000484$
$*$ NETWORKS 
PRC-STP-00187 REV 0

FAI/10-28

Page 87 of 99

Rev. 0

* BASKET 1 - FUEL PIECE SLUDGE

COND_NETWORK NET $=1 \quad 4 \quad 94$

COND NETWORK NET-2 595

COND NETWORK NET $=3 \quad 6 \quad 96$

COND

COND_NETWORK NET-4 7 97

COND_NETWORK NE $\mathrm{I}=5 \quad 8 \quad 98$

COND_NETWORK NET $=6$ 99

* BASKĒT 1 - SS-BACK-PLATE

*

BASKET 3 - FUEL PIECE SLUDGE COND_NETWORK NET=8 $204 \quad 294$ COND NETWORK NET $=9 \quad 205 \quad 295$ COND NETWORK NET $=10206 \quad 296$ COND NETWORK NET-11 $207 \quad 297$ COND NETWORK NET $=12 \quad 208 \quad 298$ COND_NETWORK NET=13 209299 BASKET 3 - SS-BACK-PLATE COND_NETWORK NET $=14203293$

*

BASKET 5 - FUEL PIECE SLUDG COND_NETWORK NET $=15 \quad 404 \quad 494$ COND_NE'TWORK NET $=16 \quad 405 \quad 495$ COND_NETWORK NET $=17 \quad 406 \quad 496$ COND_NETWORK NET $=18 \quad 407 \quad 497$ COND_NETWORK NET $=19 \quad 408 \quad 498$ COND_NETWORK NET $=20 \quad 409 \quad 499$

* BASKET 5 - SS-BACK-PLATE

COND_NETWORK NET $=21 \quad 403 \quad 493$

* Cask Wall

COND NETWORK NET $=22 \quad 676 \quad 679 \quad 680 \quad 681$

END HEATT_SINKS ! HEAT_SINKS is a comment

JUNCTIONS

* 1) MCO fuel 4 to fuel 3 5->4

* 2) MCo Euel 3 to fuel $2 \quad 4->3$

* 3) MCO Euel 2 to fuel 1 3->2

4) MCo fuel 1 to scrap 1 2->1

* 5) MCO top to outlet volume, 1->7 (deactivated)

* Syntax:

IJTYP Junction Type: 1 = Normal, 2 = HEPA, 3 = Cover, 4 = Failure,

5 = Check valve

DP1 for faiure junction, it is the pressure differential required for faiure junction, it is the pressure differential required
to fail from the upst ream compartment to the downst ream compt. for check valve junction, it is the differential pressure required to open the junction from upstream to downstream only.

DP2 for faiure junction, it is the pressure differential required to fail from the downstream compartment to the uptrean compt. for check valve junction, it is the differential pressure

at which the opened check valve closes

IFAN Fan type: 1 = constant volumetric flow fan

2 = constant delt p fan

WVEAn volumetric flow rate of the fan. for constant delt $\mathrm{P}$ fan, the volumetric flow rate is converted to the corresponding delt_p at time $=0$

Upstream Region

Downstream Region

Area $\left(m^{\wedge} 2\right)$

Bypass area for HEPA junction $\left(\mathrm{m}^{\wedge} 2\right)$

HEPA Eilter Failure pressure (Pa)

Cover Area $\left\{\mathrm{m}^{\wedge} 2\right\}$

Cover Weight (kg)

Elevation wrt floor of IR1 opening (m)

Loss coefficient multiplies $0.5^{*}$ rho*" $\mathrm{v}^{\wedge} 2$

* $21 \mathrm{JN}$

* $\quad 22 \mathrm{JN}$

orientation: 1 = horizontal, 0 = vertica

XWJN

Characteristic width, m

$\star \mathrm{XHJN}$

Characteristic height, 


\section{PRC-STP-00187 REV 0}

FAl/10-28

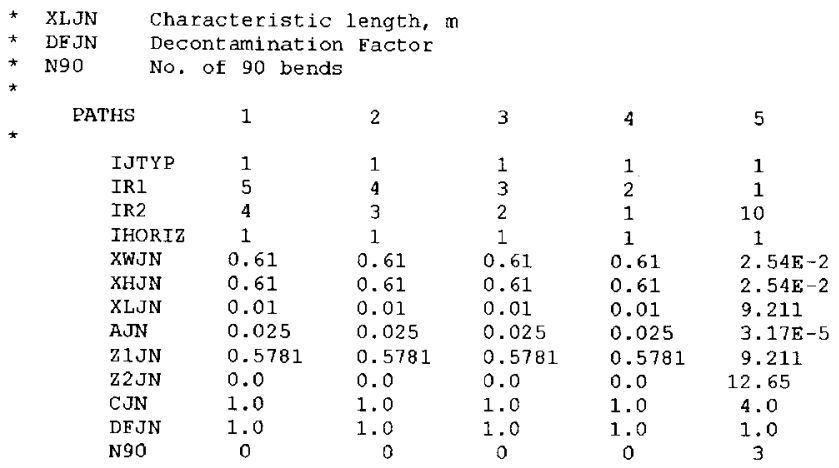

PATS ! PATHS is a comment.

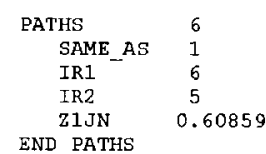

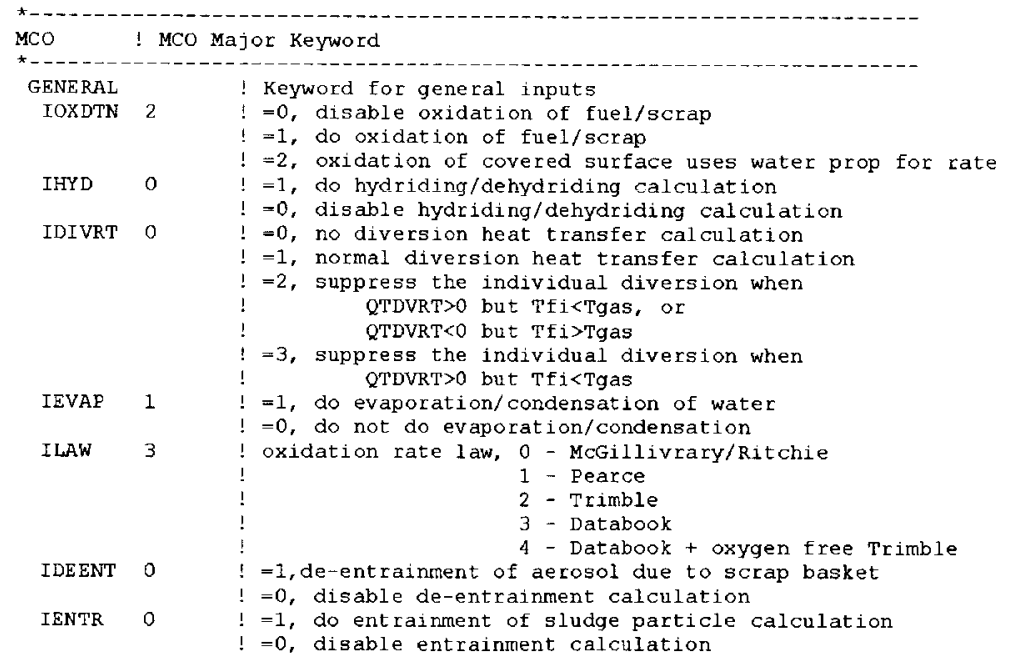




\section{PRC-STP-00187 REV 0}

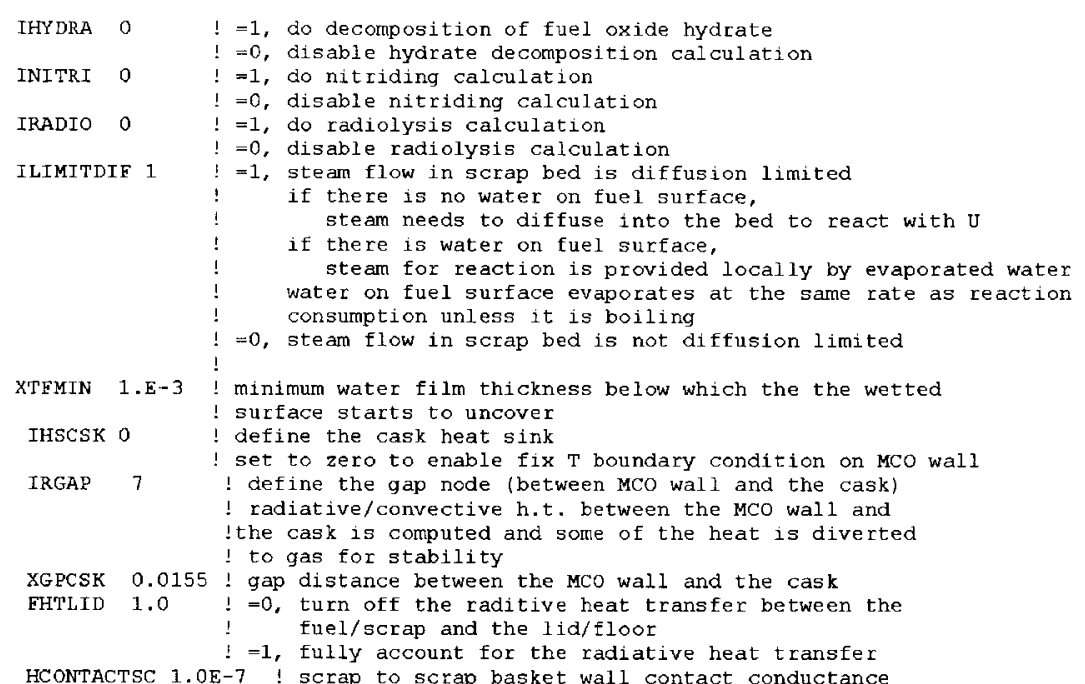

* PUMP, FEED, AND CONDENSER MODELS

* Syntax:

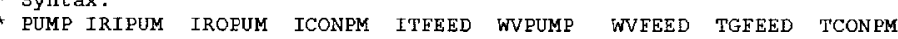

* Definitions:

* IRIPUM - Pump inlet region

* IROPUM - Purog outlet region

* ICONFM - Node to which the condensed steam is duniped for book-keeping

* ITFEED - If non-zero, overides TGFEED with the designated region

* ITEEED - If non-zero, overides TGFEED with the designated region

* WVPUMP - Pump volumetric flowrate $\left(\mathrm{m}^{\wedge} 3 / \mathrm{s}\right)$

* WVEEED - Feed volumetric flowrate (m^3/s)

* TGFBED - Feed temperature (C)

* TCONPM - Condenser cooling coil temperature (C)

* $35 \mathrm{ET}^{\wedge} 3 / \mathrm{MTN} * 1 \mathrm{MIN} / 60 \mathrm{SEC} * 0.02832 \mathrm{M}^{\wedge} 3 / 1 \mathrm{FT}^{\wedge} 3=0.01652 \mathrm{M}^{\wedge} 3 / \mathrm{SEC}$

* PUMP IRIPUM IROPUM ICONPM ITEEED WVPUMP WVFEED TGFEED TCONPM

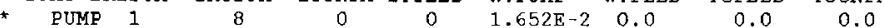

* Radiolysis parameters

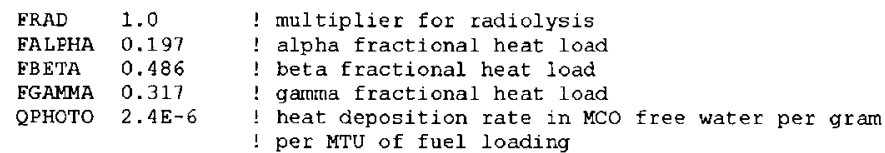

* Automatically generate the basket structure heat sinks with AxIAL command

$$
\begin{array}{ll}
\text { AUTO_INSERT } & \mathbf{1} \\
\text { AUTO_DIPTUBE } & \mathbf{1} \\
\text { AUTO_BACKPLATE } & \mathbf{1} \\
\text { AUTO_SPOKE } & \mathbf{1} \\
\text { AUTO_SHROUD } & \mathbf{1} \\
\text { AUTO_MCOWALL } & \mathbf{1}
\end{array}
$$

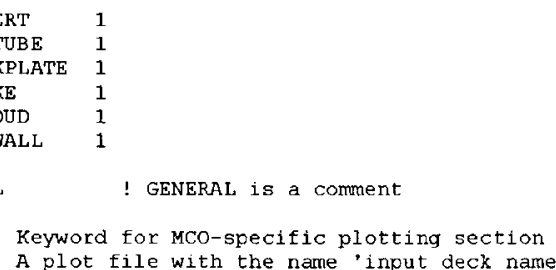

Keyword for MCO-specific plotting section 
PRC-STP-00187 REV 0

FAl/10-28

Page 90 of 99

Rev. 0

January, 2010

* PUMPH2

- Hydrogen flow rate into the vacuum pump, $\mathrm{kg} / \mathrm{s}$

* GAS-WH2 n jlist - Hydrogen flow rate through junctions, kg/s

* CORRODH2 - Hydrogen genration rate by fuel/scrap corrosion

* HS-H2O n hlist - Water mass on heat sini surfaces, kq

* HS-HYH2O n hlist- Water mass in sludge on heat sink surfaces, kq

* WH2Fl n flist - Hydrogen generation rate by corrosion/dehydriding/

radiolysis in fuel baskets, $\mathrm{kg} / \mathrm{s}$

* WH2 SC n slist - total hydrogen generation by corrosion/dehydriding/

$\begin{array}{ll}* \text { HHZTT } & \text { total hydrogen generation } \\ & \text { radiolysis in MCO, } \mathrm{kg} / \mathrm{s}\end{array}$

* MHzTT - cumulative hydrogen generated in $\mathrm{MCO}, \mathrm{kg}$

* QDECFl $n$ flist - decay heat in Euel baskets, $w$

* QDECSC n slist - decay heat in scrap baskets, $w$

* QDECTT - total decay heat in MCO, $W$

* UDECTT - cumulative decay heat in MCO, J

* OOXOFL, QOXOSC, QOXOTT, UOXOTT

* QOXWFL, QOXWSC, QOXWTT, UOXWTT

* QNTRFL, QNTRSC, QNTRTT, UNTRTT

fuel corrosion by 02 heat fuel corrosion by H2O heat nitriding heat

* QHYDFL, QHYDSC, QHYDTT, UHYDTT

hydriding/dehydriding heat total energy in

* QMCOFL, QMCOSC, QMCOTT, UMCOTT

* OLIDFL, OLIDSC, QLIDTT, ULIDTT

* QGasfl, QGASSC, QGASTT, UGASTT

heat loss to MCo wall

heat loss to lid/tloor/insert

heat loss to qas

heat loss due to evaporation

* OEVPFL, OEVPSC, OEVPTT, UEVPTT

Q QCNDFL, QCNDSC, QCNDTT, UCNDTT

heat loss by axial conduction

* QOUTEL, QOUTSC, QOUTTT, UOUTTT

* UMCO - total energy in fuel

* UINTGT - initial energy in fuel + integrated(source-sink)

* FUERR - relative energy imbalance

* TOTUO2 - total UTO2 in MCO

* Note: plot routine can only accept 99 items; can't plot all things.

* So plot all scrap T's but only 5 fuel (plus MCO)

* jlist - junction list

hlist - heat sink lis

* flist - Euel basket list

* slist - scrap basket list

CORRODH2

WH2TT

$\begin{array}{lllllll}\text { QDECSC } & 5 & 1 & 2 & 3 & 4 & 5\end{array}$

QDECSC $5 \begin{array}{llllll}5 & 6 & 7 & 8 & 9 & 10\end{array}$

QDECSC $\begin{array}{lllllll}5 & 11 & 12 & 13 & 14 & 15\end{array}$

QDECTT

UDECTT

QOXOTT

UOXOTT

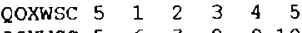

QOXWSC 5 6 $6 \begin{array}{llllll}6 & 7 & 8 & 9 & 10\end{array}$

OOXWSC $\begin{array}{lllllll}5 & 11 & 12 & 13 & 14 & 15\end{array}$

QOXWTT

voxwTT

QINTT

UINTT

QLIDTT

ULIDTT

QGASTT

$\begin{array}{lllllll}\text { OEVPSC } & 5 & 1 & 2 & 3 & 4 & 5\end{array}$

$\begin{array}{lllllll}\text { QEVPSC } & 5 & 1 & 2 & 3 & 4 & 5 \\ \text { QEVPSC } & 5 & 6 & 7 & 8 & 9 & 10\end{array}$

$\begin{array}{lllllll}\text { QEVPSC } & 5 & 6 & 7 & 8 & 9 & 10 \\ \text { QEVPSC } & 5 & 11 & 12 & 13 & 14 & 15\end{array}$

QEVPSC

QEVPTT

UEVPTT

QCNDTT 
PRC-STP-00187 REV 0

FAl/10-28

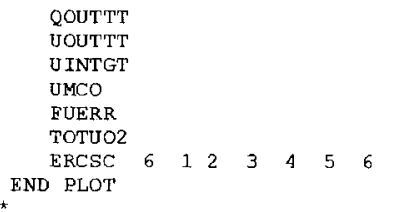

SOLAR_RAD

* pointers to heat sinks representing the cask wall and the top

* solar radiation impinges on these

* set IHCASK to zero to impose $40 \mathrm{C}$ water jacket temperature on MCO wall

* otherwise the code sets IREGo (imco) to zero

IHCASK

*

OEESET TIMDAY 21600. ! offset by six hours

EXTRAPOLLATION TIMDAY PERIOD ! repeat the diurnal cYcle

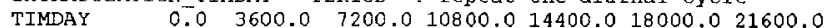

$20.028800 .032400 .036000 .039600 .0 \quad 43200.0216800 .0$

$50400.0 \quad 54000.0 \quad 57600.0 \quad 61200.0 \quad 64800.0 \quad 68400.0 \quad 72000.0$

75600.079200 .082800 .086400 .0

$\begin{array}{rrrrrrrr}\text { RADSUN } & 0.0 & 0.0 & 0.0 & 0.0 & 0.0 & 0.0 & 0.0 \\ & 0.0 & 0.0 & 0.0 & 0.0 & 0.0 & 0.0 & 0.0\end{array}$

$\begin{array}{lllllll}0.0 & 0.0 & 0.0 & 0.0 & 0.0 & 0.0 & 0.0 \\ 0.0 & 0.0 & 0.0 & 0.0 & 0.0 & 0.0 & 0.0 \\ 0.0 & 0.0 & 0.0 & 0.0 & & & \end{array}$

END SOLAR_RAD

$\begin{array}{llll}0.0 & 0.0 & 0.0 & 0.0\end{array}$

SCRAP_BSKT 3 ! Total number of scrap baskets

* First scrap basket (top)

IHSSC $\quad \begin{array}{llllllll}4 & 5 & 6 & 7 & 8 & 9 & \text { ! radial outward }\end{array}$

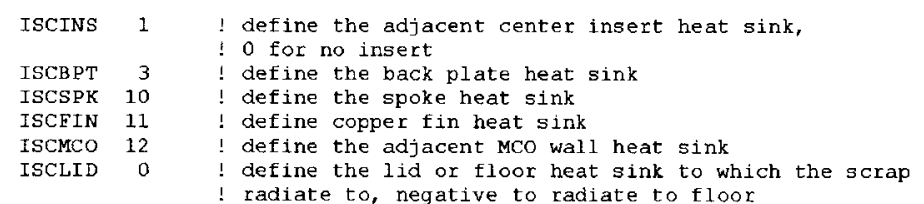

* mulitiplier for effective conductivity in scrap basket in the order read in

(only conduction part)

FKSC $1.0 \quad 1.0 \quad 1.0 \quad 1.0 \quad 1.0 \quad 1.0$

* mulitiplier for effective conductivity in scrap basket in the order read in

(only radiation part)

FRSC 1.0 1.0 1.0 1.0 1.01 .0

* porosity of the scrap for each heat sink in the order read in

* OLD:

* to match Umet of $9400 \mathrm{~kg} / \mathrm{m}^{\wedge 3},(1-\mathrm{FPOROS}) * 19000=9400$, or FPOROS $=0.50526$

* note: FPOROS includes volume of water, gas, and non-Umetal

* NEW:

* FPOROS-true porosity; adjust URANIUM properties for solids

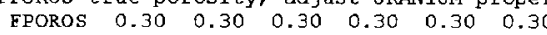

order read in (m)

$\begin{array}{lllllll}\text { XDSCRP } & 0.001 & 0.001 & 0.001 & 0.001 & 0.001 & 0.001\end{array}$

XRSCBK 0.2842 ! radius of scrap basket $(\mathrm{m})$

XHSCBK 0.5413 ! height of scrap basket (m)

* exposed surface area available for oxidation

* per unit volume of scrap $(1 / \mathrm{m})$ for

* each scrap basket heat sink in the order read in.

* 6 Cumet/D/ rhom $=6 * 9400 / 0.0006 / 19000=4947 / \mathrm{m}$

* For $30 \%$ void, Cumet $=0.7 / 0.6 * 9400=10967 \mathrm{~kg} / \mathrm{m}^{\wedge} 3$

* hence, 6 Cumet $/ \mathrm{D} /$ rhom $=6 * 10967 / 0.0006 / 19000=5772 / \mathrm{m}$ 
PRC-STP-00187 REV 0

FAl/10-28

AVOXSC 5772. 5772. 5772, 5772. 5772. 5772

FOXSC 100 ! multiplier for AVOXSC

* Sat * porosity * rhow $=0.10 * 0.3 * 1000=30 \mathrm{~kg} / \mathrm{m}^{\wedge} 3$

* $30 \mathrm{~kg} / \mathrm{m}^{\wedge} 3$ gives a total free water of $1 \mathrm{~kg}$ in $\mathrm{KOP}$.

* After the rebound test, no more than $200 \mathrm{~g}$ of water are left in the MCO.

* The refore, set MVWSCO to $200 / 1000 * 30=6.0 \mathrm{~kg} / \mathrm{m}^{\wedge} 3$

MVWSCO 6.0 ! initial amount $(\mathrm{kg})$ of water per unit bulk volume

! $\left(\mathrm{m}^{\wedge} 3\right)$ of scrap

! on the outer surface of the insert

! (per unit area, $\mathrm{m}^{\wedge} 2$ )

! on the inner surface of the MCo wall

FAwSC ! (per unit area, $\mathrm{m}^{\wedge} 2$ )

EAwSCM 1.0 - ! wetted fraction of sur

AWSCM 1.0 ? wetted fraction of MCO wall

XSCINS 1.E3 ! disable insert to scrap micro-convection

XSCMCO 0.00476 ! gap distance between scrap basket and MCO wall

* axial conduction tracked in the scrap basket

* top to bottom axial partition

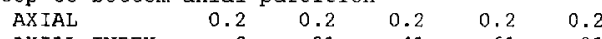
$\begin{array}{lrrrrr}\text { AXIAL_INDEX } & 0 & 21 & 41 & 61 & 81 \\ \text { AXIAL_FUEL } & 1 & 1 & 1 & 1 & 1\end{array}$

$\begin{array}{cccccc}\text { AXIALFUEL } & 1 & 1 & 1 & 1 & 1 \\ \text { muItiplier for FPOROS (porosity of scrap) } & \text { for each axial basket } \\ \text { FF POR } 1.0 & 1.0 & 1.0 & 1.0 & 1.0 & \end{array}$

multiplier for FoxSC(multiplier for oxidation area) for each axial baske FFOXSC $1.0 \quad 1.0 \quad 1.0 \quad 1.0 \quad 1.0$

* multiplier for MWSCo(initial amount of water per unit volume) for each

* axial basket.

FMVWSC $1.0 \quad 1.0 \quad 1.0 \quad 1.0 \quad 1.0$

* multiplier for XDSCR (characteristic scrap size) for each axial basket FXDSC $1.0 \quad 1.0 \quad 1.01 .01 .0$

* multiplier for FKSC(multiplier for effective conductivity (conduction)

* in scrap

FFKSC $1.0 \quad 1.0 \quad 1.0 \quad 1.0 \quad 1.0$

* multiplier for FRSC(multiplier for effective conductivity (radiation)

* in scrap)

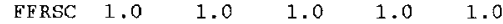

END IHSSC for 1st scrap basket

* Third scrap basket (third from top)

SAME AS SCRAP BASKET 1

IHSSC $204205206207208209 \quad$ ! radial outward

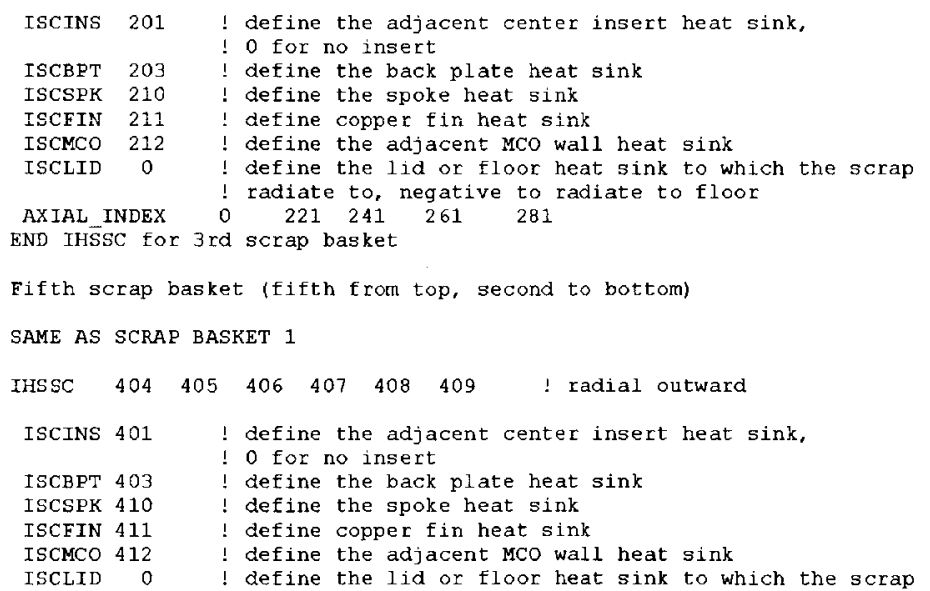




\title{
PRC-STP-00187 REV 0
}

FAl/10-28

Page 93 of 99

Rev. 0

January, 2010

\author{
I radiate to, negative to radiate to floor \\ AXIAL_INDEX $\quad 0 \quad 421 \quad 441 \quad 461 \quad 481$ \\ END IHSSC for 5 th scrap basket \\ IND SCRAP BSKT
}

END MCO 


\section{A.5 Difference between Case 1: KOPC19.DAT and Case 5: KOPC18.DAT}

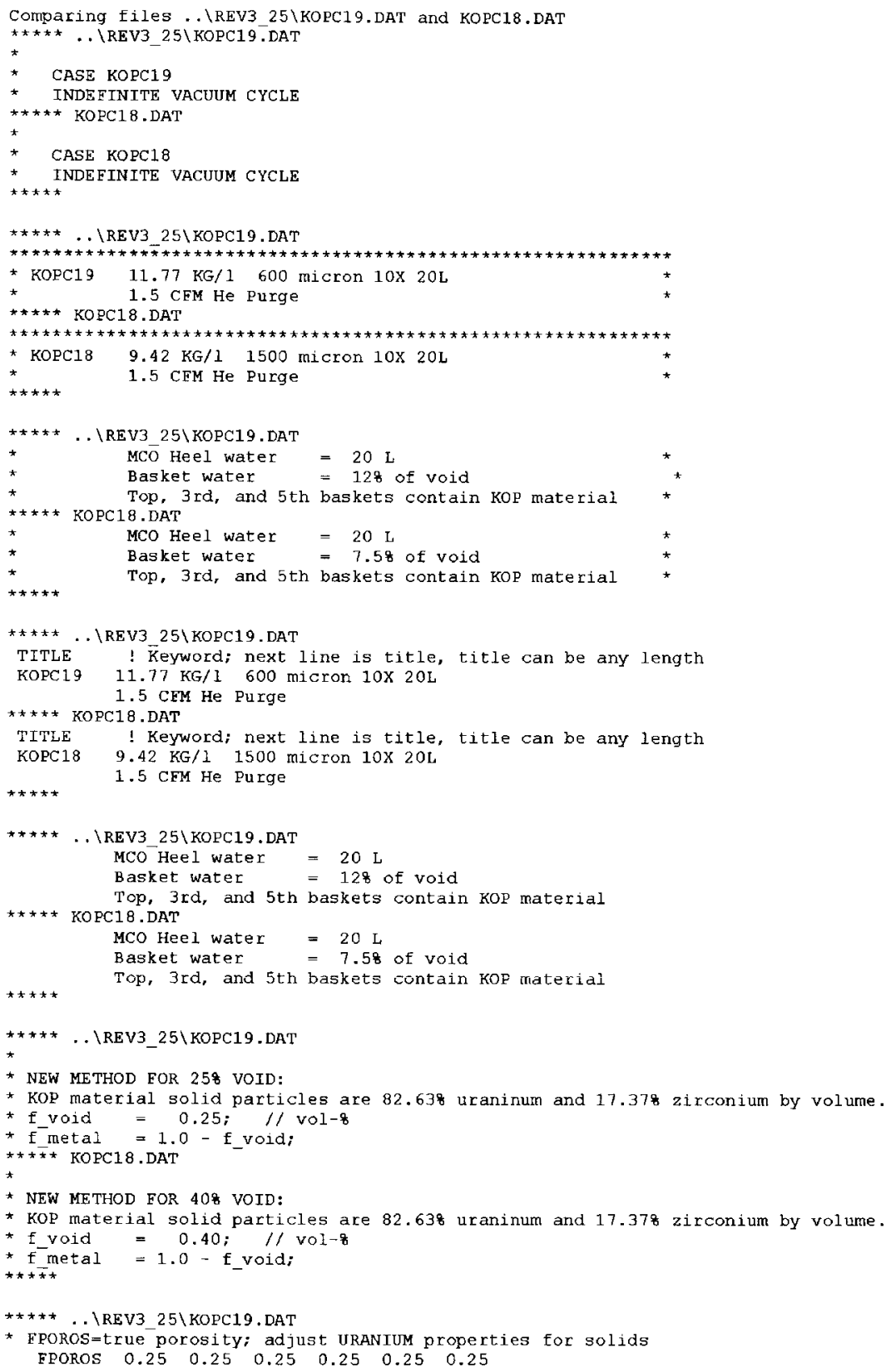


PRC-STP-00187 REV 0

FAl/10-28

* particle size for thermal conductivity in the order read in (m) ***** KOPC18.DAT

* FPOROS=true porosity; adjust JRANIUM properties for solids $\begin{array}{lllllll}\text { FPOROS } & 0.40 & 0.40 & 0.40 & 0.40 & 0.40 & 0.40\end{array}$

* particle size for thermal conductivity in the order read in (m)$$
\star \star \star * \star \text {. . \REV3_25\KOPC19.DAT }
$$$$
\text { * E_metal = } 1 \text { - f_void; }
$$$$
\text { + }=0.75 \text { : }
$$$$
\text { * d_particle }=600 . \mathrm{E}-6 ; \quad / / \mathrm{m}
$$$$
\text { * } \text { f }^{\text {sat }} \quad=0.08 \text {; }
$$$$
\star \text { rho_w } 1000 \text {; }
$$$$
\star \star \star \star \star \text { KOPC18. DAT }
$$$$
\text { * E metal }=1-\mathrm{f} \text { void }
$$$$
\text { * f_metal }=1-\text { f_voi }
$$$$
\text { * d_particle }=1500 . \mathrm{E}-6 ; / / \mathrm{m}
$$$$
\text { * } \mathrm{f} \text { sat }=0.075
$$$$
\text { * rhow }=1000 ; / / \mathrm{kg} / \mathrm{m}^{\wedge}
$$$$
\text { ***** .. }
$$

* for 258 void, cumet $=(1-0.25\} / 0.6 * 9400=11750 \mathrm{~kg} / \mathrm{m}^{\wedge} 3$

$* \mathrm{C} \mathrm{U}=(\mathrm{E}$ metal $/ 0.6) * 9400 / / \mathrm{kg} / \mathrm{m}^{\wedge} 3$

$\begin{aligned} * \mathrm{C}_{-} \mathrm{U} & =1 \mathrm{E} \text { met } \\ & =11750 .\end{aligned}$

* Hence, 6 cumet $/ D /$ rhom $=6 * 11750 / 0.0006 / 19000=6184 / \mathrm{m}$

* AdV_ox -6 *C_u / d_particle / rho_u $/ / \mathrm{m}^{n}-1$

* 6 cumet / D / rhom $=6 * 11750 / 0 . \overline{0} 006 / 19000=6184 / \mathrm{m}$ AVOXSC 6184.6184.6184. 6184.6184. 6184.

FOXSC 10 ! multiplier for AVOXSC

$$
\star \star \star \star \star \text { KOPC18.DAT }
$$

* For 408 void, cumet $=(1-0.4) / 0.6 * 9400=9400 \mathrm{~kg} / \mathrm{m}^{\wedge} 3$

$* \mathrm{C}_{-} \mathrm{U}=(\mathrm{E}$-metal $/ 0.5) * 9400 / / \mathrm{kg} / \mathrm{m}^{\wedge} 3$

$+-=9400$.

* Hence, 6 cumet $/ \mathrm{D} / \mathrm{rhom}=6 * 9400 / 0.0015 / 19000=1979 / \mathrm{m}$

*AdV_ox $=6 * C_{\text {Ut }} /$ a_particle / rho_u $/ / \mathrm{m}^{\wedge}-1$

Avoxsc 1979. 1979. 1979. 1979. 1979. 1979.

FOXSC 10 ! multiplier for AVOXSC

$$
\text { FOX }
$$

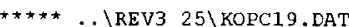

* Sat * porosity * rhow $=0.12 * 0.25 * 1000=30 \mathrm{~kg} / \mathrm{m}^{\wedge} 3$

* mVw_scrap_o = f_sat * f_void * rho_w $/ / \mathrm{kg} / \mathrm{m}^{\wedge} 3$

Mwsco $\overline{3} 0.0$ ! initial amount $(\mathrm{k} \vec{g})$ of water per unit bulk volume $\star \star \star \star \star$ KOPC18.DAT

* Sat * porosity * rhow $=0.075 * 0.4 * 1000=30 \mathrm{~kg} / \mathrm{m}^{\wedge} 3$

* mvw_scrap_o = f_sat * f_void * rho_w $/ / \mathrm{kg} / \mathrm{m}^{\wedge} 3$

MVWSCO 30.0 ! initial amount $(\mathrm{kg})$ of water per unit bulk volume

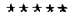


FAl/10-28

Page 96 of 99

Rev. 0

January, 2010 A.6 Case 6: KOP_VACXDG.DAT KOP with Degraded Vacuum Pumping and No
Helium Purge

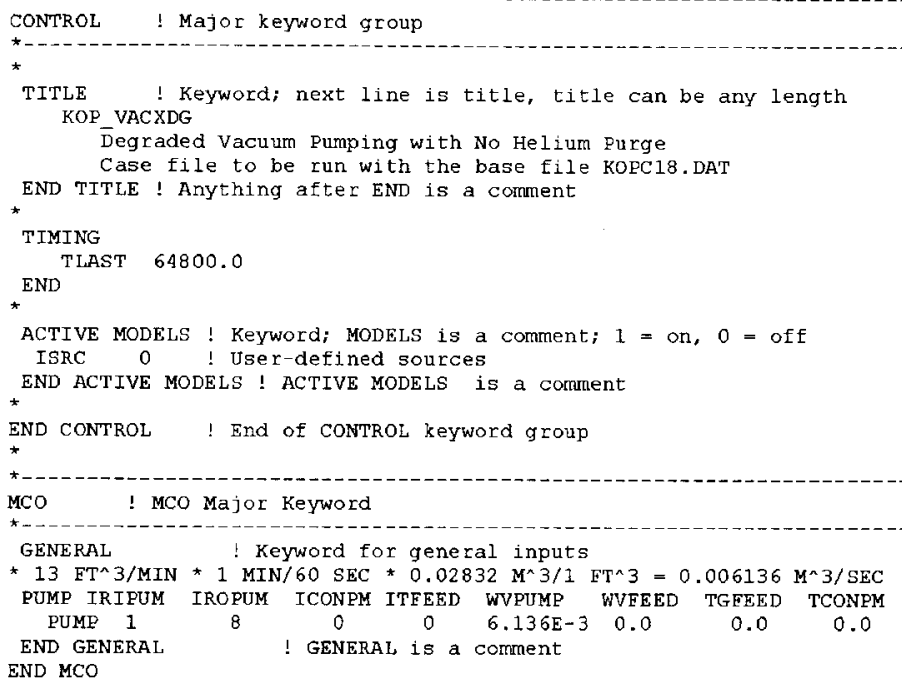




\section{PRC-STP-00187 REV 0}

FAl/10-28

Page 98 of 99

Rev. 0

\section{A.8 Difference between Case 4: KOP_COOLSPRS_19.DAT and Case 8: KOP_COOLSPRS1.DAT}

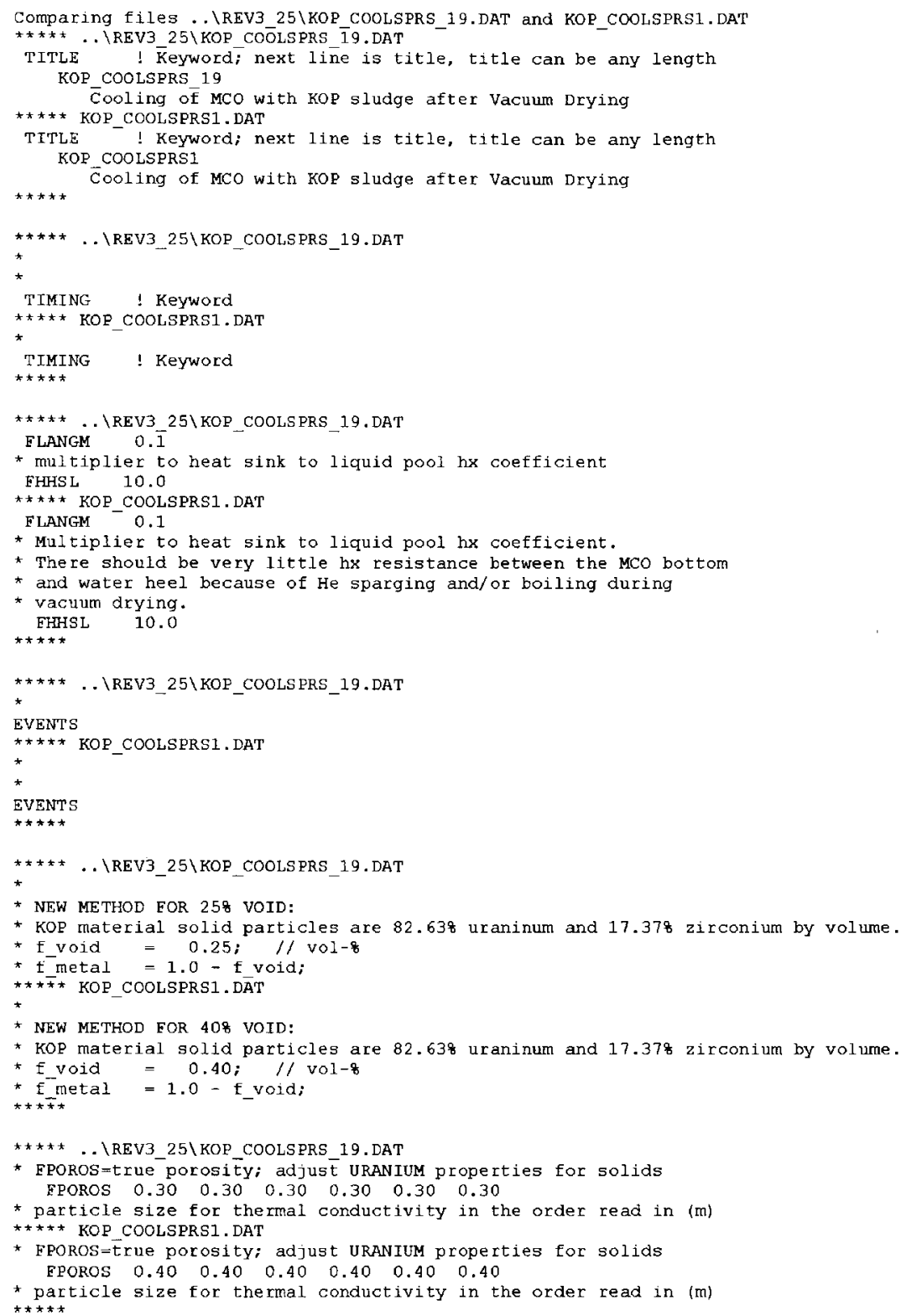




\section{PRC-STP-00187 REV 0}

FAl/10-28

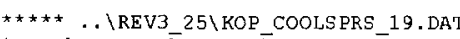

* each scrap basket heat sink in the order read in.

* 6 Cumet / D / rhom $=6 * 9400 / 0.0006 / 19000=4947 / \mathrm{m}$

* for 308 void, Cumet $=0.7 / 0.6 * 9400=10967 \mathrm{~kg} / \mathrm{m}^{\wedge} 3$

* hence, 6 cumet $/ \mathrm{D} / \mathrm{rhom}=6 * 10967 / 0.0006 / 19000=5772 / \mathrm{m}$

AVOXSC 5772. 5772.5772. 5772. 5772. 5772 .

FOXSC 10 ! multiplier for AVOXSC

* Sat * porosity * rhow $=0.10 * 0.3 * 1000=30 \mathrm{~kg} / \mathrm{m}^{\wedge} 3$

* Sat * porosity * rhow

* After the rebound test, no more than $200 \mathrm{~g}$ of water are left in the Mco.

$\star \star \star \star \star \star$ KOP_COOLSPRSI.DAT

* each scrap basket heat sink in the order read in.

t f_metal $=1-\mathrm{f}$ _void

* $=0.6$;

* d_particle $=1500 . E-6 ; / / \mathrm{m}$

* f sat $=0.075$

* rho_w $=1000 ; / / \mathrm{kg} / \mathrm{m}^{n} 3$

* for 408 void, Cumet $=(1-0.4) / 0.6 * 9400=9400 \mathrm{~kg} / \mathrm{m}^{\wedge} 3$

$* C_{-} U=\left(f_{-}\right.$metal $\left./ 0.6\right) * 9400 / / \mathrm{kg} / \mathrm{m}^{\wedge} 3$

$*-=94 \overline{0} 0$.

* Hence, 6 Cumet / D / rhom $=6 * 9400 / 0.0015 / 19000=1979 / \mathrm{m}$

* AdV_ox = 6* C_U / d_particle / rho_U // $\mathrm{m}^{n}-1$

AVOXSC 1979. 1979. 1979. 1979. 1979. 1979 .

FOXSC $10 \quad 0$ ! multiplier for AVOXSC

* Sat * porosity * rhow $=0.075 * 0.4 * 1000=30 \mathrm{~kg} / \mathrm{m}^{\wedge} 3$

$\star$ mvw_scrap_o $=$ f sat * f_void * nho w $/ / \mathrm{kg} / \mathrm{m}^{n} 3$

* After the rebound test, no more than $200 \mathrm{~g}$ of water are left in the MCO.

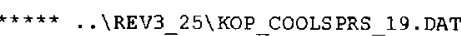

* Therefore, set MVWSC0 to $20 \overline{0} / 1000 \star 30=6.0 \mathrm{~kg} / \mathrm{m}^{\wedge} 3$

MVWSC0 6.0 ! initial amount $(\mathrm{kg})$ of water per unit bulk volume ***** KOP_COOLSPRSI.DAT

* The refore, set MWWSC to $200 / 1000 * 30=6.0 \mathrm{~kg} / \mathrm{m}^{\wedge} 3$

MVWSCO 6.0 ! initial amount $(\mathrm{kg})$ of water per unit bulk volume

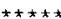

